\title{
Teoria do Funcional da Densidade Aplicada ao Modelo de Heisenberg
}

\section{Valter Luiz Líbero}

Departamento de Física e Informática Instituto de Física de São Carlos Universidade de São Paulo 


\section{VALTER LUIZ LÍBERO}

\section{Teoria do Funcional da Densidade Aplicada ao Modelo de Heisenberg}

Tese apresentada ao Instituto de Física de São Carlos, da Universidade de São Paulo, como parte dos requisitos para obtenção do título de Professor Livre Docente.

São Carlos

2011 


\section{DEDICATÓRIAS}

À Laura, Ricardo e Brianda por preencherem minha vida com tanta graça, carinho e beleza, mas sobretudo para Sibely, que com amor nos aquece, com paciência nos perdoa, e com palavras nos encoraja!

Aos meus pais, Maria e Benedito, pela determinação em minha educação, coragem e exemplo ao transporem os obstáculos da vida, mas principalmente pelo amor inabalável. 


\section{AGRADECIMENTOS}

Para se alcançar um grande objetivo na vida precisamos contar com a colaboração e amizade de muitas pessoas! Sinto-me envaidecido pela consideração que sempre recebi dos colegas de trabalho, no IFSC ou no CDCC. Agradecer a cada pessoa que foi importante em minha carreira ficaria demasiado longo, assim faço explicitamente a aqueles com quem interagi mais diretamente.

Aos Professores Luiz Nunes, Drugo, Almir e Rogério pela referência que sempre foram para mim. Eu os tenho como exemplos. Djalma e Lidério, obrigado pelas valiosas discussóes pelos corredores. Ao Klaus, pela importante colaboração que resultou neste trabalho de Tese, e pela amizade.

Às meninas da Biblioteca e ao pessoal da Seção de Alunos meu agradecimento e carinho. Bethe, grato pelo incentivo. Ao pessoal do ScInfor e da Gráfica, obrigado pelos inúmeros serviços prestadas.

Ao Schice e ao Aprígio por me confiarem a direçâo do Centro de Divulgaçâo da Astronomia, o nosso observatório. Minha gratidão aqueles que tornaram essa tarefa possivel, os monitores, mas principalmente ao meu mais longo colega de trabalho, Jorge Hönel. A todos do CDCC meu agradecimento pela indicação como Vice-Diretor; nada em minha carreira me deixa mais orgulhoso! Meu agradecimento particular à Edna e Rosana.

Meus orientandos, Sandra, Sílvia, Poliana, J. Vitor, L. Ramos, Guilherme, Fabiano, Márcio, Paulo, Amilton, Rodrigo e Necmias, ao olhar para minhas conquistas, vejo vocês. Ao Rodrigo e a Sibely sou muito grato pela leitura cuidadosa e importantes contribuiçôes na melhoria da redação deste trabalho.

À Cris um agradecimento especial, pela dedicação que vai além do dever profissional e pela paciência infindável, que nos leva a abusar de sua gentileza. A você Maria Cristina agradeço pela inestimável colabaração durante todos esses anos, mas especialmente pela amizade! 


\section{Eclipse}

All that you touch

All that you see

All that you taste

All you feel

All that you love

All that you hate

All you distrust

All you save

All that you give

All that you deal

All that you buy

beg, borrow or steal

All you create

All you destroy

All that you do

All that you say

All that you eat

everyone you meet

All that you slight

everyone you fight

All that is now

All that is gone

All that's to come

And everything under the Sun is in tune

But the Sun is eclipsed by the Moon.

The Dark Side of the Moon,

Pink Floyd, 1973 


\section{Resumo}

Líbero, Valter L. - Teoria do Funcional da Densidade aplicada ao modelo de Heisenberg, Tese Livre Docência, Instituto de Física de São Carlos. da Universidade de São Paulo, São Carlos - 2011.

Neste trabalho formulamos a Teoria do Funcional da Densidade (DFT) no contexto do modelo de Heisenberg e a aplicamos na obtenção da energia do estado fundamental (EEF) de sistemas não homogêneos de spins. Construímos funcionais locais baseados na cnergia de correlação extraída da Teoria de Ondas-de-Spin, ou de resultados advindos do Grupo de Renormalização da Matriz Densidade. Usualmente encontra-se dificuldades quando se procura diagonalizar numericamente o Hamiltoniano de Heisenberg, os funcionais no entanto, podem estimar com relativa facilidade a EEF em uma, duas, ou três dimensões, de sistemas antiferromagnéticos com tamanhos arbitrários, e na presença de contornos, impurezas ou defoitos de ligações. Comparação com resultados exatos mostram que os funcionais representam uma significativa melhora em relação ao campo médio, com custo computacional insignificante. Por exemplo, mesmo numa aproximação local, a correlação levadã con conta nos funcionais levanta degenerescências espúrias previstas por campo médio, além de fornecer energias com erros de poucos por cento em sistemas em que resultados exatos são conhecidos. Os primeiros funcionais desenvolvidos eram restritos a sistemas com interações de troca uniformes. Recentemente, formulamos uma aproximação baseada no conceito de célula unitária numa cadeia de spins, que nos permite estimar a EEF mesmo de cadeias com defeitos arbitrários de ligaçóes. Isso é de interesse, por exemplo, em cadeias de spins $1 / 2 \mathrm{com}$ ligações alternando em valor e sinal de um sítio a outro. Esses funcionais são não-locais nas interações de troca $J_{i}$; o conceito de célula unitária numa rede não uniforme pode ser uma alternativa na construção de funcionais para sistemas com valores de spins alternando sítio a sítio. Para todo funcional construído, sempre procuramos resultados exatos que dessem respaldo ao mesmo. Para isso utilizamos dois métodos numéricos. Um deles, baseado na aplicação sucessiva do Hamiltoniano em uma função tentativa, é apropriado para se obter apenas a EEF. () outro é baseado num procedimento recursivo de diagonalização que permite obter todo o espectro do Hamiltoniano, e portanto pode-se estudar a termodinâmica de cadeias ou escadas de spins não homogêneas, de tamanho moderado.

Palvras-chave: Teoria do Funcional da Densidade. Modelo de Heisenberg. Quebra de simetria translacional. Energia do estado fundamental. Diagonalização iterativa. 


\begin{abstract}
Líbero, Valter L. - Density-Functional Theory Applied to the Heisenberg Model, Tese Livre Docência, Instituto de Física de São Carlos. da Universidade de São Paulo, São Carlos - 2011.

We describe the application of the Density-Functional Theory (DFT) to obtain the ground-state energy (GSE) of inhomogeneous spin systems modeled by the Heisenberg Hamiltonian. We build local spin functionals based on the correlation energy extracted from the Spin-Wave Theory or from Density Matrix Renormalization Group results. Normally difficulties are encountered when one diagonalizes numerically the Heisenberg Hamiltonain, the functionals otherwise, can estimate the GSE in one-, two- or three-dimensional antiferromagnetic spin systems, with arbitrary size, in the presence of boundaries, impurities or defects in the bulk or on the surfaces. A comparison between exact diagonalization and DFT shows that the functionals results correspond to a significant improvement on the mean-field ones, at negligible extra computational cost. For instance, correlations taken into account in the functionals lift spurious degeneracies present in the mean-field approximation, besides they estimate energies to within a few percent when exact results are available. The first functionals were restricted to uniform exchange interactions across the bonds. Our present study paves the road to functionals of the bond interactions. This is relevant for instance in the study of the $\mathrm{S}=1 / 2$ alternating-bond Heisenberg chain, in which the exchange couplings can alternate strength or even sign from site-to-site. Based on a concept of unit cell for spin chains, this functional is non-local in the exchange coupling $J_{i}$; we are now considering the application of this idea to chains with alternating spin values. To give support to the built functionals, we developed two numerical procedure to obtain exact results for chains without translational invariance. One of then, a power method, is suited to obtain the GSE. The other, based on a recursive diagonalization of the Hamiltonian, yields the entire spectrum with controlled accuracy, openning the possibility to study thermodynamical properties of inhomogeneous chains, or even ladders, of moderate size.
\end{abstract}

Key words: Density-Functional Theory. Heisenberg model. Broken translational symmetry. Ground-state energy. Iterative diagonalization. 


\section{Sumário}

1 Introdução 14

1.1 O Modelo de Heisenberg . . . . . . . . . . . . . . . . . . . . 15

1.2 A Teoria do Funcional da Densidade . . . . . . . . . . . . . . . . . 17

1.3 Os Resultados Presentes neste Trabalho . . . . . . . . . . . . . . . . 18

1.4 Organização desta Tese . . . . . . . . . . . . . . . . . . 18

2 O Modelo de Heisenberg 20

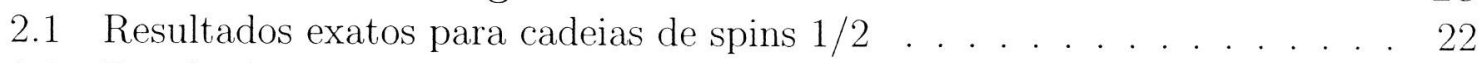

2.2 Resultados aproximados para cadeias homogêneas de spins $S \ldots$. . . . 23

3 A Teoria do Funcional da Densidade - DFT 26

3.1 DFT para sistemas eletrônicos . . . . . . . . . . . . . . . 26

3.2 O Teorema de Hohenberg-Kohn para o Modelo de Heisenberg . . . . . . 29

3.3 A conveniência da aproximação de campo médio . . . . . . . . . . . . . . 30

3.4 Aproximação Local para o Spin - LSA . . . . . . . . . . . . . . . . . . . . . . . . . . 31

3.4 .1 Aproximação Local via Ondas-de-Spin . . . . . . . . . . . . . . 31

3.4 .2 Aproximação Local via DMRG . . . . . . . . . . . . . . . . . . 32

4 Resultados para Impurezas Substitucionais 33

4.1 Sistemas unidimensionais . . . . . . . . . . . . . . . . . . . . . . . . . . . . . . . . . . . . . . .

4.2 Sistemas bidimensionais . . . . . . . . . . . . . . . . . . . . . . . . . . . . . . . . . . . . . . . . . . .

4.2.1 Vacâncias na rede . . . . . . . . . . . . . . . . . 38

4.3 Sistemas tridimensionais . . . . . . . . . . . . . . . . . 39

5 Interações de troca não uniformes 41

5.1 Funcional gerado através da Cadeia Alternada . . . . . . . . . . . . . . . . . . 42

5.2 Resultados .......................... . . . . 44

5.2.1 Cadeia Uniforme com um defeito antiferromagnético . . . . . 45

5.2.2 Ligações alternando entre ferromagnéticas e antiferromagnéticas. . . . . . . . . . . . . . . . . . . . . . . . . . . . . . . 47

5.2 .3 Cadeias com vários defeitos . . . . . . . . . . . . . . 48

6 Estado Fundamental Numericamente Exato 50

6.1 O Método de Potências Sucessivas do Hamiltoniano . . . . . . . . . . . 50

6.2 Mćtodo de Diagonalização Iterativa . . . . . . . . . . . . . 53 
6.3 Escadas de Spins . . . . . . . . . . . . . . . . . . . 57

7 Conclusões e Propostas de Trabalho 60

7.1 Spin Wave para cadeias com spins alternados . . . . . . . . . . . . . 61

7.2 Funcionais para o Modelo de Heisenberg Anisotrópico . . . . . . . . . . . 63

7.3 Termodinâmica de cadeias ou de escadas de spins . . . . . . . . . . . 63

Apêndice $\quad 65$

F.0.1 Truncamento de estados . . . . . . . . . . . . . . . . 68

References . . . . . . . . . . . . . . . . . . . . . . . . 69 


\section{Lista de Figuras}

2.1 Flutuação magnética $T \chi$ versus temperatura $T$ para os casos de alinhamento ferromagnético $(J<0)$ e antiferromagnético $(J>0)$. No inset ć mostrada a exponencial da entropia, versus temperatura, que mede o número efetivo de graus de liberdade a cada temperatura.

2.2 Na aproximação de campo médio o estado fundamental de um sistema antiferromagnético apresenta os spins vizinhos alinhados antiparalelamente uns aos outros; esse é o denominado estado Néel . . . . . . . . . . . . . . . . . . .

2.3 Na Teoria de Ondas-de-Spin, considerada-se de forma perturbativa a flutuação do spin em torno de seu estado de campo médio. Embora fosse esperado bons resultados apenas para valores altos de spins (pois a flutuação é da ordem de $1 /(2 S+1)$ ), surpreendentemente, mesmo para spin $1 / 2$, essa teoria fornece bons resultados.

4.1 Energia do estado fundamental para cadeias abertas com 10 spins $S$, para valores de $S$ desde $1 / 2$ até 2 . As aproximaçóes locais vindas da SW ou da DMRG são quantitativamente semelhantes (ver inset) e reproduzem bem melhor os resultados exatos quando compararlas com a aproximação de campo médio (CM).

4.2 Dependência com o tamanho $N$ da energia do estado fundamental, por spin, para cadeias de spins $S$. Valores obtidos pelo funcional LSA na aproximação SW (linha cheia) descrevem bem melhor os resultados exatos ( $)$ que os de CM ( $\diamond)$, particularmente para redes cada vez maiores. As linhas tracejadas demarcam o limite termodinâmico para cada spin considerado (Fig. (1) da Ref.[10]).

4.3 Energia do estado fundamental, por spin, para cadeias abertas com $N$ spins $1 / 2$, com uma impureza de spin $S_{I}=1$ na borda (linha tracejada), ou no interior da cadeia (linha cheia), ou uma impureza na borda e outra no interior (linha ponto-tracejada). Os círculos representam os resultados exatos para o caso da impureza $S=1$ na borda da cadeia. A aproximação CM prevê energia independente de $N$ para esse caso de impureza na borda (Fig. (2) da Ref.[10]).

4.4 Rede quadrada $4 \times 4$, que pode ser decomposta numa cadeia formada por dezesseis ligações (linhas cheias), mais nove ligações adicionais (linhas pontilhadas). Para condições de contorno periódicas outras ligações devem ser introduzidas.

4.5 Energia do estado fundamental para redes $N \times N$ de spins $S$. Enquanto o cálculo DFT/LSA ${ }^{S W}$ pode ser feito para redes de tamanho qualquer, apenas alguns resultados exatos são conhecidos (Fig. (2) da Ref.[10]) . . . . . . . . . . . . . . . . 
4.6 Energia do estado fundamental para redes com vacâncias. Mostramos $-E_{0}^{L S A}$ versus

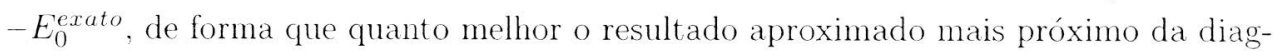
onal principal (linha tracejada) ele está representado. São consideradas redes $3 \times 3$ e $4 \times 4$, com diversas vacâncias, em diferentes posiçöes da rede. . . . . . . . . . . .

5.1 Dependência da EEF com o tamanho de aneis com $N-1$ spins $1 / 2$ e uma impureza de spin $S_{I}=3 / 2$ (triângulos), ou de aneis com $N$ spins e um defeito de intensidade $J_{D}=5 J$ (círculos), tratados exatamente (símbolos cheios) ou via LSA/LBA (símbolos abertos). Com o tratamento de campo médio (estrelas). os sistemas com a impureza ou com o defeito fornecem o mesmo valor para a EEF. A inclusão da cnergia de correlação via LSA (caso da impureza, triângulos abertos) ou via LBA (caso do defeito, círculos abertos) remove essa degenerescència espúria (Fig. (1) da Ref.[59]) . . . . . . . . .

5.2 Cadeia de spins $1 / 2$ com ligaçóes alternando entre os valores $J$ e $\alpha . J$. O dímero formado pelas ligaçōes $\{J, \alpha J\}$ forma uma célula unitária, em termos da qual a cadeia pode ser considerada homogenca. Convencionamos chamar as ligações dentro de uma célula representadas por linhas cheias de tipo 1 e as por linhas pontilhadas de tipo 2 .

5.3 Comparação entre os resultados de Barnes et al para a energia do estado fundamental, por spin, no limite termodinâmico, com os exatos para una cadcia alternada finita com 24 spins $1 / 2$. Observe a boa concordância mesmo para $\alpha$ próximo da unidade. A razão $\alpha$ entre sucessivas interações de troca é definida na Eq. (5.3) . . . . . . . . . .

5.4 Estado fundamental de um anel homogêneo de 24 spins $1 / 2$, por unidade do número de ligações $N_{b}$, como função da intensidade de um único defeito antiferromagnético $J^{\prime}$. A concordância entre os resultados advindos do funcional $(\triangle)$ e os numericamente exatos (-) é muito boa. A diferença desses valores para os de campo médio $(\bullet)$ é a correlação, que como se nota é da ordem do valor exato (Fig. (2) da Ref.[60]). . . . .

5.5 Efeito da posição de un defeito $J^{\prime}=0.5 J$ na energia do estado fundamental de uma cadeia aberta com 24 spins $1 / 2$. A aproximação LUCA se aproxima mais dos resultados exatos que a LBA (Fig. (3) da Ref.[60]). . . . . . . . . . . . . . . .

5.6 Dependência de $-E_{0} / J N_{b}$ com o número $N$ de spins $1 / 2 \mathrm{em}$ um anel com um defeito de intensidade $J^{\prime}=5 J$, isto é, um valor alto para $\alpha$ no defeito, enquanto o restante da cadeia tem $\alpha=1$. Resultados de LUCA $(\triangle)$ concordam melhor com os resultados exatos $(\mathbf{-})$, que aqueles advindos da $\operatorname{LBA}^{S W}(\mathbf{v})$ ou mesmo da $\mathrm{LBA}^{D M R G}(\star)$ (Fig. (4) da Ref.[60])

5.7 Dependência com $\alpha$ da energia do estado fundamental para um anel de 24 spins $1 / 2$ com ligações ferromagnética e antiferromagnética intercaladas (Fig. (5) da Ref.[60]). .

5.8 Ancl com ligações alternadas, mas com três defcitos, $J^{\prime}=0.5 . J \mathrm{~cm}$ uma ligação tipo 2 , defeitos $J^{\prime \prime}=0.7 J$ e $J^{\prime \prime \prime}=0.9 J$ em ligaçōes tipo 1 (Fig. (7) da Ref. [60]).

5.9 Dependência com $\alpha$ da EEF para um anel contendo 24 spins $1 / 2$ e três defeitos. dispostos conforme a Fig. (5.8). Os resultados obtidos via LUCA $(\Delta)$ desviam no máximo em $3 \%$ dos exatos $(\mathbf{\square}) \ldots \ldots \ldots$. . . . . . . . . . . . . 
6.1 Comparação entre as diferentes implementações do método de potência: (o) $\left|\psi_{T}\right\rangle$ como definido na Eq. (6.5) mais aceleração via Aitken; $(\bullet)\left|\psi_{T}\right\rangle$ como definido na Eq. (6.5), porém sem a aceleração Aitken: $(\star)\left|\psi_{T}\right\rangle$ igual a campo médio, porém sem a combinação linear presente em Eq. (6.5). Finalmente, ( $\diamond)$ escolhendo um vetor qualquer da base para ser o $\left|\psi_{T}\right\rangle \ldots \ldots \ldots \ldots \ldots \ldots$

6.2 Crescimento iterativo da cadeia de $N$ spins. A partir da diagonalização de uma cadeia com $N$ spins construímos a base de estados em que a cadeia com $N+1$ spins será diagonalizada. . . . . . . . . . . . . . . . . . . .

6.3 Desvio no valor da energia do estado fundamental em função do número $m$ de estados mantidos após o truncamento, para cadeias com $N=20,32,64$ ou 128 spins $1 / 2$ e condições abertas de contorno. A Ref.[52] forneceu os valores exatos para $N=32,64$ e 128. (Fig. (3.1) da Ref.[36]).

6.4 Desvio no valor da energia de estados excitados em função do número $m$ de estados mantidos após o truncamento, para uma cadeia com $N=20$ spins $1 / 2$ e condição aberta de contorno. Os valores exatos são obtidos diagonalizando essa cadeia sem truncamento (Fig. (3.13) da Ref.[36]) . . . . . . . . . . . . . . . . .

6.5 Escada $2 \times L$ de spins, com acoplamentos $J_{1, l}$ e $J_{2, l}$ nas pernas e $J_{l}^{\prime}$ entre spins dos degraus. A dupla de spins $\hat{\mathbf{S}}_{1, L}$ e $\hat{\mathbf{S}}_{2, L}$ é acrescida à escada para dar sequência ao processo iterativo. . . . . . . . . . . . . . . . . . .

6.6 Gap singleto-tripleto para escadas $2 \times L$ de spins $1 / 2$, em funçāo da razão $J^{\prime} / J$, sendo os acoplamentos $J_{1, l}=J_{2, l}=J$ nas pernas e $J_{l}^{\prime}=J^{\prime}$ nos degraus. O limite termodinâmico (LT) foi extraído da Ref[53] (Fig. (4.6) da Ref.[36]) . . . . . . . . .

7.1 Energia do estado fundamental em função do número de sítios $N$ para cadeias contendo somente spins $1 / 2$, ou somente spins 1 . Nestes casos, os funcionais reproduzem bem os resultados exatos, com $\operatorname{LSA}^{D M R G}$ ligeiramente melhor. Para uma cadeia altamente não homogênea, com spins $1 / 2$ e 1 intercalados, os funcionais já nâo repoduzem bem os resultados exatos, sendo neste caso LSA ${ }^{S W}$ um pouco melhor (Fig. (3.19) da Ref.[36]). 61

7.2 Comparação entre os resultados do funcional LSA ${ }^{S W}$ dado na Eq. (3.27) e aqueles fornecidos pelo funcional local gerado através da Eq. (7.1) acima, para uma cadeia aberta de $N$ spins $1 / 2$ e 1 intercalados, $\operatorname{LSA}^{S W-a l t}$. Os pontos $(\bullet)$ representam resultados exatos e a linha tracejada indica o limite termodinâmico obtido da Eq. (7.1). 62

7.3 Dependência com a temperatura do calor específico de uma cadeia com 18 spins $1 / 2$, com ligações alternada para diversas razões $\alpha$ entre interaçōes de trocas vizinhas. Note valores de $\alpha$ negativos. que correspondem à alternância de ligações ferro- antiferromagnética. Há uma temperatura, $\approx 0.15 . J / k_{B}, \mathrm{em}$ que o valor do calor específico depende muito fracamente de $\alpha$ (Fig. (3.12) da Ref.[36]) . . . . . . . . . . . . 


\section{Lista de Tabelas}

2.1 Estado fundamental, em unidades de $J$ e por spin, $-E_{0} / N J$, obtidos por diversos métodos. HF refere-se a um cálculo Hartrec-Fock[47] para spin 1/2. Os dados exatos foram extraídos da Ref.[46]. Este autor desconhece alguns dos valores. . . . . . . . 25

4.1 Estado fundamental, $-E_{0} / N J$, para sistemas abertos com 100 spins $S$, em diferentes geometrias, desde uma cadeia $1 \times 100$ até un cubo de spins $2 \times 5 \times 10$, passando pela geometria de escadas. A Eq. (3.27) fornece os valores do funcional $E\left[\vec{S}_{i}\right]^{S W}$ (Tab.1 da Ref.[10]) . . . . . . . . . . . . . . . . . . . . . . . . 37

4.2 Estado fundamental $-E_{0} / N J$ nas aproximações CM e $\mathrm{LSA}^{S W}$ para um cubo $4 \times 4 \times 4$, com 63 spins $1 / 2$ mais uma impureza de spin $S_{I}=1 / 2, \ldots, 3$ que pode estar em um dos vértices, em unna das faces, numa das arestas ou no interior do cubo. Observe que a correlação presente no funcional LSA ${ }^{S W}$ levanta degenerescências previstas por campo médio, salientadas em negrito (Tab. 2 da Ref.[56]). . . . . . . . . . . . . 40

6.1 EEF, $-E_{0} / 2 L J$, para escadas de tamanho $2 \times L$, em função da razão $J^{\prime} / J$ entre os acoplamentos dos degraus e das pernas. Foram matidos 12000 estados a cada iteraçāo. O erro indicado é na última casa decimal e ć relativo às energias obtidas mantendo-se 6000 estados. Para cadeias com até 64 spins, as energias são exatas até a sexta casa. A última linha da tabela mostra os resultados da Ref.[53] para o limite termodinâmico, extrapolados de cadcias finitas (Tab. 4.3 da Ref.[36]). . . . . . . . . . . . . 58 


\section{Capítulo 1}

\section{Introdução}

O desenvolvimento no campo do magnetismo tem acompanhado a evolução da humanidade de forma marcante, desde os primeiros relatos na antiguidade de propriedades ferromagnéticas de certos materiais (Tales, VI a.C.), até os primeiros avanços científicos do século XVII, particularmente com Gilbert.[1] Modernamente, podemos citar a presença de materiais ferro e antiferromagnéticos responsáveis por importantes propriedades em dispositivos usados cotidianamente, como nos computadores, em dispositivos de telecomunicações, sensores, etc. A importância do magnetismo transcende a ampla gama de aplicações tecnológicas que oferece e, sobretudo, cria enorme potencialidade para se estudar fenômenos básicos da natureza, permitindo assim uma compreensão mais íntima da matéria. Por exemplo, nos modernos sistemas nanoestruturados, ele é explorado como ferramenta para se compreender o comportamento de dispositivos sob situações de interesse para a Física básica.

A abordagem teórica do início do século XX começou com modelos que inicialmente eram pouco realistas e somente depois de certo tempo é que procurou-se incorporar ingredientes fundamentais dos sistemas magnéticos reais. Foram estudados sistcmas de baixa dimensionalidade, homogêneos, exibindo perfeita invariância translacional. Um dos mais importantes modelos é o de Heisenberg, [2] criado em 1928, apenas três anos após o conceito de spin ter sido introduzido. Originalmente esse modelo foi utilizado para explicar ferromagnetismo. A ideia de ordenamento antiferromagnético aparece em 1932, com Néel,[3] mas a evidência experimental só vem em 1938 com Bizette[4] e confirmada apenas em 1949,[5] por espalhamento de neutrons. Evidências de comportamento unidimensional aparecem já na década de 60.[6] É por essa época que a pesquisa em magnetismo tem início no Brasil.[8] () estudo experimental da dinânica de cadeias antiferromagnéticas foi feita somente em 1974, utilizando novamente espalhamento de neutrons.[7]

Os primeiros modelos, mesmo que pouco realistas, impunham desafios a então recente Mecânica Quântica. Isso já os tornavam relevantes, mas com o tempo, impelido em parte pelo esforço tcórico, novos materiais foram descobertos e outros fabricados com propriedades antes apenas imaginadas no âmbito de modelos. Atualmente, técnicas refinadas de nanofabricação tornam viável o limite unidimensional, quebram controladamente invariância translacional introduzindo impurezas substitucionais, efeitos de 
borda. defeitos topológicos, o que abre amplas possibilidades de estudo.

Apesar deste trabalho tratar principalmente de sistemas unidimensionais, naturalmente, sistemas em duas ou três dimensões são de enorme interesse prático, pois aumentan as possibilidades, não só de aplicações tecnológicas. mas também de esturlos de situações complexas, como linhas e migrações de defeitos. condições de contorno mais sofisticadas, etc.

O objetivo principal deste trabalho é apresentar o formalismo da Teoria do Funcional da Densidade (DFT) a sistemas de spins localizados descritos pelo modelo de Heisenberg e obter a energia do estado funclannental de cadeias ou redes. A intenção ó tratar modelos com quebra de simetria translacional, devido a efeitos de bordas, impurezas substitucionais, ou mesmo defeitos nas ligações entre spins, dando assim um pequeno passo na direção de tratar sistemas mais realistas.

Como é bem conhecido, a DFT tem tido enorme sucesso na abordagem de sistemas eletrônicos, onde a abordagem tradicional de funções de onda cede lugar a de densidades de carga. Diversas aproximações foram implementadas no estudo de sistemas eletrônicos não homogêneos, a mais famosa conhecida por LDA (de Local Density Approximation). Como demonstrado recentemente, [9] podemos implementar a DFT para o modelo de Heisenberg, onde teremos o valor esperado do operador de spin fazendo o papel da densidade de carga dos sistemas eletrônicos. Os funcionais são, até o momento, formulados dentro de aproximações locais a semelhança da LDA, aqui denominada de LSA (de Local Spin Approximation).[10] Queremos sempre que possivel confrontar os resultados obtidos através dos funcionais con dados exatos, mas como estes são escassos para sistemas em duas ou três dimensões, apresentaremos em sua maioria dados para cadeias unidimensionais.

As próximas seçoes deste Capítulo abordan de forma introdutória os dois temas básicos deste trabalho, o modelo de Heisenberg e a Teoria do Funcional da Densidade. Eles são tratados com mais detalhes em capítulos posteriores, uma vez que constituem a base de toda esta Tese.

\section{$1.1 \quad$ O Modelo de Heisenberg}

() trabalho de Pierre Weiss[11] que data de 1907 é um marco na aplicação da Mecânica Estatística ao magnetismo. Nele, é apresentada a proposta de que cada momento magnético do material está submetido a um campo proporcional à magnetização média da amostra. A competição entre o alinhamento forçado por esse campo médio e flutuações térmicas levaria o sistema a exibir uma transição de fase magnética. Dentre as teorias que melhoram a de Picre Weiss, cstá a aplicação feita for P. R. Weiss[12] (que não é o Pierre) da teoria de Bethe e Peierls.[13] No entanto. essas abordagens que utilizam a ideia de um campo médio atuando sobre cada momento magnético desprezam flutuações quânticas, o que acaba limitando bastante a aplicação das mesmas.[14, 15]

Embora parecesse bastante convincente, quantitativamente havia uma séria deficiência na proposta de Pierre Weiss: o valor da suposta interação magnética teria que ser muito grande para explicar valores típicos de temperaturas de transições de fase encontradas em diversos materiais. Com o advento da Mecânica Quântica, tornou-se claro 
¿̇ue a interação é na verdade eletrostática e se manifesta como consequência direta do princípio de exclusão de Pauli:[16] a função de onda eletrônica, por ser antissimétrica pela troca de variáveis espaciais e de spin, torna as autoenergias dependentes da orientação dos spins. Para o caso de dois elétrons localizados. Dirac[17] mostrou que um termo da forma $\hat{\mathbf{S}}_{1} \cdot \hat{\mathrm{S}}_{2}$ em um Hamiltoniano levaria em conta o princípio de exclusão, sendo $\hat{\mathbf{S}}_{i}$ um operador de spin agindo no estado do $i$-ésimo sítio. Heisenberg. * então, propôs que um modelo para spins localizados poderia ser descrito pelo Hamiltoniano[2]

$$
\hat{H}=\sum_{i, j} J_{i, j} \hat{\mathbf{S}}_{i} \cdot \hat{\mathbf{S}}_{j},
$$

com $J_{i, j}$ a energia de troca entre os elétrons dos sítios $i$ e $j$. O sinal de $J_{i, j}$ define a tendência para ordenamento ferromagnético $(J<0)$ ou antiferromagnético $(J>$ 0).[18, 19] Contudo, o modelo ganhou aplicações também para outros ordenamentos, como ferrimagnetismo ou mesmo helimagnetismo,[16] em áreas importantes como supercondutividade de alta temperatura, onde descreve interações de supertroca antiferromagnética entre átomos de cobre do plano cobre-oxigênio.[20] Suas aplicações rompem as fronteiras da Física e, por exemplo, em Química Quântica tem sido usado na descrição de propriedades magnéticas e estados de spin em hidrocarbonetos conjugados, [21, 22] além de ser referencia para o estudo de una grande variedade de compostos metálicos e organometálicos.[23, 24, 25, 26]

A despeito de seu sucesso, o modelo possui diversas limitações. Por exemplo, toda contribuição dos momentos magnéticos $\hat{\mu}$ vem da parte de spin, sendo a parte angular desconsiderada: $\hat{\mu}=-g \mu_{B} \hat{\mathrm{S}}$. Para íons com $L=0$, como $\mathrm{Mn}^{++}$ou $\mathrm{Gd}^{3+}$, isso é exato; é uma ótima aproximação para metais de transição, devido ao quenched do momento angular (efeito devido ao campo cristalino). Por exemplo, para $\mathrm{Cu}^{++}$, que exibe $S=1 / 2$ e $L=2, \mu_{\text {eff }}=g \sqrt{S(S+1)} \mu_{B}=1.73 \mu_{B}$ (adotando $g=2$ para spin), próximo do valor experimental, $1.99 \mu_{B}$. Levando em conta o momento angular temos que escrever $\mu_{e f f}=g_{J} \sqrt{J(J+1)} \mu_{B}$, com $J=L+S$ e $g_{J}$ o fator de Landé; obteríamos, então, $\mu_{\text {eff }}=3.55 \mu_{B}$, longe do valor experimental. Por exemplo, para $\mathrm{Ce}^{3+}$, que tem $S=1 / 2$ e $L=3, \mu_{\text {eff }}=g \sqrt{S(S+1)} \mu_{B}=1.73 \mu_{B}$, enquanto $\mu_{\text {eff }}=g J \sqrt{J(J+1)} \mu_{B}=2.535 \mu_{B}$, este último sim bem mais próximo do valor experimental $2.6 \mu_{B}$. [16]

Outra limitação usualmente imposta ao modelo é a de considerar a interação de troca apenas entre pares de spins vizinhos mais próximos. Isso, na prática, é justificável uma vez que se espera que haja superposição apreciável apenas de orbitais vizinhos. É o caso considerarlo cm todo este trabalho. Outras limitações usuais são tomar $J_{i, j}$ independentes do sítio e toda a rede constituída de spins de mesmo valor. São exatamente estas últimas limitações que neste trabalho queremos superar, ao menos em parte, através da DFT aplicada em sistemas de spins com defeitos nas ligações ou com spins substitucionais na rede, desta forma quebrando a simetria translacional e tornando a abordagem mais realista.

A forma mais geral do Hamiltoniano de Heisenberg considera anisotropia de troca,

${ }^{*}$ Heisenberg foi laureado com o Prêmio Nobel em 1932 pelos seus trabalhos em Mecânica Quântica. 
isto é, $J_{i, j}$ dependente da direção. Neste caso, a Eq. (1.1) é reescrita como

$$
\hat{H}=\sum_{i, j}\left(J_{i, j}^{x} \hat{S}_{i}^{x} \hat{S}_{j}^{x}+J_{i, j}^{y} \hat{S}_{i}^{y} \hat{S}_{j}^{y}+J_{i, j}^{z} \hat{S}_{i}^{z} \hat{S}_{j}^{z}\right)
$$

Dois limites deste modelo são interessantes. Com $J_{i, j}^{x}=J_{i, j}^{y}=0$ temos o tradicional modelo de Ising, [27] uma vez que a dinâmica dos operadores $\hat{S}^{z}$ sozinhos é a mesma de uma variável clássica que assume valores discretos (dois valores no caso de spin 1/2); flutuações quânticas, portanto, são inexistentes. Neste limite o modelo é útil quando se tem uma enorme anisotropia no espaço de spin, como é o caso do composto $\mathrm{MnF}_{2}$. Como se sabe, o modelo de Ising apresenta ordenamento em temperatura não nula apenas para dimensões maiores que 1 . Outro limite é quando $J_{i, j}^{z}=0$, que recai no modelo de Heisenberg XY, onde os spins são operadores vetoriais em duas dimensões. [28] Transição de fase no sentido convencional (isto é, com comprimento de correlação infinito na temperatura crítica) existe somente para dimensões acima da unidade.

Dada a complexidade do modelo, só é conhecida solução analítica no limite termodinâmico para cadeias homogêneas de spins $1 / 2$, graças ao formalizmo do ansatz de Bethe.[29. 30] Para spins além de $1 / 2$ ou dimensionalidades mais altas, soluções exatas são numericamente conhecidas apenas para redes relativamente pequenas e, via de regra, homogêneas. Na presença de inomogeneidades, soluções exatas são inexistentes. O uso da Teoria do Funcional da Densidade estende os resultados conhecidos nos sistemas homogêneos para situaçóes com inomogencidades. Progressos nesse sentido devem eolaborar para enriquecer os desenvolvimentos acerca de estruturas nanomagnéticas, em particular na emergente área de spintrônica, onde defeitos são cruciais para se obter as propriedades desejadas.

\subsection{A Teoria do Funcional da Densidade}

A Teoria do Funcional da Densidade, ou DFT. é baseada em uma afirmação relativamente simples mas com grandes consequências: as grandezas observáveis de um sistema quântico de $N$ elétrons são completamente determinadas pela densidade de carga do estado fundamental.[31] Essa afirmação constitui o cólebre teorema de Hohenberg e Kohn, $[31,32]$ de $1964 .^{\dagger}$ Como a densidade de carga é uma função de três coordenadas espaciais, $n=n(\vec{r})$, os observáveis tornam-se funções dessa função, ou, funcionais da densidade. Então, a princípio, podemos dispensar as funções de onda e trabalhar somente com a distribuição de carga. Via de regra isso é feito resolvendo-se as equações de Kohn e Sham, [33] utilizando uma das várias aproximações disponíveis para a energia de troca e correlação.

Métodos computacionais são hoje em dia importantes ferramentas para tratar problemas de muitos corpos, existindo métodos numéricos muito apropriados para simular sistemas homogêneos de spins cuja interação é dada por Hamiltonianos do tipo de Heisenberg. Apesar do grande desenvolvimento de métodos consagrados, como Monte

\footnotetext{
†Walter Kohn recebeu o Prêmio Nobel de Química em 1998 pela grande contribuição que a DFT trouxe a essa área.
} 
Carlo Quântico (QMC) ou mesmo do Grupo de Renormalização da Matriz Densidade (DMRG), eles impõem sérias restrições quanto ao tamanho da rede de spins e, usualmente, são aplicáveis a redes com invariância translacional. Com o intuito de superar essas linitaçooes. utilizamos neste trabalho a DFT, recentemente adaptada por nós para sistemas não-homogêneos descritos pelo Hamiltoniano de Heisenberg. [9, 10] Enquanto outros métodos comumente encontrados na literatura se baseiam na função de onda de muitos corpos do sistema, na DFT as propriedades físicas são funcionais de uma densidade eletrônica, em nosso caso funcionais do valor esperado do operador de spin cm cada sítio, como vercmos. É nessa dependência com uma função densidade $n(\vec{r})$, mais simples que uma função de onda $\psi\left(\vec{r}_{1}, \vec{r}_{2}, \ldots\right)$, que a DFT, em geral, ganha enorme vantagem computacional em relação a outros métodos.

\subsection{Os Resultados Presentes neste Trabalho}

Os desenvolvimentos apresentados neste trabalho são em parte fruto das colaboraçöes com o Dr. Klaus Capelle. $[9,10]$ ()s resultados foram obtidos, em sua grande maioria, nas minhas orientações de Iniciação Científica dos alunos Paulo E. G. Assis e Rodrigo S. Veiga, de Mestrado de Poliana H. Penteado[34] e Guilherme N. Prata,[35] e de Doutorado de Fabiano C. de Souza. [36] Nos trabalhos desses alunos está a base da aplicação da DFT ao modelo de Heisenberg.

Esta tese é escrita tendo em mente a sua utilização por estudantes interessados nesta linha de pesquisa. Longe de ser um trabalho completo, uma vez que aborda duas grandes áreas, o magnetismo e o formalismo DFT, esta Tese procura reunir de forma didática os descnvolvimentos até cutão conseguidos.

\subsection{Organização desta Tese}

Como orientação à leitura, descrevemos abaixo sucintamente o conteúdo dos capítulos subsequentes, que podem, em princípio, ser lidos em qualquer ordem:

1. No Capítulo II descrevemos o modelo de Heisenberg e compilamos alguns resultados, cxatos ou aproximados, que são relevantes para a definição dos funcionais.

2. No Capítulo III é formulada a Teoria do Funcional da Densidade para o modelo de Heisenberg. Apresentamos uma prova alternativa a nossa presente na literatura[9] do teorema central da DFT, o teorema de Hohenberg-Kohn, para sistemas de spins descritos pelo Hamiltoniano de Heisenberg. São definidos também funcionais via aproximação local (LSA), através da energia de correlação obtida da teoria de SW ou via DMRG.

3. No Capítulo IV são apresentados resultados obtidos via funcional de spin para sistemas com invariância translacional quebrada, tanto em uma, como em duas ou três dimensões. Também são apresentados resultados para sistemas bidimensionais com vacâncias de spins. Todos eles são comparados com valores extraídos da 
literatura ou obtidos por métodos numéricos aplicados a sistemas com tamanho adequado para serem simulados em microcomputadores.

4. No Capítulo V sistemas com defeitos de ligações são abordados e dados obtidos de un funcional baseado en resultados numéricos para cadeias conn ligações alternadas são mostrados. Introduzimos também o conceito de aproximação local por células unitárias (LUCA), para se gerar um funcional não local nas ligações.

5. No Capítulo VI mostramos dois métodos numéricos de obtenção de resultados exatos, que seviram para dar respaldo aos valores estimados pelos funcionais. Um deles é tradicional, onde, a partir de potêneias sucessivas do Hamiltoniano aplicadas em uma função tentativa, é extraída a energia do estado fundamental. No outro, implementamos um método de diagonalização iterativa do Hamiltoniano, explorando a conservação dos operadores spin total e sua componente $z$. Esse precedimento fornece todos os autoestados do Hamiltoniano, com boa precisão para cadeias de tamanho moderado (exato até 20 spins $1 / 2$ e com cerca de cinco casas decimais de precisão para 100 spins 1/2). A partir dessa abordagem podemos computar propriedades termodinâmicas de cadeias, ou mesmo escadas, de spins com impurezas. No Apendice fornecemos detalhes da implementação desse método iterativo; a análise completa é feita na Tese de Doutorado de Fabinao C. de Souza.[36]

6. Finalmente, no Capítulo VII apresentamos sugestões de continuidade dos problemas abordados nos capítulos anteriores. Naturalmente, como nossa abordagem de todos os sistemas até então analisados é restrita a aproximaçóos locais, fica a tarefa importante de se introduzir funcionais mais sofisticados, a exemplo da própria evolução dos mesmos para sistemas eletrônicos descritos por densidades de carga. 


\section{Capítulo 2}

\section{O Modelo de Heisenberg}

O modelo de Heisenberg é dos mais importante no estudo dos fenômenos magnéticos na matéria quando momentos magnéticos localizados desempenhan o papel principal. O modelo é definido pelo Hamiltoniano[2]

$$
\hat{H}=\sum_{<i, j>}^{N} J_{i, j} \hat{\mathbf{S}}_{i} \cdot \hat{\mathbf{S}}_{j},
$$

onde $\hat{\mathbf{S}}_{i}$ ć um operador que atuam no spin residente no sítio $i$ de uma rede de $N$ sítios. A notação $\langle i, j\rangle$ significa que apenas spins primeiros vizinhos interagem diretamente.

Para termos uma noção do que esse Hamiltoniano pode descrever, consideremos o caso de apenas dois spins $1 / 2, \operatorname{com} J_{1,2} \equiv J$. Então, $\hat{H}=J \hat{\mathrm{S}}_{1} \cdot \hat{\mathrm{S}}_{2}$, é facilmente reescrito como

$$
\hat{H}=\frac{J}{2}\left(\hat{\mathbf{S}}_{T}^{2}-\hat{\mathbf{S}}_{1}^{2}-\hat{\mathbf{S}}_{2}^{2}\right),
$$

sendo $\hat{\mathbf{S}}_{T}=\hat{\mathrm{S}}_{1}+\hat{\mathrm{S}}_{2}$ o spin total do sistema. Usando como base de estados os autovetores dos operadores quadrado do spin total e quadrado dos spins individuais, $\left|s_{T}, s_{1}=1 / 2, s_{2}=1 / 2\right\rangle$, é imediato que os níveis de energia do sistema são dados por *

$$
E_{S_{T}}=\frac{J}{2}\left[s_{T}\left(s_{T}+1\right)-\frac{3}{2}\right] \text {, }
$$

com $s_{T}=0$ ou 1.

Com esse espectro de energias, podemos calcular a dependência com a temperatura de propriedades termodinâmicas. como a susceptibilidade magnética $\chi$, definida por

$$
\frac{k_{B} T \chi}{\left(g \mu_{B}\right)^{2}}=\left\langle\hat{S}_{T, z}^{2}\right\rangle-\left\langle\hat{S}_{T, z}\right\rangle^{2},
$$

que neste caso de dois spins $1 / 2$ resulta em

$$
\frac{k_{B} T \chi}{\left(g \mu_{B}\right)^{2}}=\frac{2}{3+e^{3 . J}} .
$$

*Também ć trivial diagonalizar esse $\hat{H}$ na base da componente $z$ de cada spin: isso resulta numa matriz $4 \times 4$, com um bloco diagonal $2 \times 2$ e dois blocos $1 \times 1$. 
onde $\beta=1 / k_{B} T$. A entropia $S$, por exemplo, pode ser facilmente calculada via $S / k_{B}=$ $\ln Z+\beta \bar{E}$, sendo $Z$ a função de partição e $\bar{E}$ a energia média:

$$
\frac{S}{k_{B}}=\ln \left(3+e^{\beta J}\right)-\beta J \frac{e^{\beta J}}{3+e^{\beta J}} .
$$

A Fig. (2.1) ilustra o comportamento dessas funções. Em baixas temperaturas a flutuação do momento magnético, proporcional ao produto $T \chi$, vai a zero se $J>0$, como resultado da formação do estado fundamental singleto $\left|s_{T}=0\right\rangle=|\uparrow \downarrow\rangle-|\downarrow \uparrow\rangle$; dizemos que o ordenamento é antiferromagnético. Veja que a exponencial da entropia tende ao valor unitário. Já para $J<0$, a flutuação magnética tem valor máximo em $T=0$, o estado fundamental é degenerado, podendo ser qualquer combinação linear dos estados do tripleto: $|\uparrow, \uparrow\rangle,|\downarrow, \downarrow\rangle$ ou $|\uparrow, \downarrow\rangle+|\downarrow, \uparrow\rangle$; o ordenamento agora é denominado ferromagnético. A exponencial da entropia neste caso tende ao valor três, que é o número de estados do tripelo. Em altas temperaturas, tipicamente $k_{B} T>>J$, temos o limite de dois spins $1 / 2$ livres, portanto, quatro estados igualmente prováveis, e assim a entropia assintoticamente tendo ao valor $\ln 4$. O valor assintótico $k_{B} T \chi /\left(g \mu_{b}\right)^{2}=1 / 2$ reflete a lei de Curie neste regime.

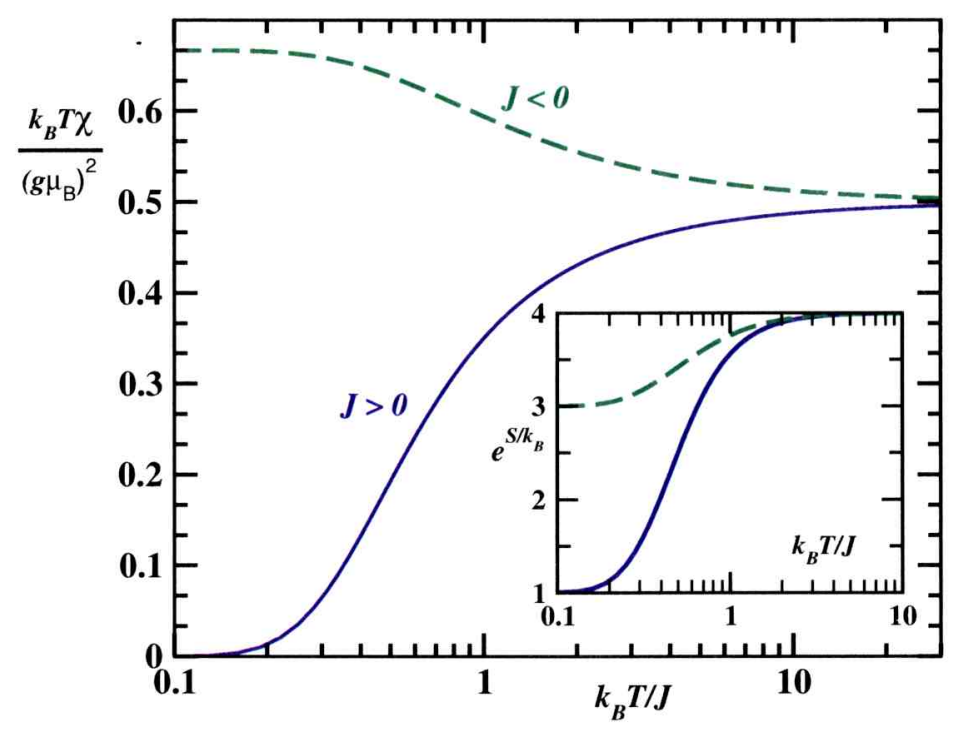

Figura 2.1: Flutuação magnética $T \chi$ versus temperatura $T$ para os casos de alinhamento ferromagnético $(J<0)$ e antiferromagnético $(J>0)$. No inset é mostrada a exponencial da entropia, versus temperatura, que mede o número efetivo de graus de liberdade a cada temperatura.

Podemos atribuir um significado físico à constante $J$. Observe que ela se iguala, pelo menos de forma visível neste caso de dois spins, à diferença de energia entre o singleto e o tripleto, ou seja, se origina do princípio de exclusão de Pauli, que obriga a antissimetrização das funções de onda envolvidas.[16] É de origem eletrostática, portanto, e não magnética como a primeira vista seria pensada uma vez que $\hat{H}$ acopla dois spins. ${ }^{\dagger}$.

${ }^{\dagger} \mathrm{A}$ interação magnética entre dois dipolos é da ordem de $m_{1} m_{2} / r^{3} \approx\left(\mu_{B}\right)^{2} / a_{o}^{3} \approx \alpha^{4} m c^{2} \approx 10^{-3} \mathrm{eV}$. Por outro lado, $J$ é da ordem de $0.1 \mathrm{eV}$ 
As flutuações quânticas introduzidas pela não comutatividade dos operadores $\hat{S}_{x}, \hat{S}_{y}$ e $\hat{S}_{z}$ tornam a diagonalização de $\hat{H}$ nada trivial. No entanto, para um anel de $N$ spins $1 / 2 \mathrm{com}$ ordenamento ferromagnético, o estado fundamental é facilmente obtido: $\left|\psi_{0}\right\rangle=|\uparrow: \uparrow, \ldots, \uparrow\rangle$ com energia $E_{0}=-N J / 4$, a mesma solução obtida pela aproximação de campo médio. Todavia, no caso antiferromagnético não é tão simples e a solução de campo médio, o chamado estado Néel, $\left|\psi_{0}\right\rangle=|\uparrow, \downarrow . \uparrow, \ldots, \downarrow\rangle$, não representa mais o estado fundamental.

Em sólidos a situação acima ganha ainda mais complexidade, uma vez que temos muitos spins, não apenas de valor $1 / 2$, interações de troca $J_{i, j}$ que podem ir além de primeiros vizinhos, depender do sítio, apresentar anisotropias de troca $\left(J_{x} \neq J_{y} \neq J_{z}\right)$, etc. Naturalmente, as abordagens teóricas são limitadas quando se inclui tais complexidades e por isso é natural que diversas aproximações tenham surgido na abordagem desse modelo. As seções seguintes resumem alguns resultados relevantes para sistemas

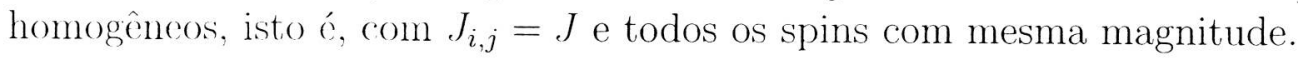

\subsection{Resultados exatos para cadeias de spins $1 / 2$}

Sistemas tridimensionais são naturalmente de grande interesse, e de longa data compostos com características de cadeias lineares de spins são conhecidos e tem merecido atenção.[7] Usualmente são redes em que ao longo de uma direção os spins são fortemente acoplados, mas muito fracamente interagentes com os demais spins, conferindo ao composto propriedades unidimensionais.

O Hamiltoniano (2.1) para o caso de cadeias homogêneas de spins $1 / 2$ foi abordado por Bloch[37] na década de 1930 no caso de acoplamentos $J_{i, j}=J$ ferromagnéticos. O estado fundamental é trivial, com todos os spins paralelos e apontando no mesmo sentido. $\hat{H}$ conserva a componente $z$ do spin total, ou equivalentemente, o número de spins reversos em relação ao estado fundamental. Introduzindo o conceito de ondas de spins, Bloch determinou o estado fundamental exato para o setor de um spin reverso. Logo em seguida, 1931, Bethe ${ }^{\ddagger}$ obtem os autocstados exatos para um número qualquer de spins reversos,[29] utilizando a técnica hoje denominada de ansatz de Bethe. A profundidade desse trabalho foi além do que Bethe podia imaginar; hoje essa técnica é aplicada em diversos modelos importantes, como o de Hubbard,[38]. Em 1938 Hulthén [30] utiliza o procedimento de Bethe para deduzir uma equação integral e assim obter o valor exato do limite termodinâmico da energia do estado fundamental de um cadeia de spins $1 / 2$ com acoplamentos antiferromagnéticos:

$$
\frac{E_{o}}{N J}=1 / 4-\ln 2 \approx-0.44314718 \ldots
$$

O impacto do trabalho de Bethe não foi muito grande em sua época, a julgar pelo lapso de tempo para a sua utilização em outros modelos. Por exemplo, somente em 1958 a técnica foi estendida, por Orbach, ao modelo de Heisenberg anisotrópico.[39] definido

\footnotetext{
‡Em 1928 cle obtem o PhD sob orientação de Sommerfeld; recche o prêmio Nobel em 1967 devido aos seus trabalhos sobre reações nucleares em estrelas.
} 
por

$$
\hat{H}=J \sum_{<i, j>}^{N}\left(\hat{S}_{i, x} \hat{S}_{j, x}+\hat{S}_{i, y} \hat{S}_{j, y}+\Delta \hat{S}_{i, z} \hat{S}_{j, z}\right) .
$$

Ele mostrou que as singularidades presentes na energia e na ordem de curto alcance preristas pelo cálculo variacional de Kasteleijn eram espúrias. [40] Walker [41] logo em seguida, resolvendo analiticamente a equação integral de Orbach, mostra que o estado fundamental antiferromagnético $E_{0}(\Delta)$ é uma função não analítica em $\Delta=1$. Sua expressão para a energia no limite termodinâmico é (para $\Delta \geq 1$ )

$$
\frac{E_{0}(\Delta)}{N J}=\frac{\Delta}{2}\left[\frac{1}{2}-\left(1+\sum_{1}^{\infty} \frac{4}{1+e^{2 n \lambda}}\right) \tanh \lambda\right],
$$

onde $\Delta=\cosh \lambda$. Para $\Delta<1$, ver Ref.[42].

$\mathrm{O}$ modelo definido pela Eq. (2.8) mas com $\Delta=0$ denomina-se Heisenberg XY e tem solução exata, como mostrou a Ref.[28]. No limite $\Delta \rightarrow \infty$ ele recai no modelo de Ising, que apresenta solução analítica em uma e duas dimensões.

\subsection{Resultados aproximados para cadeias homogê- neas de spins $S$}

Para implementar o procedimento da DFT precisamos de resultados para cadeias com spins $S$, mesmo que não scjam exatos. A aproximação mais simples para o Hamiltoniano de Heisenberg. Eq. (2.1), é a de campo médio (CM), onde os operadores vetoriais $\hat{\mathbf{S}}$ são substituídos por vetores clássicos $\vec{S}$. Nessa aproximação, a energia, por spin, do estado fundamental antiferromagnético para um sistema homogêneo de $N$ spins $S$ em $d$ dimensões, com condições periódicas de contorno, é

$$
e_{0}^{C M}(S) \equiv \frac{E_{0}^{C M}(S)}{N J}=-d S^{2}
$$

que corresponde ao ordenamento ilustrado na Fig. (2.2). Para uma cadeia $(d=1)$ de spins $1 / 2$ temos $e_{0}^{C M}=-0.25$, um desvio de $43.6 \%$ do valor exato, que é $1 / 4-\ln 2 \approx$ $-0.44314718 \ldots$, obtido pelo ansatz de Bethe.[29, 30]

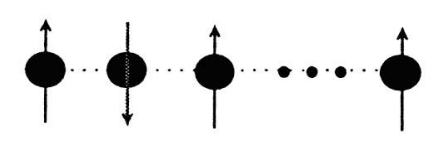

Figura 2.2: Na aproximação de campo médio o estado fundamental de um sistema antiferromagnético apresenta os spins vizinhos alinhados antiparalelamente uns aos outros; esse é o denominado estado Nócl.

Anderson. [43] usando argumentos variacionais, mostrou que a energia por spin, $e_{0}^{\text {And }}$, do estado fundamental antiferromagnético de um sistema de spins $S$ em $d$ dimensões 
tem os seguintes limites:

$$
-d S^{2}\left(1+\frac{1}{2 d S}\right) \leq e_{0}^{A n d} \leq-d S^{2}
$$

e, portanto. uma aproximação é tomar o centro desse intervalo:[44]

$$
e_{0}^{\text {And }}(S)=-d S^{2}\left(1+\frac{1}{4 d S}\right) .
$$

Isso fornece, para $d=1$ e $S=1 / 2$, o valor $e_{0}^{\text {And }}=-0.375$, baixando o erro para $15.4 \%$.

Resultados melhores são obtidos da Teoria de Ondas-de-Spin (SW),[44] a qual leva en conta perturbativamente a flutuação do spin cm torno de sua posição de campo médio (ver Fig. (2.3)):

$$
e_{0}^{S W}(S)=-d S^{2}+d^{-1 / 5}\left(\frac{2}{\pi}-1\right) S,
$$

onde o fator $d^{-1 / 5}$ reproduz os coeficientes obtidos por Anderson para $d=1,2$ ou 3 (é uma hipótese de escala conjecturada por nós na Ref.[9]). Por exemplo, para $d=1$ e $S=1 / 2$, temos $e_{0}^{S W}=-0.431690$, apenas $2.6 \%$ do valor exato; para $S=2, c_{0}^{S W}=$ -4.72676 , com desvio de somente $0.7 \%$ do valor exato -4.761244 .

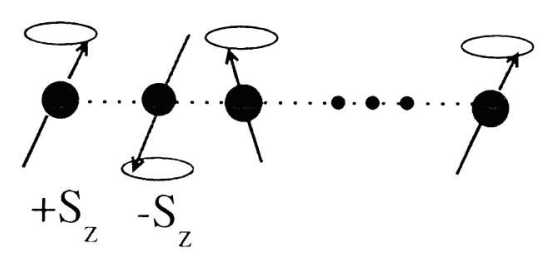

Figura 2.3: Na Teoria de Ondas-de-Spin, considerada-se de forma perturbativa a flutuação do spin em torno de seu estado de campo médio. Embora fosse esperado bons resultados apenas para valores altos de spins (pois a fluturação é da ordem de $1 /(2 S+1)$ ), surpreendentemente, mesmo para spin $1 / 2$, essa teoria fornece bons resultados.

Expressivamente melhores são os resultados obtidos pela técnica numérica do Grupo de Renormalização da Matriz Densidade (DMRG). ${ }^{\S}$ Baseados em dados de DMRG, os autores da Ref. [46] propuseram a seguinte função ajuste para a encrgia do estado fundamental de uma cadeia antiferromagnética de spins $S$ :

$$
\begin{aligned}
e_{0}^{D M R G}(S) & =-S^{2}+\left(\frac{2}{\pi}-1\right) S-0.03262-\frac{0.0030}{S}+\frac{0.0015}{S^{3}} \\
& -\left(0.338-\frac{0.28}{S}+\frac{0.035}{S^{3}}\right) e^{-\pi S} \cos (2 \pi S)
\end{aligned}
$$

Observe que os dois primeiros termos da Eq. (2.14) coincidem com $e_{0}^{S W}(S)$, enquanto os demais correspondem a correções menores. Os dois termos cúbicos em $S$ foram por

\footnotetext{
§A Ref.[45] trás uma apresentação didática dessa técnica.
} 
Tabela 2.1: Estado fundamental, em unidades de $J$ e por spin, $-E_{0} / N J$, obtidos por diversos métodos. HF refere-se a um cálculo Hartree-Fock[47] para spin 1/2. Os dados exatos foram extraídos da Ref.[46]. Este autor desconhece alguns dos valores.

\begin{tabular}{l|l|l|l|l|l|l} 
& $1 / 2$ & 1 & $3 / 2$ & 2 & $5 / 2$ & 3 \\
\hline $\mathrm{CM}$ & 0.25 & 1 & 2.25 & 4 & 6.25 & 9 \\
$\mathrm{HF}$ & 0.4196 & - & - & - & - & - \\
$\mathrm{SW}$ & 0.43169 & 1.36338 & 2.79507 & 4.72676 & 7.15845057 & 10.09014068 \\
DMRG & 0.4431471 & 1.4014841 & 2.82833 & 4.761243 & 7.1922313 & 10.1237525 \\
Exato & 0.44314718 & 1.401484038971 & 2.82833 & 4.761244 & - & -
\end{tabular}

nós introduzidos empiricamente[9] para tornar a expressão precisa para spin $1 / 2$, obtendo assim $e_{0}^{D M R G}=-0.446253$, um desvio de apenas $0.7 \%$ do valor exato. Sem eles obteríamos um desvio de $17 \%$ no caso de spin 1/2. Esses termos, no entanto, praticamente não alteram os resultados da expresssão original da Ref.[46] para spins maiores que $1 / 2$, mas são impressindíveis para se gerar um funcional através de $e_{0}^{D M R G}(S)$. Na Tab. 2.1 podemos comparar alguns valores da energia do estado fundamental obtidos por diferentes técnicas. Observe como CM e SW fornecem melhores resultados para spins mais altos.

As expressões ou os resultados acima são restritos a sistemas homogêneos, o que representa uma grande limitação, uma vez que é comum em sistemas reais encontrarmos inomogeneidades, por exemplo induzidas por campos externos, criadas por anisotropias cristalinas, por efeitos de borda, por impurezas localizadas ou mesmo por defeitos nas ligações da rede. Essas situações trazem enormes dificuldades aos métodos tradicionais que exploram invariância translacional. Para superar essas restrições, utilizaremos a DFT para estimar a energia do estado fundamental de sistemas inomogêneos descritos pelo modelo de Heisenberg. O próximo Capítulo introduz os conceitos necessários à aplicação da DFT ao modelo de Heiscnberg. 


\section{Capítulo 3}

\section{A Teoria do Funcional da Densidade - DFT}

A seguir apresentamos uma breve introdução à DFT para sistemas eletrônicos, visando à formulação da mesma ao modelo de Heisenberg, feita logo em seguida na Seção 3.2. Está longe de ser completa, mas detalha aspectos de interesse para nossas aplicações.

\subsection{DFT para sistemas eletrônicos}

O vetor de onda $|\Psi\rangle$ de um sistema (não relativístico) de muitos elétrons submetidos a un potencial externo independente do tempo obedece à equação de Schrödinger

$$
\hat{H}|\Psi\rangle=(\hat{T}+\hat{U}+\hat{V})|\Psi\rangle=E|\Psi\rangle
$$

onde $\hat{T}$ é o termo de energia cinética, $\hat{U}$ a energia de interação Coulombiana entre os elétrons e $\hat{V}$ a energia devido a um potencial externo. A função de onda $\psi=$ $\left\langle\vec{r}_{1}, \vec{r}_{2}, \ldots, \vec{r}_{N} \mid \Psi\right\rangle$ tem como argumento as coordenadas $\vec{r}_{1}, \vec{r}_{2}, \ldots, \vec{r}_{N} \operatorname{dos} N$ elétrons do sistema (além de números quânticos, como momentos angulares). De posse de $|\Psi\rangle$ determina-se todos os observáveis do sistema. No entanto, todos sabemos o nível de dificuldade para se resolver a equação acima, mesmo para sistemas contendo poucos elétrons interagentes. Um procedimento alternativo para se obter os observáveis sem necessariamente determinar $|\Psi\rangle$ foi desenvolvido por Hohenberg e Kohn[31] em 1964, em que a densidade $n(\vec{r})$ desempenha papel central; daí a denominação Density-Functional Theory, ou simplesmente DFT. A demonstração do teorema de Hohenberg-Kohn pode ser encontrada em diversos livros textos, [49] ou teses, [19] e usualmente se baseia numa prova por contradição. Seguiremos, no entanto, o procedimento elaborado por Levy[50] e Lieb[51] no contexto dos sistemas eletrônicos, que é bem mais instrutivo.[48]

Pelo princípio variacional, a energia $E_{0}$ do estado fundamental de um sistema descrito por um Hamiltoniano $\hat{H}$ obedece a desigualdade

$$
E_{0} \leq\langle\Psi|\hat{H}| \Psi\rangle
$$


sंendo $|\Psi\rangle$ um vetor de onda qualquer (normalizado). Para determinar $E_{0}$, procuramos dentre todos os vetores $|\Psi\rangle$ aquele que minimiza o valor esperado $\langle\Psi|\hat{H}| \Psi\rangle$. Isso pode ser feito seguindo alguma estratégia conveniente, em função de cada Hamiltoniano em questão. Em sistemas descritos pelo Hamiltoniano (3.1), a Eq. (3.2) induz a calcular o valor esperado $\langle\Psi|\hat{V}| \Psi\rangle$. No caso de potenciais da forma

$$
\hat{V}=\sum_{i}^{N} \hat{V}\left(\vec{r}_{i}\right)
$$

temos que

$$
\langle\Psi|\hat{V}| \Psi\rangle=\int d^{3} r n(\vec{r}) V(\vec{r})
$$

onde

$$
n(\vec{r})=N \int d^{3} r_{2} d^{3} r_{3} \ldots d^{3} r_{N}\left|\Psi\left(\vec{r}, \vec{r}_{2}, \vec{r}_{3} \ldots \vec{r}_{N}\right)\right|^{2}
$$

ć a densidarle de partículas na posição $\vec{r}$. Então, o potencial externo se acopla diretamente à densidade $n(\vec{r})$, e não à função de onda propriamente, o que sugere definir um processo de minimização que utiliza a densidade como protagonista. Na formulação de Levy e Lieb isso é feito explicitamente. Primeiro define-se o funcional de $n(\vec{r})$

$$
E[n]=\min _{|\Psi\rangle \rightarrow n}\langle\Psi|\hat{H}| \Psi\rangle
$$

onde para cada escolha de uma função $n(\vec{r})$ positiva semi-definida procuramos por $|\Psi\rangle$ antissimétrico que minimize $\langle\Psi|\hat{H}| \Psi\rangle$. Esse valor mínimo ainda não é $E_{0}$, uma vez que a simples escolha $n(\vec{r})$ dificilmente será a densidade $n_{0}(\vec{r})$ do estado fundamental. Com esse procedimento, tem-se densidades $n(\vec{r})$ que são $N$-representáveis, isto é, atreladas a funções de onda antissimétricas $|\Psi\rangle$ de $N$ elétrons. Substituindo $\hat{H}=\hat{T}+\hat{U}+\hat{V}$ na equação acima temos

$$
E[n]=\min _{|\Psi\rangle \rightarrow n}[\langle\Psi|\hat{T}+\hat{U}| \Psi\rangle+\langle\Psi|\hat{V}| \Psi\rangle] \equiv F[n]+\int d^{3} r n(\vec{r}) V(\vec{r}),
$$

onde $F[n] \equiv \min _{|\Psi\rangle \rightarrow n}\langle\Psi|\hat{T}+\hat{U}| \Psi\rangle$ é um funcional universal, isto é, independente do potencial externo.

A densidade $n_{0}(\vec{r})$ correspondente ao estado fundamental $\left|\Psi_{0}\right\rangle$ é aquela que minimiza $E[n]$ :

$$
E_{0}=\min _{n} E[n]
$$

Para esse $n_{0}(\vec{r})$ o vetor $|\Psi\rangle$ que resulta da procura $F\left[n_{0}\right]=\min _{|\Psi\rangle \rightarrow n_{0}}\langle\Psi|\hat{T}+\hat{U}| \Psi\rangle$ corresponde à função de onda $\Psi_{0}$ do estado fundamental de $\hat{H}$. Assim, tem-se que $\Psi_{0}$ é um funcional de $n_{0}(\vec{r})$, ou seja, $n_{0}(\vec{r})$ determina completamente o estado fundamental do sistema.

Na prática o esquema descrito acima requer aproximações para ser implementado, as quais são feitas em etapas e a primeira consiste em escrever

$$
\langle\Psi|\hat{T}+\hat{U}| \Psi\rangle=T[n]+U[n] \equiv T_{s}[n]+U_{H}[n]+E_{x c}[n] .
$$


ònde $T_{s}[n]$ é o termo de energia cinética de um sistema de elétrons independentes e $U_{H}[n]$ a energia de interação na aproximação de Hartree. * Essa equação define $E_{x c}[n]$, denominado funcional de troca e correlação, que incorpora tudo que falta em $T_{s}[n]+$ $U_{H}[n]$ para resultar no funcional $T[n]+U[n]$ exato. Enquanto $U_{H}[n]$ ć conhecido, para se obter $T_{s}[n]$ precisamos de um procedimento adicional. No esquema de Kohn e Sham[33], $T_{s}[n]$ é escrito em termos de orbitais de partículas independentes obtidos de uma equação de Schrödinger para uma partícula num potencial efetivo, que após um procedimento iterativo, auto consistente, determina-se $n(\vec{r})$.

()utra possibilidarle, bem menos eficiente na prática para os sistemas elctrônicos, mas conveniente para nossa aplicação da DFT ao modelo de Heisenberg, é recorrer à aproximação Thomas-Fermi, que consiste em primeiro introduzir uma aproximação local para o funcional $T[n]$ :

$$
T[n] \approx T^{L D A}[n]=\left.\int d^{3} r t^{h o m}(n)\right|_{n \rightarrow n(\vec{r})},
$$

sendo $t^{\text {hom }}(n)$ a energia cinética por volume de um sistema eletrônico homogêneo em função da densidade uniforme $n$, no lugar da qual se substitui a densidade local $n(\vec{r})$. A sigla $L D A$ refere-se a Local-Density Approximation, que designa o tipo de aproximação feita. Como a função $t^{\text {hom }}(n)$ é de um sistema interagente e por isso não é conhecida com a precisão necessária para cálculos ab initio, há a necessidade de una aproximação adicional: simplesmente troca-se $t^{\text {hom }}(n)$ pela energia cinética, por volume, de um sistema de partículas independentes, $t_{s}^{\text {hom }}(n)$, que é bem conhecida $\left(t_{s}^{\text {hom }}(n) \propto n^{5 / 3}\right)$. Isso completa a aproximação Thomas-Fermi, sintetizada da seguinte forma:

$$
T[n] \approx T^{L D A}[n] \approx T_{s}^{L D A}[n]=\left.\int d^{3} r t_{s}^{h o m}(n)\right|_{n \rightarrow n(\vec{r})}
$$

() termo de troca e correlação também pode ser aproximardo no mesmo estilo da Eq. $(3.10)$ :

$$
E_{x c}[n] \approx E_{x c}^{L D A}[n]=\left.\int d^{3} r e_{x c}^{h o m}(n)\right|_{n \rightarrow n(\vec{r})},
$$

sendo $e_{x c}^{h o m}(n)$ a energia de troca e correlação por volume de um gás homogêneo de elétrons de densidade $n$.

Então, diferentemente do esquema Kohn-Sham, no de Thomas-Fermi minimizamos diretamente o funcional da energia. Esse também é o caso no modelo de Heisenberg, com o adicional de que não há necessidade de aproximar o termo de energia cinética, já que este inexiste. A ideia de aproximação local para o funcional será também explorada de forma análoga no mortelo de Heisenberg.

Uma revisão bem mais rica do formalismo DFT aplicado a sistemas eletrônicos pode ser encontrada na Ref.[48].

${ }^{*} \mathrm{O}$ termo Hartree é a energia potencial clássica para um sistema de elétrons:

$$
U_{H}[n]=\frac{e^{2}}{2} \int d^{3} r d^{3} r^{\prime} \frac{n(\vec{r}) n(\vec{r})}{\left|\vec{r}-\vec{r}^{\prime}\right|} .
$$




\subsection{O Teorema de Hohenberg-Kohn para o Modelo de Heisenberg}

A prova do teorema de Hohenberg e Kohn para o caso do modelo de Heisenberg[9] segue de perto a apresentada acima para sistemas eletrônicos. No entanto, vamos explicitá-la aqui, uma vez que se trata do sistema de interesse neste trabalho. Diferentemente daquela apresentada por nós na literatura, [9] vamos utilizar aqui a formulação de Levy e Lieb.

Com um campo magnético externo não uniforme $\vec{B}_{i}$ aplicado a um sistema de spins, o Hamiltoniano de Heisenberg torna-se

$$
\hat{H}=\sum_{i, j} J_{i j} \hat{\mathbf{S}}_{i} \cdot \hat{\mathbf{S}}_{j}+\sum_{i} \vec{B}_{i} \cdot \hat{\mathbf{S}}_{i}
$$

Pelo princípio variacional, a energia do estado fundamental, $E_{0}$, obedece à desigualdade

$$
E_{0} \leq\langle\Psi|\hat{H}| \Psi\rangle
$$

Assim, na procura de $|\Psi\rangle$ que minimize o lado direito dessa equação, somos levados a calcular o valor esperado

$$
\left\langle\Psi\left|\sum_{i} \vec{B}_{i} \cdot \hat{\mathrm{S}}_{i}\right| \Psi\right\rangle=\sum_{i} \vec{B}_{i} \cdot\left\langle\Psi\left|\hat{\mathrm{S}}_{i}\right| \Psi\right\rangle \equiv \sum_{i} \vec{B}_{i} \cdot \vec{S}_{i}
$$

sendo

$$
\vec{S}_{i}=\left\langle\Psi\left|\hat{\mathbf{S}}_{i}\right| \Psi\right\rangle
$$

Então, é o vetor clássico $\vec{S}_{i}$ que se acopla ao campo externo e não propriamente a função de onda do sistema. Portanto, $\vec{S}_{i}$ faz aqui o papel que $n \cdot(\vec{r})$ faz nos sistemas eletrônicos. Seguindo o procedimento de Levy e Lieb, definimos primeiro o funcional

$$
E\left[\vec{S}_{i}\right]=\min _{|\Psi\rangle \rightarrow \vec{S}_{i}}\langle\Psi|\hat{H}| \Psi\rangle
$$

que introduz a seguinte estratégia: para cada distribuição $\left\{\vec{S}_{i}\right\}$, procuramos pelo vetor $|\Psi\rangle$ que minimize $\langle\Psi|\hat{H}| \Psi\rangle$, mantendo o campo externo fixo. Naturalmente que, por construção, este $|\Psi\rangle$ já é um funcional de $\vec{S}_{i}$. Substituindo $\hat{H}$ temos

$$
E\left[\vec{S}_{i}\right]=\min _{|\Psi\rangle \rightarrow \vec{S}_{i}}\left[\left\langle\Psi\left|\sum_{i, j} J_{i, j} \hat{\mathbf{S}}_{i} \cdot \hat{\mathbf{S}}_{j}\right| \Psi\right\rangle+\sum_{i} \vec{B}_{i} \cdot \vec{S}_{i}\right] \equiv F\left[\vec{S}_{i}\right]+\sum_{i} \vec{B}_{i} \cdot \vec{S}_{i} .
$$

onde $F\left[\vec{S}_{i}\right]=\min _{|\Psi\rangle \rightarrow \vec{S}_{i}}\left\langle\Psi\left|\sum_{i, j} J_{i, j} \hat{\mathrm{S}}_{i} \cdot \hat{\mathrm{S}}_{j}\right| \Psi\right\rangle$ é um funcional universal, isto é, não dependente do campo externo, para uma dada distribuição das interações de troca $J_{i, j}$ e dos números quânticos $S_{i}$ de cada operador de spin $\hat{\mathbf{S}}_{i}{ }^{\dagger}$ Novamente pelo princípio

\footnotetext{
${ }^{\dagger}$ Essa universalidade para cada escolha das distribuições $\left\{J_{i, j}\right\}$ e $\left\{S_{i}\right\}$ corresponde à universalidade do funcional $T[n]+U[n]$ nos sistemas eletrônicos dada as massas e cargas dos constituintes.
} 
variacional, a distribuição específica $\left\{\vec{S}_{i}^{0}\right\}$ correspondente ao estado fundamental deve ser aquela que minimiza $E\left[\vec{S}_{i}\right]$ :

$$
E_{0}=\min _{\vec{S}_{i}} E\left[\vec{S}_{i}\right]
$$

Para essa distribuição $\left\{\vec{S}_{i}^{0}\right\}$, o vetor $|\Psi\rangle$ que resulta da procura

$$
F\left[\vec{S}_{i}\right]=\min _{|\Psi\rangle \rightarrow \vec{S}_{i}}\left\langle\Psi\left|\sum_{i, j} J_{i, j} \hat{\mathrm{S}}_{i} \cdot \hat{\mathrm{S}}_{j}\right| \Psi\right\rangle
$$

corresponde ao vetor do estado fundamental $\left|\Psi_{0}\right\rangle$ que, consequentemente, ć unn funcional da distribuição $\left\{\vec{S}_{i}^{0}\right\}$. Em outras palavras, uma distribuição $\left\{\vec{S}_{i}\right\}$ determina uma única função de onda e vice-versa:

$$
\Psi_{0}=\Psi_{0}\left[\vec{S}_{i}\right] \rightarrow E_{0}=E_{0}\left[\vec{S}_{i}\right] .
$$

Essa equação resume a afirmação do teorema de Hohenberg-Kohn para sistemas descritos pelo Hamiltoniano de Heisenberg. A demonstração identifica o vetor $\vec{S}_{i}$ como a variável clássica fundamental dos sistemas de spins, tal qual $n(\vec{r})$ é para os sistemas eletrônicos no contínuo ou $n\left(\vec{r}_{i}\right)$ para o modelo de Hubbard.[38] Também estabelece um procedimento em princípio mais simples para se determinar a energia do estaro fundamental: minimiza-șe o funcional $E\left[\vec{S}_{i}\right]$ em relação à distribuição clássica de spins $\left\{\vec{S}_{i}\right\}$. Note que, não havendo um termo de energia cinética, não há necessidade de se implementar o esquema Kohn-Sham.

\subsection{A conveniência da aproximação de campo médio}

Normalmente quando nos referimos a campo médio estamos pensando numa aproximação das mais simples, que fazemos quando em geral não temos uma melhor! No contexto da DFT aplicada ao modelo de Heisenberg, utilizamos o termo de campo médio

$$
E^{C M}\left[\vec{S}_{i}\right]=\sum_{i, j} J_{i, j} \vec{S}_{i} \cdot \vec{S}_{j}
$$

porém, aqui ele desempenha um papel fundamental, pois ele já é um funcional explícito de $\vec{S}_{i}$. Assim, a energia como funcional de $\vec{S}_{i}$ pode ser convenientemente escrita como

$$
E\left[\vec{S}_{i}\right] \equiv E^{C M}\left[\vec{S}_{i}\right]+E_{c}\left[\vec{S}_{i}\right]
$$

sendo o termo de correlação $E_{c}\left[\vec{S}_{i}\right]$ aquele que falta ao de campo médio para se recuperar o resultado exato $E\left[\vec{S}_{i}\right]$. O termo de campo médio faz o papel de $T_{s}[n]+U_{H}[n]$ dos sistemas eletrônicos. Sendo $E^{C M}\left[\vec{S}_{i}\right]$ já um funcional de $\vec{S}_{i}$, precisamos apenas procurar pelo funcional $E_{c}\left[\vec{S}_{i}\right]$. Em geral isso requer aproximações adicionais, como as que descrevemos nas seçoes seguintes.

É bom salientar que a separação dos termos presentes na Eq. (3.23) não tem o espírito da teoria de perturbação, que é separar o grande do pequeno, pois, em geral o termo de correlação é de mesma ordem, se não maior, que o de campo médio e, portanto, não pode ser considerado uma perturbação. 


\subsection{Aproximação Local para o Spin - LSA}

A implementação prática da DFT em sistemas de spins exige aproximações para o funcional de correlação, o que é feito em dois passos. Primeiro, recorremos a um sistema homogêneo de spins $S$ em que saibamos a energia $E_{0}(S)$, se não exata, pelo menos numa aproximação melhor que a de campo médio. Utilizando a Eq. (3.23) obtemos $E_{c}(S)$ para esse sistema homogêneo simplesmente escrevendo

$$
E_{c}(S)=E_{0}(S)-E^{C M}(S) \equiv N e_{c}^{h o m}(S) .
$$

sendo, portanto, $e_{c}^{\text {hom }}(S)$ a cuncrgia de correlação por spin. () segundo passo consiste em fazer uma aproximação local para se obter o funcional $E_{c}\left[\vec{S}_{i}\right]$, nos moldes da aproximação LDA feita para os sistemas eletrônicos. Neste contexto ela é feita nos números quânticos de spin, que consiste em substituir $S$ pelo seu valor local $S_{i}$ em $e_{c}^{\text {hom }}(S)$ :

$$
E_{c}\left[\vec{S}_{i}\right] \approx E_{c}\left[\vec{S}_{i}\right]^{L S A}=\left.\sum_{i} e_{c}^{h o m}(S)\right|_{S \rightarrow S_{i}}
$$

Chamamos essa aproximação de LSA, de Local-Spin Approximation. Observe que $S_{i}$ ć o número quântico do $i$-ésimo spin, c nãa o valor esperardo $\vec{S}_{i}=\left\langle\Psi_{0}\left|\hat{\mathbf{S}}_{i}\right| \Psi_{0}\right\rangle$. Lembre que sendo homogêneo esse valor esperado é nulo em cada sítio, portanto, $\vec{S}_{i}$ nem mesmo aparece como variável em $e_{c}^{\text {hom }}(S)$, que só depende mesmo de $S$. ‡

Não existem muitas funções $E_{0}(S)$ conhecidas, válidas para qualquer $S$, ou para qualquer dimensão espacial. Vamos nos limitar a usar duas expressões para $E_{0}(S)$ : a darla pela Eq. (2.13) obtida da Teoria de ()ndas-de-Spin, válicla en qualquer dinnensão, ou a Eq. (2.14) obtida pelos autores da Ref.[46] que propõem uma função $E_{0}(S)$ baseados em resultados da técnica DNIRG para sistemas unidimensionais.

\subsubsection{Aproximação Local via Ondas-de-Spin}

Usando a aproximação SW dada na Eq. (2.13) para $e_{0}^{\text {hom }}(S)$ obtemos

$$
E_{c}\left[\vec{S}_{i}\right]^{L S A-S W}=J d^{-1 / 5}\left(\frac{2}{\pi}-1\right) \sum_{i} S_{i}
$$

e, então, o funcional para a energia do estado fundamental na aproximação SW (e local) é

$$
E\left[\vec{S}_{i}\right]^{S W}=J \sum_{\langle i j\rangle} \vec{S}_{i} \cdot \vec{S}_{j}+J d^{-1 / 5}\left(\frac{2}{\pi}-1\right) \sum_{i} S_{i} .
$$

Minimizando esse funcional diretamente nas variáveis $\left\{\vec{S}_{i}\right\}$ obtemos a energia do estado fundamental correspondente ao sistema com a distribuição $\left\{\vec{S}_{i}\right\}$ minimizante. Note que essa distribuição corresponde à configuração de campo médio, já que o termo de correlação depende apenas dos números quânticos $S_{i}$.

\footnotetext{
${ }^{\ddagger}$ Nas referencias $[9,10]$ a aproximação local foi desiguinada por $S \rightarrow|\vec{S}|$, que é um caso especial da afinmação acima, una vez que a minimização de $E\left[\vec{S}_{i}\right]$ nessas referências sempre resultou no estado Néel, para o qual $S_{i}=\left|\vec{S}_{i}\right|$.
} 


\subsubsection{Aproximação Local via DMRG}

Utilizando a expressão (2.14) para a energia do estado fundamental obtida pela DMRG, temos que a energia de correlação, por spin, para un sistema homogêneo de spins $S$ é dada por

$$
e_{c}^{D M R G}(S)=e_{0}^{D M R G}(S)-e_{0}^{C M}(S)
$$

Portanto, o funcional de spin, local e na aproximação DMRG. é

$$
E^{D M R G}\left[\vec{S}_{i}\right]=J \sum_{\langle i j\rangle} \vec{S}_{i} \cdot \vec{S}_{j}+\left.J \sum_{i} e_{c}^{D M R G}(S)\right|_{S \rightarrow S_{i}}
$$

É importante salientar que na Ref. [46] a expressão analítica para $e_{0}^{D M R G}$, Eq. (2.14), foi obtida a partir de dados numéricos. Portanto, esse procedimento pode ser bastante conveniente em sistemas complexos onde não se tem uma expressão analítica. Por exemplo, dados numéricos vindos de simulações de Monte Carlo poderiam gerar uma curva que em princípio pode ser utilizada para se construir um funcional. Isso viria a ampliar em muito as possibilidades de se estudar sistemas mais realistas. 


\section{Capítulo 4}

\section{Resultados para Impurezas Substitucionais}

Embora os cálculos via LSA possam ser feitos para sistemas com muitos spins e diferentes dimensionalidades, para viabilizar sua comparação com resultados exatos, na maioria dos exemplos a seguir nos limitamos a cadeias pequenas, com até três dezenas de spins. Em todos os casos neste Capítulo as interações $J_{i, j}$ entre os spins são uniformes e isotrópicas. As impurezas são na forma de spins substitucionais em meio a um substrato de spin 1/2. Também consideramos alguns casos em que há falta de spins numa rede, ou seja, quando temos vacâncias.

Os resultados exatos apresentados nas figuras a seguir, com rara excessão, foram obtidos por dois métodos numéricos desenvolvidos por nós e apresentados no Cap. VII: o métod de potências e o de diagonalização iterativa. Uma discussão detalhada desses resultados, e dos métodos numéricos, pode ser encontrada nas Ref.[34, 35. 36]

\subsection{Sistemas unidimensionais}

Consideremos uma cadeia de apenas 10 spins $S$ com condição aberta de contorno, portanto bastante não homogênea. A Fig. (4.1) compara os valores obtidos pela aproximação CM com os obtidos dos funcionais $E^{S W}\left[\vec{S}_{i}\right]$ e $E^{D M R G}\left[\vec{S}_{i}\right]$, para alguns valores do spin $S$. Comparando com os dados exatos notamos a supremacia dos funcionais em relação aos valores de CM, sendo a aproximação vinda da DMRG um pouco melhor em todo intervalo de $S$ considerado que aquela vinda da SW. No inset temos a diferença $E_{0}^{D M R G}-E_{0}^{S W}$ versus $S$, mostrando que os dois funcionais praticamente coincidem. Nessa figura notannos que o desvio relativo, ( $\left.E^{\text {exato }}-E^{C M}\right) / E^{\text {exato }}$, é da ordem de 0.5 para spins 0.5 ou 1, e diminui para 0.2 para spins 2 , ou seja, a aproximação CM é melhor para spins mais altos, uma vez que a flutuação dos spins é menor nesse limite.

Para cadeias maiores, ou spins maiores, a diagonalização exata torna-se impraticável, mas é de se esperar que os funcionais forneçam estimativas ainda melhores, pois devemos lembrar que cles foram gerados de expressões válidas para sistemas homogêneos e portanto válidas no limite termodinâmico. 


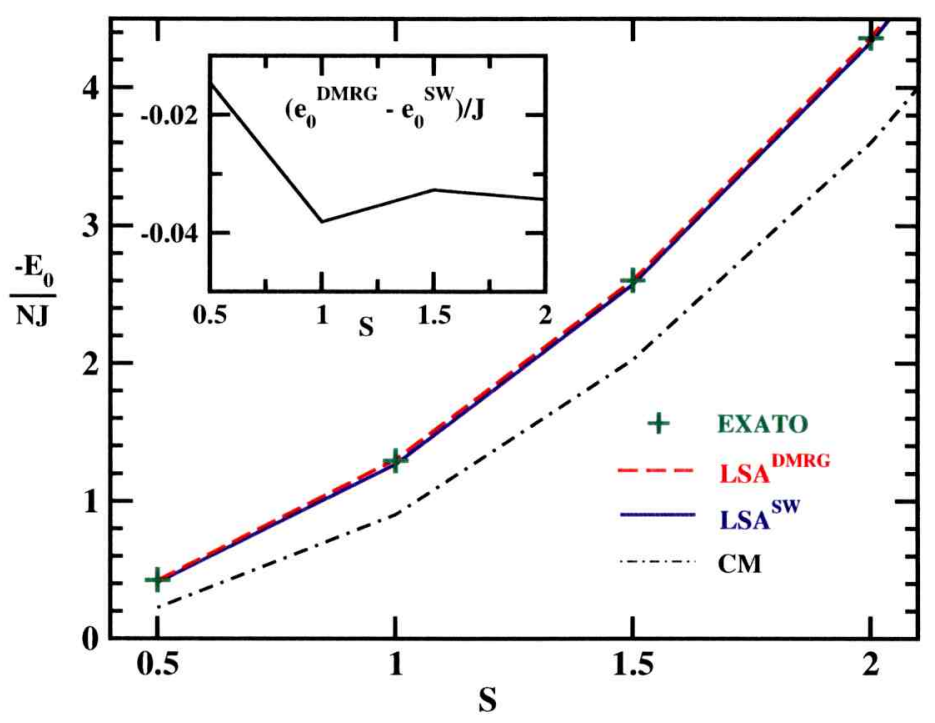

Figura 4.1: Energia do estado fundamental para cadeias abertas com 10 spins $S$, para valores de $S$ desde $1 / 2$ até 2 . As aproximações locais vindas da SW ou da DMRG são quantitativamente semelhantes (ver inset) e reproduzem bem melhor os resultados exatos quando comparadas com a aproximação de campo médio (CM).

Na Fig. (4.2) consideramos cadeias de $N$ spins, para diversos valores do spin $S$, e comparamos as energias $E_{0}$ obtidas por duas aproximações diferentes, CM $(\diamond)$ e LSA via SW (linha contínua), e com resultados da diagonalização exata (o). A única fonte de inomogeneidade aqui se deve ao tamanho finito e à condição de contorno aberta da cadeia. A linha tracejada indica o valor da energia no limite termodinâmico para cada $S$ considerado (extraído da Ref.[46]). Está claro na figura que o funcional fornece resultados mais próximos dos exatos do que aqueles de CM; estes naturalmente são melhores a medida que $S$ aumenta. No entanto, o funcional não reproduz as oscilações nos valores de $E_{0}$, cuja amplitude é relativamente grande para pequenos $N$, mas cai a medida que a cadeia cresce. Observe que o valor da energia de correlação, que é a diferença $E^{\text {exato }}-E^{C M}$, não pode ser tratada como uma perturbação, pois é da ordem de grandeza da energia de campo médio (ou do próprio valor exato).

Como uma aplicação da LSA a Hamiltonianos de spins com simetria translacional quebrada pela presença de impurezas, consideramos a seguir uma cadeia com uma impureza de spin 1 num fundo de spins 1/2. A Fig. (4.3) mostra a energia do estado fundamental desse sistema com a impureza colocada em posições distintas. Nela, os círculos indicam os resultados exatos, enquanto que a curva tracejada mostra como a solução LSA se aproxima do resultado exato, especialmente para redes com mais de 10 spins. Para comparação, também incluímos nessa figura resultados da LSA para uma impureza no interior da cadeia e para um sistema com duas impurezas, uma na borda e outra no interior. Diferentemente do alto custo computacional em cálculos exatos ao se colocar mais impurezas, a LSA pode fornecer boas estimativas para $E_{0}$ mesmo para um número arbitrário de impurezas. É de se esperar que essa estimativa se deteriore a medida que o número de impurezas aumente, uma vez que os funcionais são baseados 


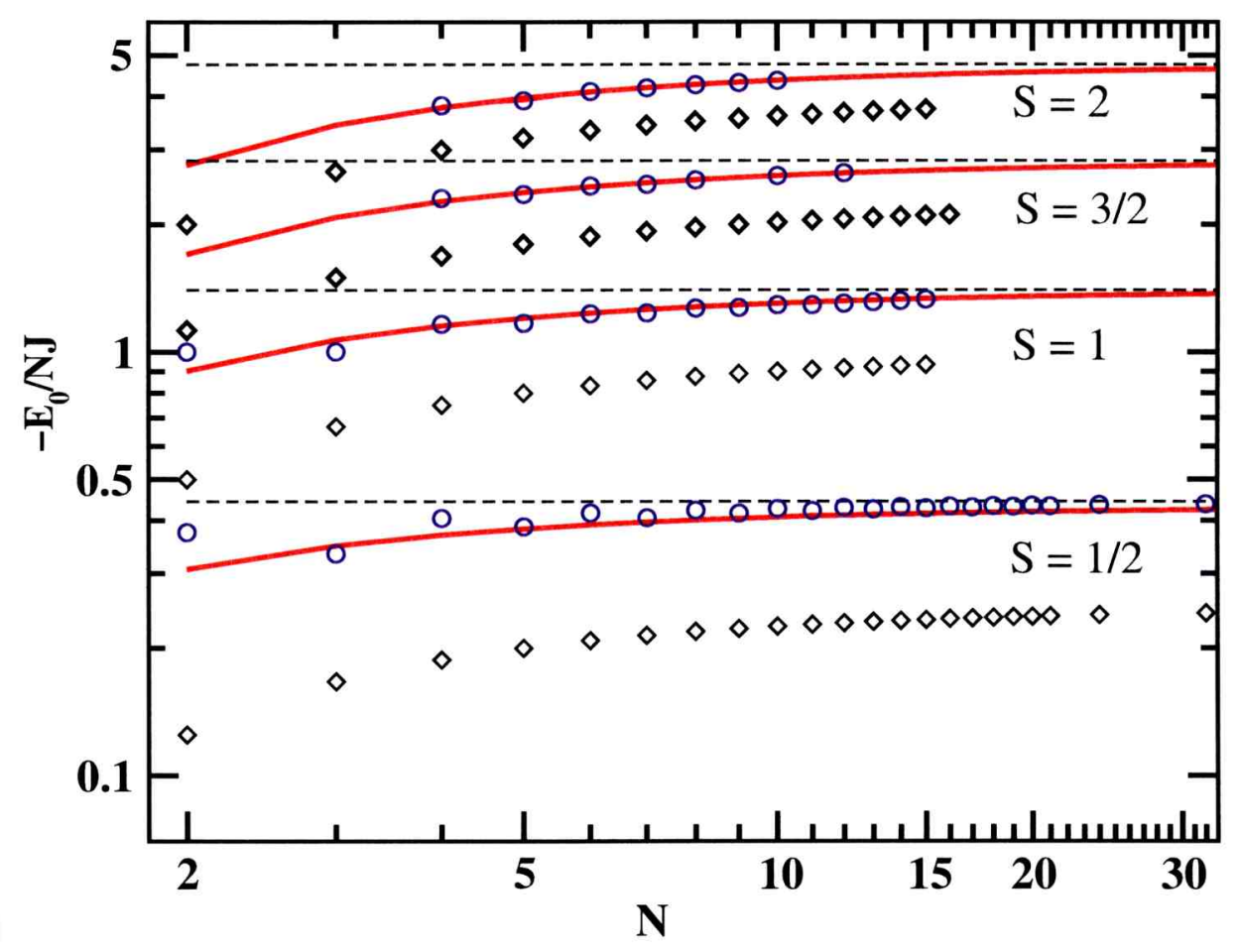

Figura 4.2: Dependência com o tamanho $N$ da energia do estado fundamental, por spin, para cadeias de spins $S$. Valores obtidos pelo funcional LSA na aproximação SW (linha cheia) descrevem bem melhor os resultados exatos $(\circ)$ que os de CM $(\diamond)$, particularmente para redes cada vez maiores. As linhas tracejadas demarcam o limite termodinâmico para cada spin considerado (Fig. (1) da Ref.[10]).

num sistema homogêneo de spins.

Poderíamos nos perguntar se ao invés de implementarmos a aproximação local no termo de correlação, como feito na Eq. (3.25), tivéssemos feito diretamente no termo de energia do estado fundamental, Eq. (2.13), teríamos obtido resultados satisfatórios. Esse procedimento teria nos levado ao funcional (para $d=1$ )

$$
E 0\left[S_{i}\right]=\sum_{i}\left[-S_{i}^{2}+\left(\frac{2}{\pi}-1\right) S_{i}\right],
$$

lembrando que $S_{i}$ é o número quântico do spin do $i$-ésimo sítio. Para uma cadeia de dez spins, nove deles 1/2 e um na borda de valor 1 (como um dos casos da Fig. (4.3)), o resultado exato para a EEF vale $-4.496939 \mathrm{~J}$, enquanto esse funcional $E 0$ estima em $-5.24859 \mathrm{~J}$, um desvio de $16.7 \%$. Já o funcional $E_{0}^{L S A}$ estima em $-4.49859 \mathrm{~J}$, um desvio de apenas $0.04 \%$. A razão é que o termo de campo médio em $E\left[S_{i}\right]$ já é um funcional da distribuição de spins e por isso pode lidar bem com inomogeneidades; a aproximação, então, recai apenas no termo de correlação, e não no termo todo de energia como é o caso do funcional $E 0\left[S_{i}\right]$. 


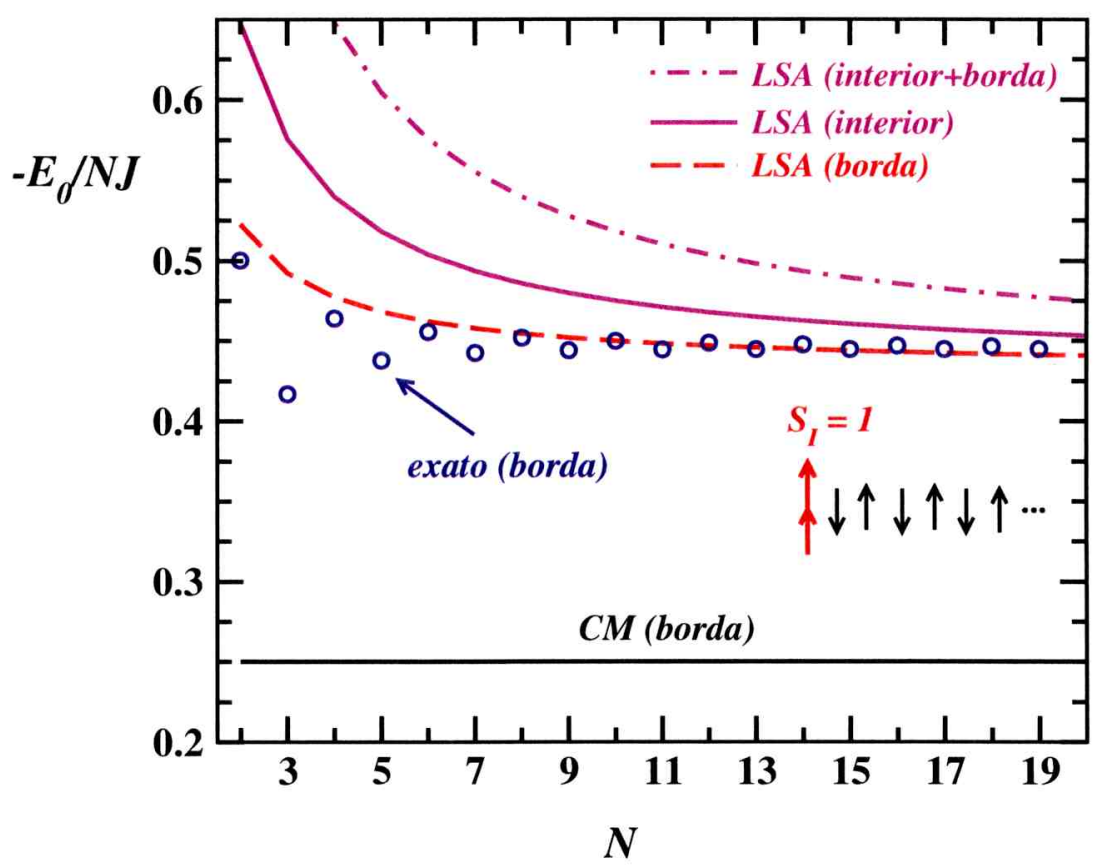

Figura 4.3: Energia do estado fundamental, por spin, para cadeias abertas com $N$ spins $1 / 2$, com uma impureza de spin $S_{I} \doteq 1$ na borda (linha tracejada), ou no interior da cadeia (linha cheia), ou uma impureza na borda e outra no interior (linha ponto-tracejada). Os círculos representam os resultados exatos para o caso da impureza $S=1$ na borda da cadeia. A aproximação CM prevê energia independente de $N$ para esse caso de impureza na borda (Fig. (2) da Ref.[10]).

\subsection{Sistemas bidimensionais}

Mostraremos agora resultados para redes quadradas ou retangulares, situações em que a diagonalização exata demanda alto custo computacional mesmo para poucos spins. Para aproveitar os códigos computacionais feitos para cadeias, usamos um artifício que é identificar internamente à rede uma cadeia e completá-la com ligações adicionais, como ilustra a Fig. (4.4). Com isso, continuamos a usar o método de potências para extrair a EEF de redes bidimensionais; é relativamente simples adicionar uma interação entre quaisquer dois spins da rede nesse método.

A limitação em se obter resultados exatos evidentemente é muito grande em sistemas bidimensionais. Primeiramente, apresentamos na Fig. (4.5) a energia do estado fundamental para redes quadradas com $N^{2}$ spins e comparamos os resultados de LSA com apenas alguns pontos exatos. Não consideramos impurezas neste caso (devido ao alto custo computacional dos resultados exatos), de forma que as inomogeneidades entram apenas pela presença do contorno, que quebra a invariância translacional.

Em seguida, vamos investigar a dependência da energia do estado fundamental com a geometria da rede, obtidas pela aproximação LSA ${ }^{S W}$. A Tab. (4.1) compara resultados para uma cadeia $(1 \times 100)$, uma escada de duas pernas $(2 \times 50)$, uma escada de cinco pernas $(5 \times 20)$, uma rede quadrada $(10 \times 10)$ e um paralelepípedo de spins $(2 \times 5 \times 10)$, todos contendo 100 spins $S$. Podemos concluir dos dados da tabela que: 


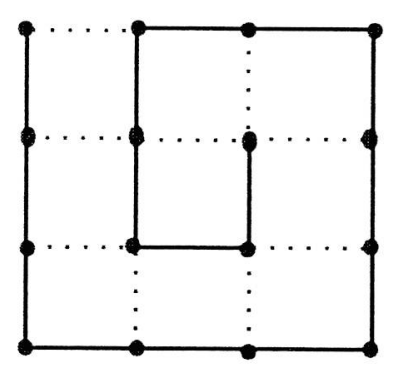

Figura 4.4: Rede quadrada $4 \times 4$, que pode ser decomposta numa cadeia formada por dezesseis ligações (linhas cheias), mais nove ligações adicionais (linhas pontilhadas). Para condições de contorno periódicas outras ligações devem ser introduzidas.

1. quanto maior o módulo do spin, mais acentuado é o efeito da borda do sistema. Isso pode ser visto comparando a variação da energia $E_{0}$ ao longo de uma linha horizontal da tabela; para spin $1 / 2$ esta variação é da ordem de 1.6, enquanto para spin 2 ela alcança o valor 2 ;

2. quanto maior a dimensão do sistema, mais lenta a convergência para o limite termodinâmico: enquanto a cadeia linear $1 \times 100$ de spins $1 / 2$ difere por apenas $3 \%$ do limite do ansatz de Bethe, $\approx-0.443$, para a rede $10 \times 10$, com o mesmo número de spins, a diferença alcança $9 \%$ do valor estimado na Ref.[20] para o respectivo limite termodinâmico. Un desvio de $3 \%$ desse limite só é alcançado para uma rede $50 \times 50$;

3. a diferença entre as redes lineares e a escada de duas pernas é maior do que entre essa escada e a rede quadrada, indicando que no que se refere ao estado fundamental, mesmo redes pouco bidimensionais são mais parecidas com sistemas quadrados do que com lineares. Essa diferença aumenta com o aumento do valor do spin do sistema;

4. quanto maior a dimensionalidade do sistema, maior a variação da energia com o aumento do valor do spin. Para a cadeia, entre $S=1 / 2$ e $S=2$, temos um aumento de $E_{0}$ pelo fator 10.9. Já para o paralelepípedo esse aumento é de 13.5 vezes.

Tabela 4.1: Estado fundamental, $-E_{0} / N J$, para sistemas abertos com 100 spins $S$, em diferentes geometrias, desde uma cadeia $1 \times 100$ até um cubo de spins $2 \times 5 \times 10$, passando pela geometria de escadas. A Eq. (3.27) fornece os valores do funcional $E\left[\vec{S}_{i}\right]^{S W}$ (Tab.1 da Ref.[10]).

\begin{tabular}{l|c|c|c|c|c}
\hline$S$ & $1 \times 100$ & $2 \times 50$ & $5 \times 20$ & $10 \times 10$ & $2 \times 5 \times 10$ \\
\hline $1 / 2$ & 0.429 & 0.528 & 0.596 & 0.608 & 0.696 \\
1 & 1.353 & 1.796 & 2.066 & 2.116 & 2.491 \\
$3 / 2$ & 2.795 & 3.804 & 4.412 & 4.524 & 5.387 \\
2 & 4.687 & 6.552 & 7.632 & 7.832 & 9.382 \\
\hline
\end{tabular}




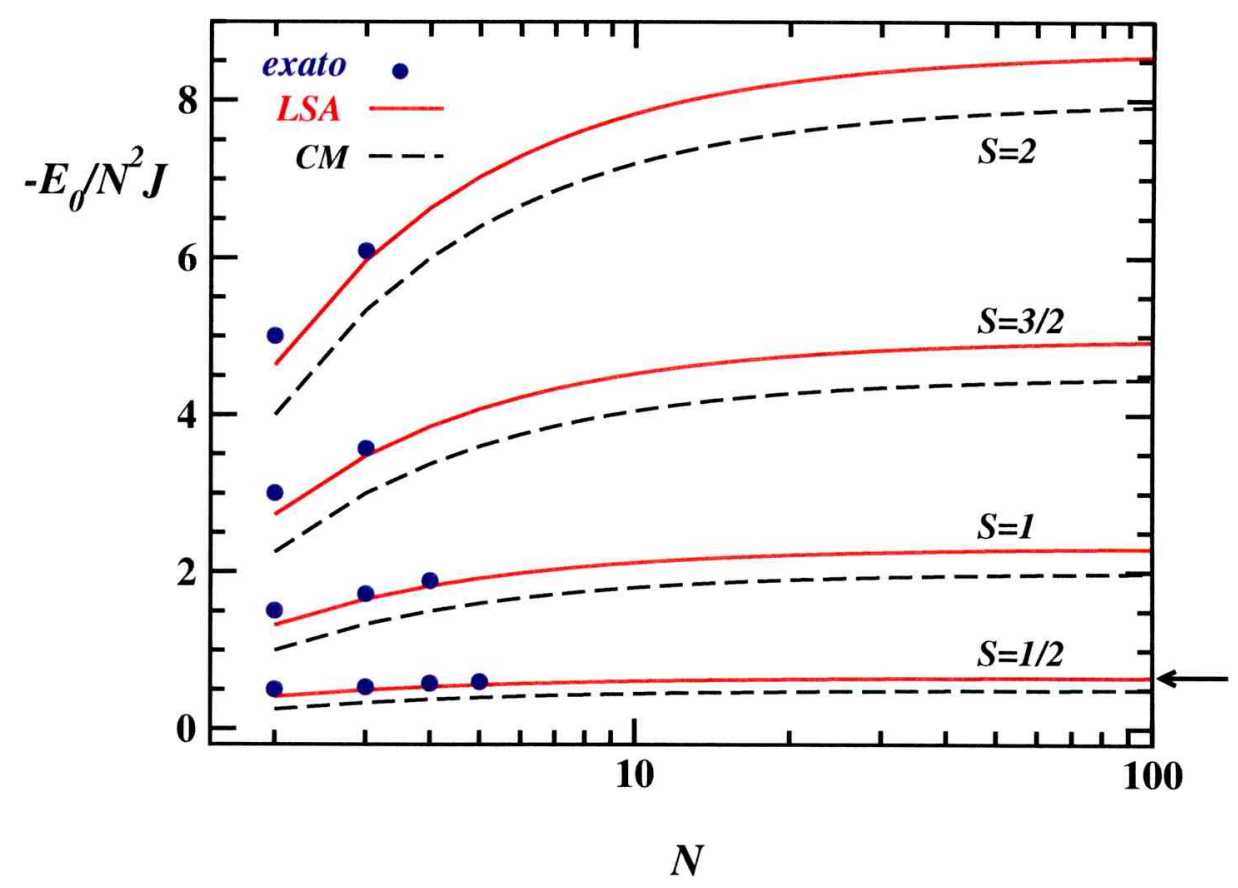

Figura 4.5: Energia do eștado fundamental para redes $N \times N$ de spins $S$. Enquanto o cálculo DFT/LSA ${ }^{S W}$ pode ser feito para redes de tamanho qualquer, apenas alguns resultados exatos são conhecidos (Fig. (2) da Ref.[10]).

\subsubsection{Vacâncias na rede}

A aplicação do modelo de Heisenberg se destina principalmente a sistemas antiferromagnéticos de momentos localizados, incluindo até mesmo supercondutores de alta temperatura. A evidência de que, sob dopagem, buracos parcialmente localizados sejam criados no plano $\mathrm{CuO}_{2}$ tem motivado o estudo de vacâncias em redes bidimensionais de spins.[54] Vacâncias também são importantes na estabilidade energética de nanotubos de carbono, como estudado na Ref. [55] via DFT. A formação de vacâncias localizadas, que se agrupam em diferentes configurações, quebra a invariância translacional, o que torna a nossa abordagem via DFT uma alternativa para se estimar a energia do estado fundamental de tais sistemas. Isso pode ajudar no estudo da estabilidade configuracional dessas vacâncias na rede, estimando-se o custo energético para criá-las ou deslocá-las. Na Fig. (4.6) comparamos os resultados de campo médio com os obtidos da aproximação local LSA construídos via Teoria de Ondas-de-Spin. Nessa figura, quanto melhor o resultado aproximado, mais perto da diagonal (linha tracejada) ele é representado. São consideradas as seguintes redes: $3 \times 3$ aberta, uma $4 \times 4$ aberta e outra $4 \times 4$ periódica. Elas podem não conter vacâncias, ou ter uma no canto, ou uma na lateral, uma no interior da rede, ou quatro no interior para o caso da rede $4 \times 4$ (que então recai numa cadeia fechada com 12 spins). Todos os resultados de campo médio subestimam a energia do estado fundamental. 


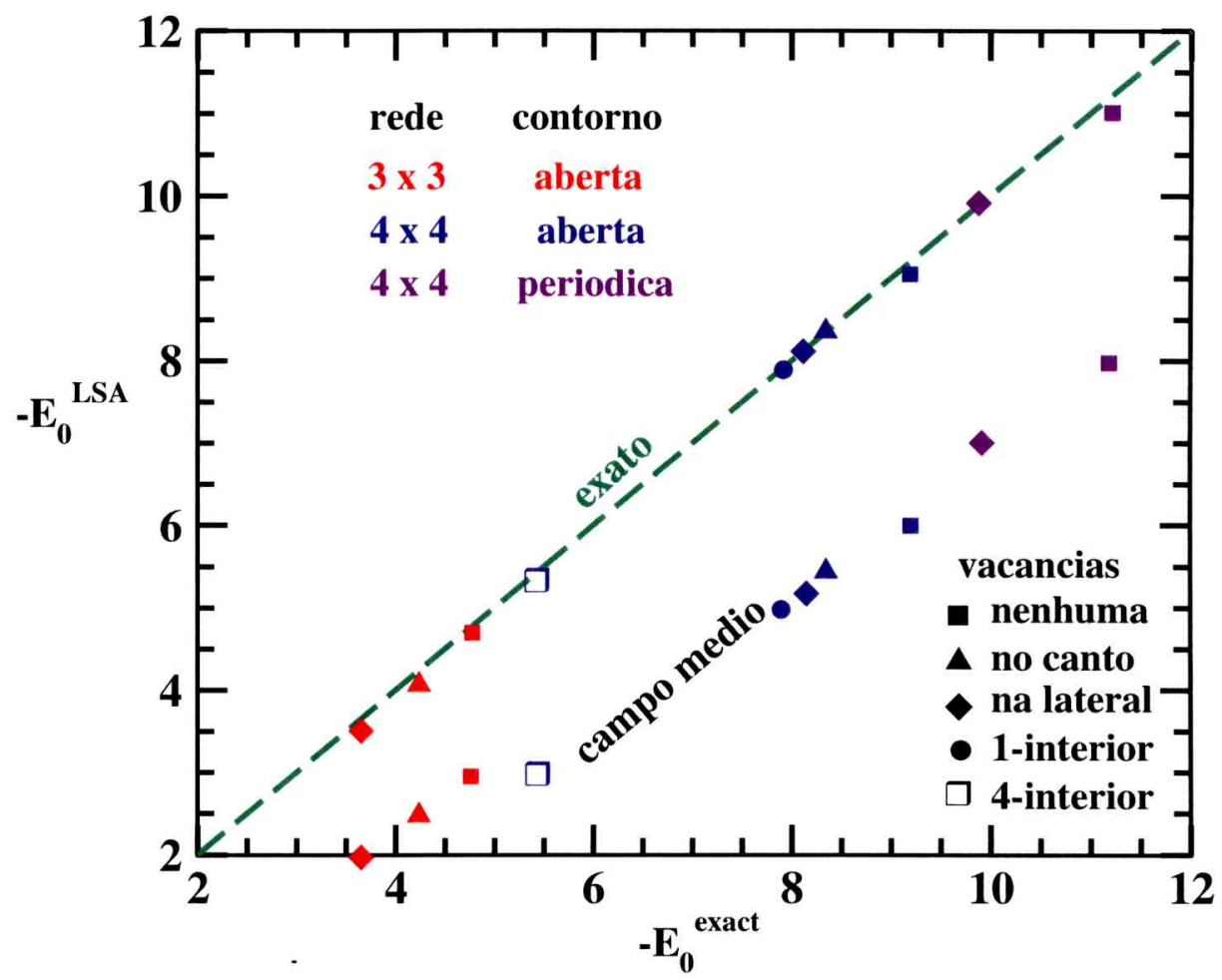

Figura 4.6: Energia do estado fundamental para redes com vacâncias. Mostramos $-E_{0}^{L S A}$ versus $-E_{0}^{\text {exato }}$, de forma que quanto melhor o resultado aproximado mais próximo da diagonal principal (linha tracejada) ele está representado. São consideradas redes $3 \times 3$ e $4 \times 4$, com diversas vacâncias, em diferentes posições da rede.

\subsection{Sistemas tridimensionais}

Finalmente, consideremos uma rede cúbica contendo 64 spins $1 / 2$ e condições abertas de contorno. Neste caso, uma impureza substitucional de spin $S_{I}$ pode estar presente em quatro tipos diferentes de sítios: vértices ( 8 posições equivalentes), faces ( 24 posições equivalentes), arestas (24 posições equivalentes), ou interior (8 posições). A Tabela 4.2 mostra a energia do estado fundamental, em unidades de $J$ e por sítio, para diversos valores de $S_{I}$. [56] É interessante notar que a aproximação de campo médio prevê degenerescência para diversas configurações de spins. Por exemplo, para os estados com $S_{I}=2$ na face ou $S_{I}=3$ no vértice, campo médio fornece $e_{0}^{C M}=-0.6211$ para ambas as situações. Já, como vemos nessa Tabela, a energia de correlação incluída no funcional LSA $^{S W}$ quebra essa degenerescência, mostrando que a impureza de spin 3 no vértice é mais estável; o mesmo ocorre, por exemplo, com $S_{I}=3 / 2$ no interior, $S_{I}=2$ na face ou $5 / 2$ no vértice, todos com $e_{0}^{C M}=-0.6094$, enquanto a LSA ${ }^{S W}$ mostra que a situação com $S_{I}=5 / 2$ no vértice do cubo é a mais estável. Esses resultados podem ser interessantes no estudo de migração de impurezas magnéticas em materiais nanoscópicos. Resultados exatos neste caso são custosos computacionalmente, de forma que uma estimativa da energia para diferentes configurações pode ser importante.

Outras aplicações dos funcionais acima são encontradas nas Ref. [9, 10, 56, 57], ou 
ṅas discertações $[34,35,36]$.

Tabela 4.2: Estado fundamental $-E_{0} / N J$ nas aproximaçōes CM e $\operatorname{LSA}^{S W}$ para um cubo $4 \times 4 \times 4$, com 63 spins $1 / 2$ mais uma impureza de spin $S_{I}=1 / 2, \ldots, 3$ que pode estar em um dos vértices, em uma das faces, numa das arestas ou no interior do cubo. Observe que a correlação presente no funcional LSA ${ }^{S W}$ levanta degenerescèncias previstas por campo médio, salientadas em negrito (Tab). 2 da Ref. [56]).

\begin{tabular}{|c|c|c|c|c|c|c|c|}
\hline$S_{I} \rightarrow$ & & $1 / 2$ & 1 & $3 / 2$ & 2 & $5 / 2$ & 3 \\
\hline \multirow{3}{*}{$\mathrm{CM}$} & vértice & 0.5625 & 0.5742 & $\mathbf{0 . 5 8 5 9}$ & 0.5977 & $\underline{\mathbf{0 . 6 0 9 4}}$ & $\mathbf{0 . 6 2 1 1}$ \\
& face & 0.5625 & 0.5781 & 0.5938 & $\underline{\mathbf{0 . 6 0 9 4}}$ & 0.6250 & 0.6406 \\
& aresta & 0.5625 & 0.5820 & 0.6016 & $\mathbf{0 . 6 2 1 1}$ & 0.6494 & 0.6602 \\
& interior & 0.5625 & $\mathbf{0 . 5 8 5 9}$ & $\underline{\mathbf{0 . 6 0 9 4}}$ & 0.6328 & 0.6562 & 0.6797 \\
\hline \multirow{3}{*}{ LSA $^{S W}$} & vértice & 0.7080 & 0.7220 & 0.7360 & 0.7500 & 0.7640 & 0.7780 \\
& face & 0.7080 & 0.7259 & 0.7438 & 0.7617 & 0.7796 & 0.7975 \\
& aresta & 0.7080 & 0.7298 & 0.7516 & 0.7734 & 0.7952 & 0.8170 \\
& interior & 0.7080 & 0.7337 & 0.7594 & 0.7851 & 0.8108 & 0.8366 \\
\hline
\end{tabular}




\section{Capítulo 5}

\section{Interações de troca não uniformes}

Todos os funcionais utilizados nos resultados até aqui mostrados são restritos a sistemas de spins com interaçócs de troca uniformes, isto é, com o mesmo $J$ em todos os sítios. Neste capítulo queremos estudar cadeias de spins $1 / 2 \mathrm{com}$ uma distribuição não uniforme das interações de troca $\left\{J_{b}\right\}$, onde o subíndice $b$ indica uma ligação entre dois spins primeiros vizinhos. Um exemplo particularmente importante seria a alternância entre dois valores de $J$ de ligação a ligação, como é o caso de compostos como $(\mathrm{VO})_{2} \mathrm{P}_{2} \mathrm{O}_{7}$ ou $\mathrm{Cu}\left(\mathrm{NO}_{3}\right)_{2} \cdot 2.5 \mathrm{H}_{2} \mathrm{O}$. (Outro excmplo é quando o sistema sofre una dinerização, por exemplo, devido a uma transição spin-Peierls, como em $\mathrm{CuGeO}_{3}$. Neste exemplos a palavra defeito não é apropriada, mas nós a usaremos genericamente para qualquer situação em que haja não uniformidade na cadeia devido às interações $J_{b}$

O primeiro tratamento de cadeias com interações não uniformes utilizando a DFT no modelo de Heisenberg foi feito nas referências[19, 59], onde foi considerado um procedimento análogo aquele que levou à aproximação LSA. porém, implementado em $J_{b}$ e não nos spins $\vec{S}_{i}$ :

$$
E_{c}\left[J_{b}: S\right] \approx E_{c}^{L B A}\left[J_{b}, S\right]=\left.\sum_{b=1}^{N_{b}} \frac{E_{c}^{h o m}(J, S)}{N}\right|_{J \rightarrow J_{b}},
$$

onde LBA é uma sigla para Local-Bond Approximation e lembra que a aproximação é feita nas ligações; a soma acima é feita nas $N_{b}$ ligações da cadeia. Para a energia de correlação $E_{c}^{h o m}(J, S)$ usou-se as mesmas expressões utilizadas na LSA (vindas da DMRG ou da SW). Portanto, o funcional na aproximação LBA é

$$
E\left[J_{b}, S_{i}\right]=\sum_{i} J_{i} \vec{S}_{i} \cdot \vec{S}_{i+1}+\left.\sum_{b=1}^{N_{b}} \frac{E_{c}^{h o m}(J, S)}{N}\right|_{J \rightarrow J_{b}} .
$$

Não podemos esquecer que a cadeia contém apenas um tipo de spin, $S$, ou seja, neste trataunento não há impurezas no sistcma.

A Fig. (5.1) mostra energias dos estados fundamentais de dois conjuntos de cadeias com $N$ spins cada, ambas com condições periódicas de contorno. Num conjunto, temos uma impureza $S_{I}$ de spin $3 / 2$, enquanto no outro um defeito de ligação, isto é. uma ligação com $J_{D}=5 J$ diferente das demais. A aproximação CM (estrelas). para essas 
éscolhas específicas. não distingue as duas situações, enquanto os resultados via LSA (triângulos vazios) e LBA (círculos abertos), por incluirem correlação, distinguem e dão resultados mais próximos dos valores exatos (símbolos cheios). Obserre, nessa figura, que a LSA é mais eficiente em reproduzir seus respectivos resultados exatos do que a LBA para os seus.

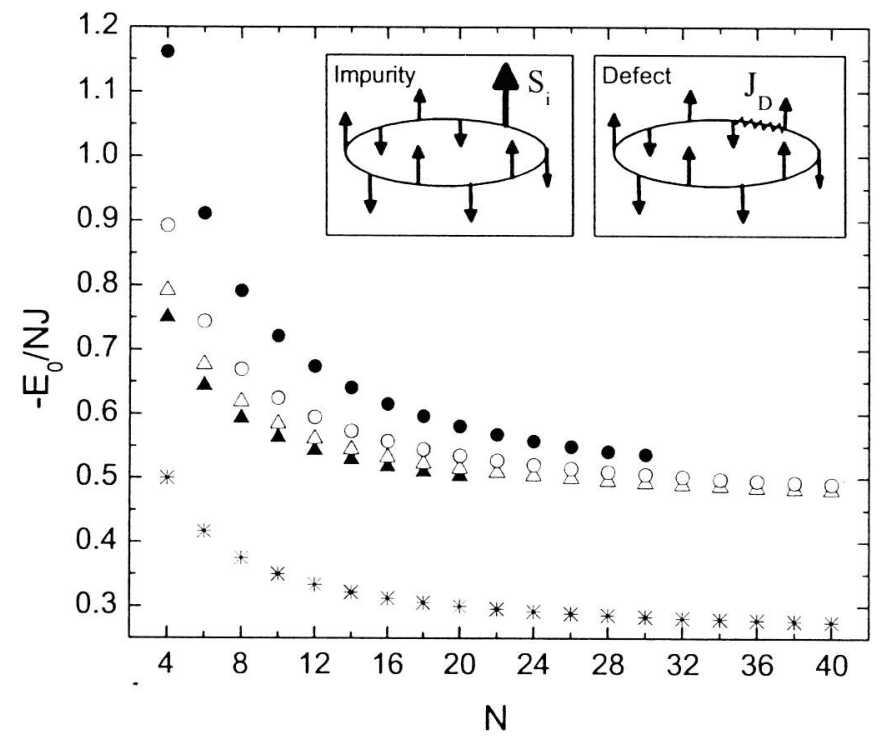

Figura 5.1: Dependência da EEF com o tamanho de aneis com $N-1$ spins $1 / 2$ e uma impureza de spin $S_{I}=3 / 2$ (triângulos), ou de aneis com $N$ spins e um defeito de intensidade $J_{D}=5 . J$ (círculos). tratados exatamente (śmbolos cheios) ou via LSA/LBA (śmbolos abertos). Com o tratamento de campo médio (estrelas), os sistemas com a impureza ou com o defeito fornecem o mesmo valor para a EEF. A inclusão da energia de correlação via LSA (caso da impureza, triângulos abertos) ou via LBA (caso do defeito, círculos abertos) remove essa degenerescência espúria (Fig. (1) da Ref.[59]).

\subsection{Funcional gerado através da Cadeia Alternada}

A energia de correlação presente na equação acima, e utilizada na Ref. [59], foi obtida através do formalismo da SW para um sistema homogêneo, mais a aproximação local LBA. Nas Ref.[34. 60] propusemos um procedimento alternativo, válido apenas para cadeias de spins $1 / 2$, mas que tem se mostrado mais preciso que a LBA em diversas situações. Nossa proposta é partir do modelo de Heisenberg para uma cadeia de spins $1 / 2$ com ligaçóes alternarlas:

$$
\hat{H}(J, \alpha)=J \sum_{i=1}^{N}\left(\hat{\mathbf{S}}_{2 i-1} \cdot \hat{\mathbf{S}}_{2 i}+\alpha \hat{\mathbf{S}}_{2 i} \cdot \hat{\mathbf{S}}_{2 i+1}\right) .
$$

isto é, uma cadeia em que as ligações se alternam entre $J$ e $\alpha J$, conforme ilustra a Fig. (5.2). Por convenção. denominaremos a primeira ligação dentro de uma célula (linha cheia na Fig. (5.2)) de tipo 1, e a segunda ligação (linha pontilhada) de tipo 2. 


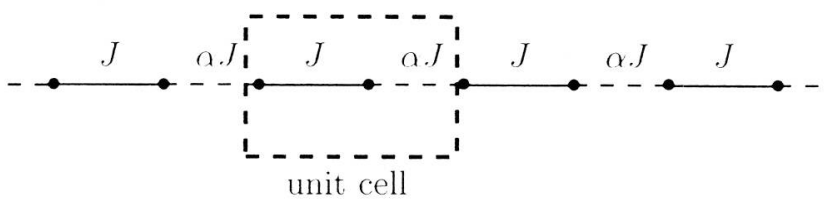

Figura 5.2: Cadcia de spins $1 / 2$ com ligaçōes alternando entre os valores $J$ e $\alpha . J$. O dímero formado pelas ligações $\{J . \alpha J\}$ forma uma célula unitária, em termos da qual a cadeia pode ser considerada homogênea. Convencionamos chamar as ligaçōes dentro de uma célula representadas por linhas cheias de tipo 1 e as por linhas pontilhadas de tipo 2.

Segundo Barnes e colaboradores, [61] a energia do estado fundamental de uma cadeia alternada no limite termodinâmico, para $0 \leq \alpha<1$, pode ser expressa com precisão pelo polinômio

$$
e_{0}(\alpha)=-\frac{3}{8}-\mathcal{P}(\alpha)
$$

com

$$
\begin{aligned}
\mathcal{P}(\alpha) & =\frac{3}{2^{6}} \alpha^{2}+\frac{3}{2^{8}} \alpha^{3}+\frac{13}{2^{12}} \alpha^{4}+\frac{89}{3 \times 2^{14}} \alpha^{5}+\frac{463}{3 \times 2^{17}} \alpha^{6} \\
& +\frac{7 \times 61 \times 191}{3^{3} \times 2^{22}} \alpha^{7}+\frac{11 \times 139 \times 271}{5 \times 3^{4} \times 2^{21}} \alpha^{8}+\frac{107 \times 22005559}{5^{2} \times 3^{5} \times 2^{30}} \alpha^{9} .
\end{aligned}
$$

Para $\alpha>1$ utilizamos a relação $e_{0}(\alpha>1)=\alpha e_{0}\left(\alpha^{-1}\right)$, que segue direto da definição de $\hat{H}$. Relação semelhante vale também para qualquer outro autoestado de $\hat{H}$.

A Fig. (5.3) compara os resultados advindos do polinômio acima com resultados exatos que obtivemos utilizando o método de potências (ver Cap. 6).

Utilizaremos o resultado de Barnes como base para a construção de um funcional. Mas, o procedimento padrão na DFT para se definir a energia de correlação é partir de um sistema homogêneo e o nosso é claramente não homogêneo! Porém, se a cadeia da Fig. (5.2) for vista como uma sequência de células unitárias formadas pelo dímero $\{J, \alpha J\}$ ela passa a ser homogênea na variável $\alpha$. Então, para se construir um funcional aplicável a cadeias com quaisquer $J_{b}$, poderemos implementar uma aproximação local em a através do seguinte procedimento:

$$
E_{c}\left[\alpha_{b}\right] \approx E_{c}^{L U C A}\left[\alpha_{b}\right]=\left.\sum_{b=1}^{N_{b}} \frac{E_{c}^{a l t}(\alpha)}{N_{b}}\right|_{\alpha \rightarrow \alpha_{b}},
$$

sendo

$$
\alpha_{b}=J_{b+1} / J_{b}
$$

a razão entre interações de troca sucessivas, e $E_{c}^{a l t}(\alpha)$ a correlação da cadeia alternada. A sigla LUCA (do Inglês, local unit-cell approximation) diferencia essa aproximação dacpucla inplementada nas ligaçoes. a LBA. Note que o funcional $E_{c}^{L U C A}\left[\alpha_{b}\right]$ não é local em $J_{b}$.

A energia de correlação para o sistema homogêneo em $\alpha, E_{c}^{a l t}(\alpha)$, por definição, é obtida da relação

$$
E_{0}(\alpha)=E_{0}^{C M}(\alpha)+E_{c}^{a l t}(\alpha)
$$




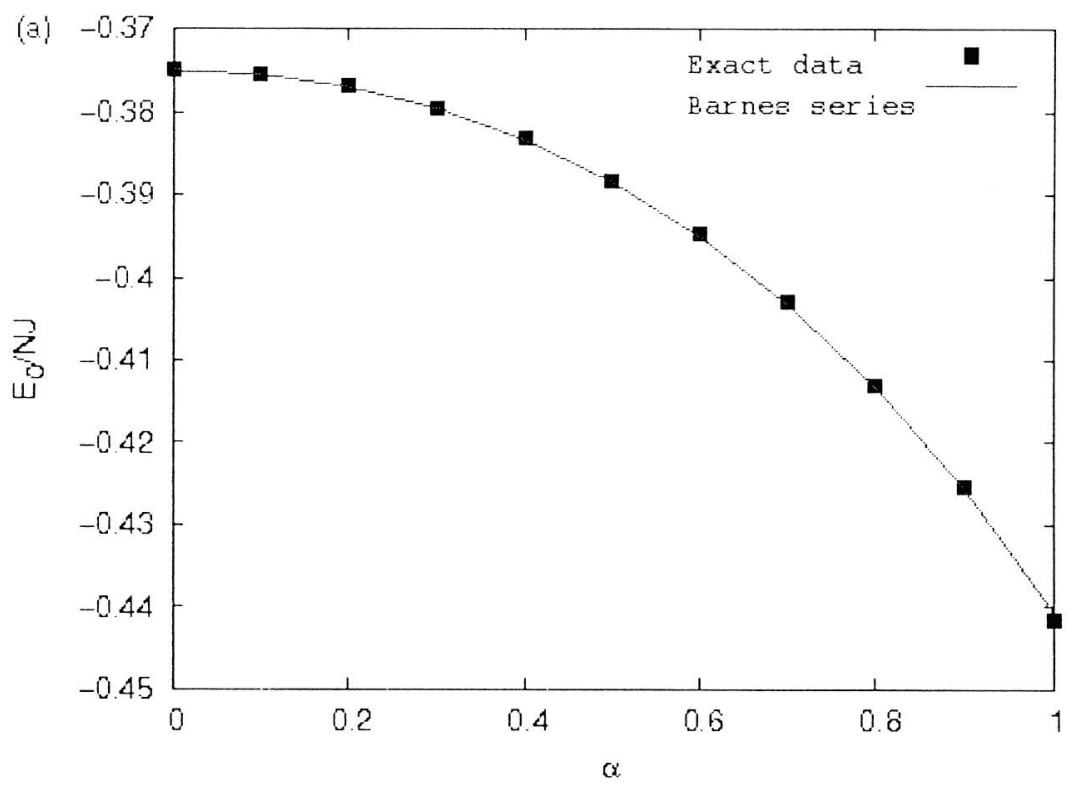

Figura 5.3: Comparação entre os resultados de Barnes et al para a energia do estado fundamental, por spin, no limite termodinâmico, com os exatos para uma cadeia alternada finita com 24 spins $1 / 2$. Observe a boa concordância mesmo para $\alpha$ próximo da unidade. A razão a entre sucessivas interações de troca é definida na Eq. (5.3).

e como

$$
E_{0}^{C M}(\alpha)=-N_{b} J S^{2}\left(\frac{1+\alpha}{2}\right)
$$

da Eq. (5.4), e de $E_{0}(\alpha)=N_{b} J e_{0}(\alpha)$, ficamos com

$$
E_{c}^{a l t}(\alpha) / N_{b}=J\left[-\frac{1}{4}+\frac{\alpha}{8}-\mathcal{P}(\alpha)\right] .
$$

Portanto, o funcional na aproximação LUCA é dado por

$$
E^{L U C A}\left[\alpha_{b}, \vec{S}_{i}\right]=J \sum_{i} \alpha_{i} \vec{S}_{i} \cdot \vec{S}_{i+1}+J \sum_{b=1}^{N_{u}} 2\left[-\frac{1}{4}+\frac{1}{8} \alpha_{b}-\mathcal{P}\left(\alpha_{b}\right)\right]
$$

A minimização desse funcional nas variáveis de spin (presentes somente no termo de campo médio) resultará na energia do estado fundamental para o sistema com a distribuição de ligações $\left\{J_{b}\right\}$.

\subsection{Resultados}

Vamos considerar cadeias de spins $1 / 2$ contendo defeitos de ligações e efeitos de tamanho finito. Os resultados serão melhores quanto mais similares forem essas cadeias com a cadeia alternada (com ligações somente tipo $J$ - $\alpha J$ ) e tendo $0 \leq \alpha_{b}<<1$ ou 
$\alpha_{b}>>1$, uma vez que esta foi a cadeia base para a construção do funcional. Para $\alpha$ fora desse intervalo, o funcional ainda é bastante eficiente e fornece boas estimativas. Embora ele possa ser aplicado a cadeias de tamanho arbitrário sem custo adicional de processamento, nossos exemplos se limitam a cadeias com 24 spins $1 / 2$ porque queremos comparar com resultados exatos.

\subsubsection{Cadeia Uniforme com um defeito antiferromagnético}

Neste exemplo temos um anel de spins com ligações antiferromagnéticas $J$, exceto numa ligação, onde vale $J^{\prime}$. Este caso se desvia bastante da cadeia alternada, uma vez que temos $\alpha_{b}=1 \mathrm{em}$ todas as células unitárias, com excessão de uma, onde $\alpha_{b}=J^{\prime} / J$. A Fig. (5.4) mostra os resultados advindos do funcional $(\triangle)$ para a EEF como função da razão $J^{\prime} / J$. A concordância com os resultados exatos (-) é muito boa, mesmo para $J^{\prime} / J$ próximo da unidade, onde o erro é $\approx 0.7 \%$. Observe o valor alto da energia de correlação, cerca de metade do valor da energia do estado fundamental. O sistema se enquadra na classe dos fortementes correlacionados e a energia de correlação $E_{c}$ não deve ser vista como uma perturbação sobre o termo de CM, como poderia dar a entender a Eq. (5.8).

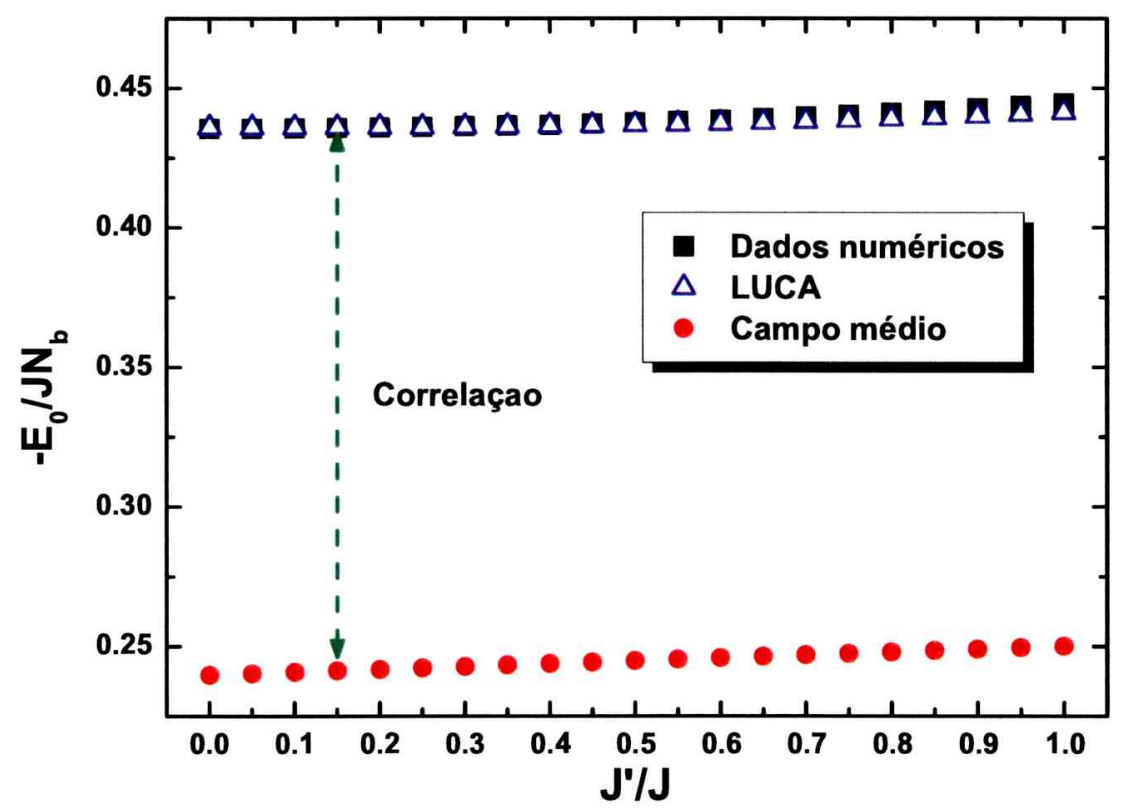

Figura 5.4: Estado fundamental de um anel homogêneo de 24 spins 1/2, por unidade do número de ligações $N_{b}$, como função da intensidade de um único defeito antiferromagnético $J^{\prime}$. A concordância entre os resultados advindos do funcional $(\triangle)$ e os numericamente exatos $(\boldsymbol{\bullet})$ é muito boa. A diferença desses valores para os de campo médio $(\bullet)$ é a correlação, que como se nota é da ordem do valor exato (Fig. (2) da Ref.[60]). 
Na Fig. (5.5) nós fixamos $J^{\prime} / J=0.5$ e mostramos a EEF por ligação como função da posição desse defeito em uma cadeia aberta. As oscilações nos resultados vindos do funcional devem-se ao fato de que quando o defeito $J^{\prime}$ estiver numa ligação tipo 1 o erro é maior do que quando esse defeito cai numa ligação tipo 2, pois neste exemplo $\alpha$ é menor do que a unidade. Portanto, essas oscilações não devem ser confundidas com as presentes nos resultados exatos. Veja que a amplitude dessas oscilações é constante e sua fase é contrária a do resultado exato. Os desvios entre funcional e os resultados exatos envolvidos aqui são maiores que os da figura anterior, provavelmente devido ao efeito adicional de tamanho finito introduzido pela condição de contorno aberta.

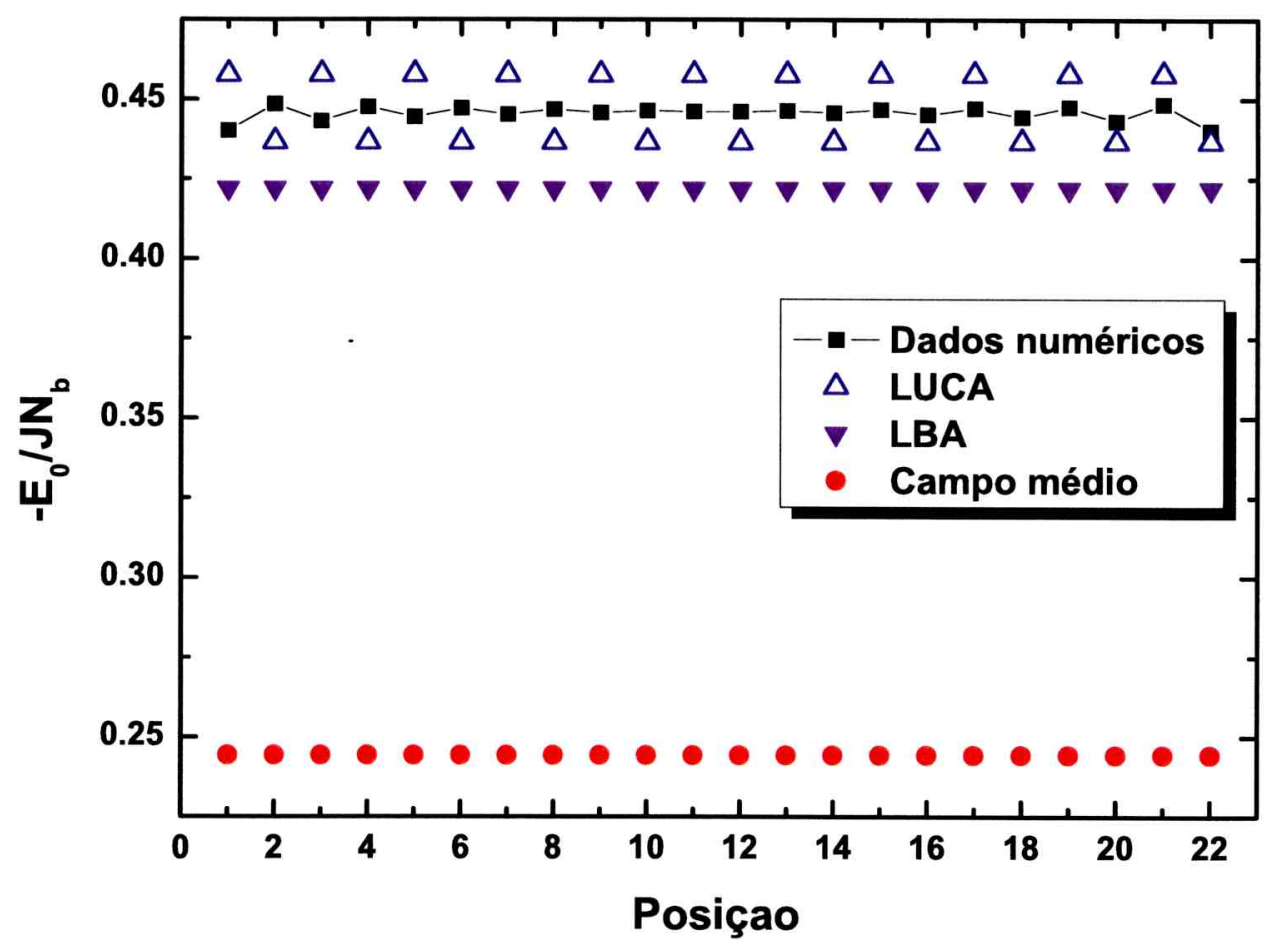

Figura 5.5: Efeito da posição de um defeito $J^{\prime}=0.5 \mathrm{~J}$ na energia do estado fundamental de uma cadeia aberta com 24 spins $1 / 2$. A aproximação LUCA se aproxima mais dos resultados exatos que a LBA (Fig. (3) da Ref.[60]).

Na Fig. (5.6) comparamos nossos resultados usando LUCA com duas aproximações tipo LBA, [59] para cadeias com diferentes tamanhos e com um defeito $J^{\prime}=5 J$ de grande intensidade. A aproximação $\operatorname{LBA}^{S W}(\boldsymbol{\nabla})$ usa os resultados da Teoria de Ondas-de-Spin (SW) para obter a energia de correlação, enquanto $\operatorname{LBA}^{D M R G}(\star)$ usa a técnica do Grupo de Renormalização da Matriz Densidade (DMRG) para isso. As duas aproximações definem funcionais da distribui cão $\left\{J_{b}\right\}$. Creditamos a vantagem da aproximação LUCA $(\triangle)$ a sua dependência com a razão $J_{b+1} / J_{b}$. 


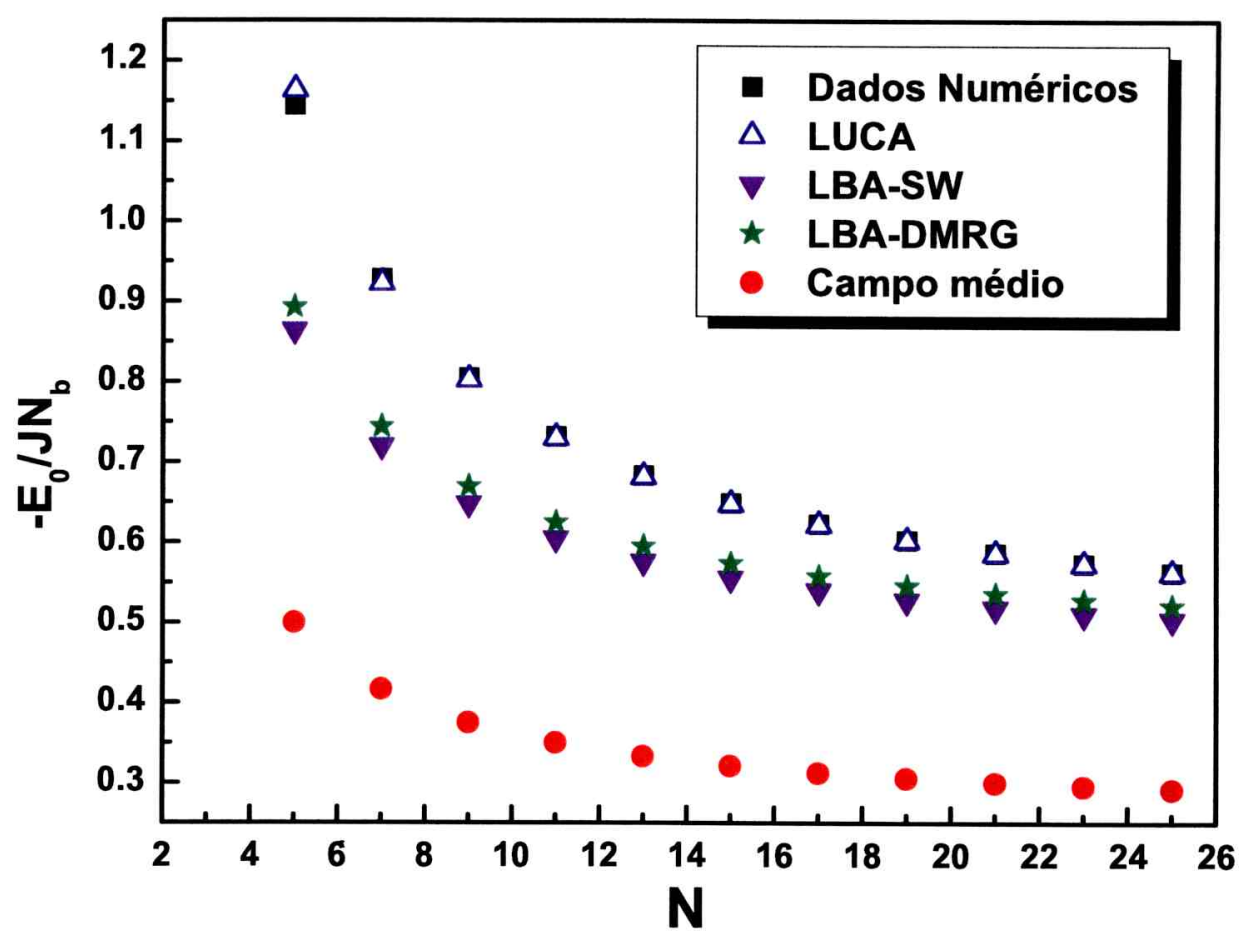

Figura 5.6: Dependência de $-E_{0} / J N_{b}$ com o número $N$ de spins $1 / 2 \mathrm{em}$ um anel com um defeito de intensidade $J^{\prime}=5 J$, isto é, um valor alto para $\alpha$ no defeito, enquanto o restante da cadeia tem $\alpha=1$. Resultados de LUCA $(\triangle)$ concordam melhor com os resultados exatos $(\boldsymbol{\bullet})$, que aqueles advindos da $\operatorname{LBA}^{S W}(\mathbf{\nabla})$ ou mesmo da LBA ${ }^{D M R G}(\star)$ (Fig. (4) da Ref.[60]).

\subsubsection{Ligações alternando entre ferromagnéticas e antiferromagnéticas.}

Diversos compostos exibem alternância ferro-antiferromagnética nas interações de troca entre os spins, alguns materiais até com características unidimensionais.[62, 63] Aqui vamos considerar um exemplo simples de um anel de spins $1 / 2$. Os resultados da Fig. (5.7) mostram que o funcional LUCA $(\triangle)$ reproduz, no intervalo $-1 \leq \alpha<0$, bastante bem os dados exatos ( $)$, com erros menores que $3 \%$. Já a aproximação CM $(\bullet)$ é razoável apenas para $J^{\prime} \approx 0$; exatamente em $J^{\prime}=0$ a cadeia se quebra em doze dímeros ferromagnéticos e a solução de CM é exata, uma vez que não há correlação neste caso. Para o limite $\alpha=-1$, nossa estimativa baseada em LUCA é $E_{0} / J N_{b}=-0.41210$, enquanto o resultado exato vale -0.41225829 , um ótimo resultado para um funcional gerado de um polinômio válido para $\alpha$ positivo. 


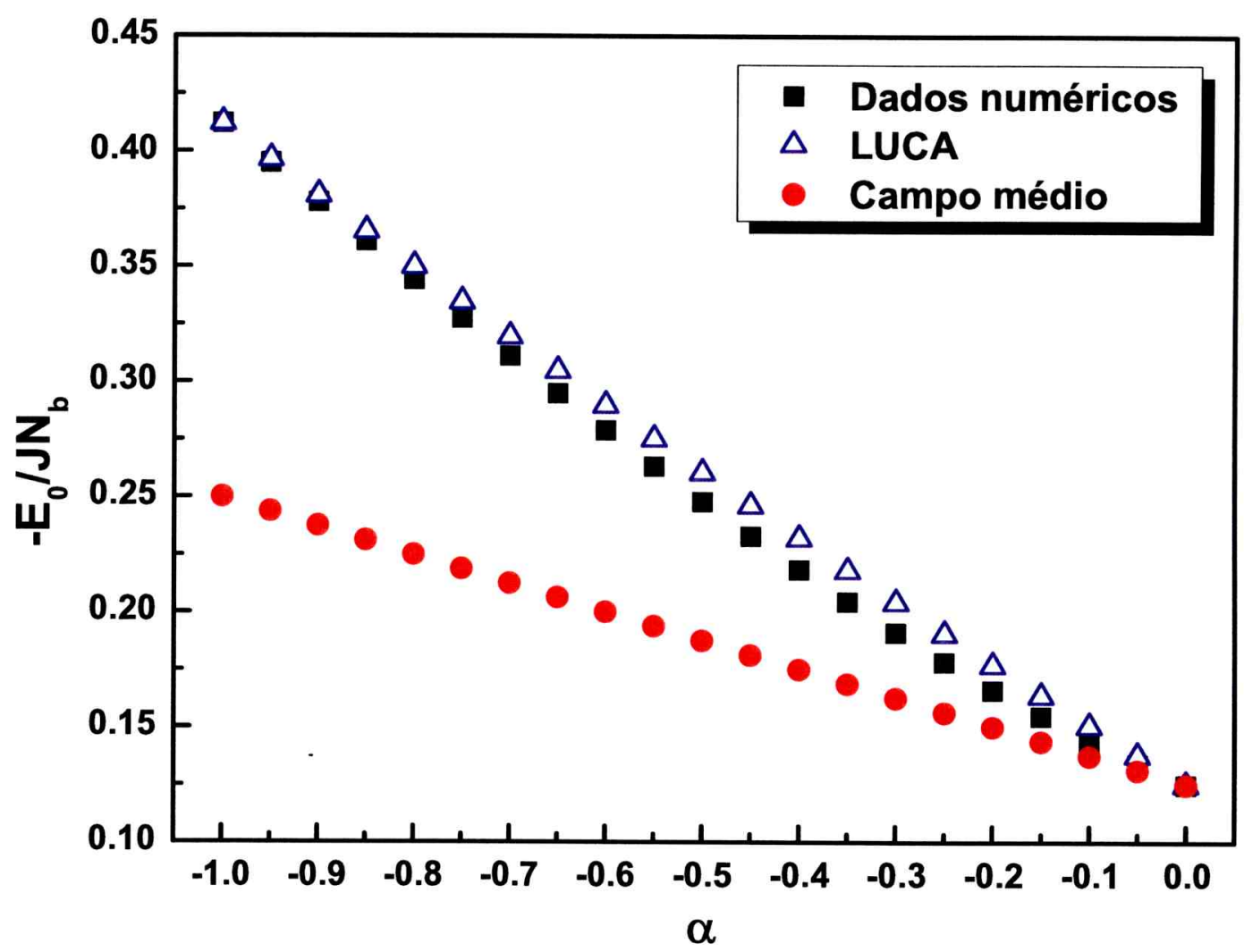

Figura 5.7: Dependência com $\alpha$ da energia do estado fundamental para um anel de 24 spins $1 / 2$ com ligações ferromagnética e antiferromagnética intercaladas (Fig. (5) da Ref.[60]).

\subsubsection{Cadeias com vários defeitos}

Para ilustrar esta situação, consideremos um anel com ligaçõe uniformes por toda rede, isto é, $\alpha=1$, exceto em três ligações, com defeitos, $J^{\prime}=0.1 J, J^{\prime \prime}=0.7 J$ e $J^{\prime \prime \prime}=0.9 J$, arranjados conforme ilustra a Fig. (5.8). O primeiro defeito está em uma ligação tipo 2 e os outros dois em ligações tipo 1.

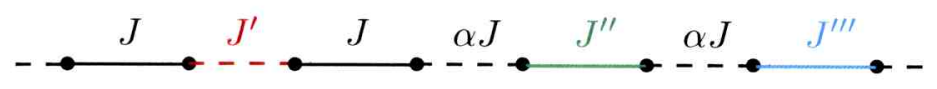

Figura 5.8: Anel com ligações alternadas, mas com três defeitos, $J^{\prime}=0.5 J$ em uma ligação tipo 2, defeitos $J^{\prime \prime}=0.7 J$ e $J^{\prime \prime \prime}=0.9 J$ em ligações tipo 1 (Fig. (7) da Ref.[60]).

Na Fig. (5.9) são mostrados dados do funcional LUCA, que deviam cerca de $3 \%$ dos exatos. Os defeitos $J^{\prime \prime}$ e $J^{\prime \prime \prime}$ estão em ligações tipo 1, o que sempre tende a aumentar os desvios. Por exemplo, com $J^{\prime}$ and $J^{\prime \prime}$ em ligações tipo 2 e $J^{\prime \prime \prime}$ em uma ligação tipo 1 , o 
éro cai para $0.5 \%$ para $0 \leq \alpha<1$.

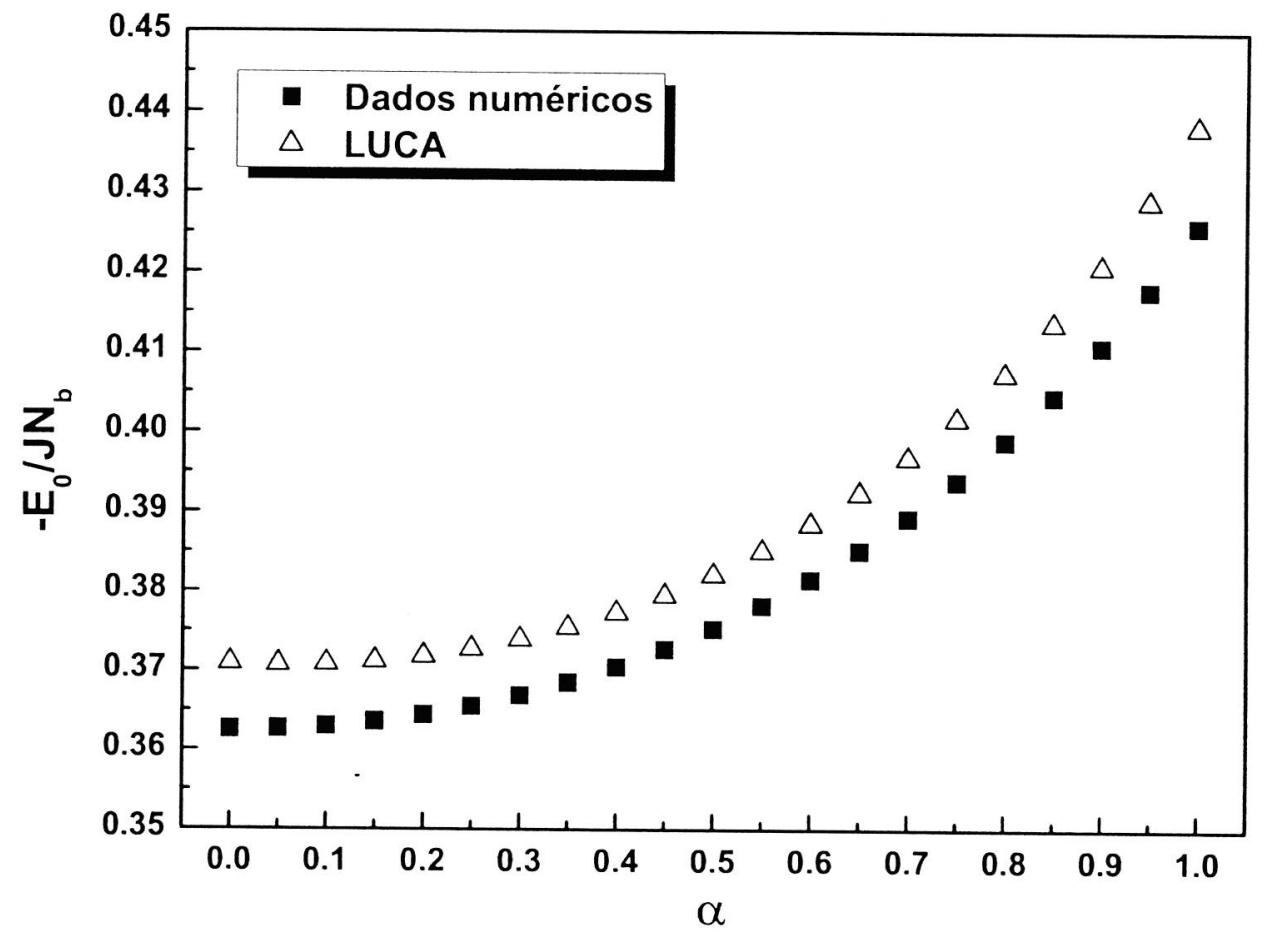

Figura 5.9: Dependência com $\alpha$ da EEF para um anel contendo 24 spins $1 / 2$ e três defeitos, dispostos conforme a Fig. (5.8). Os resultados obtidos via LUCA $(\triangle)$ desviam no máximo em $3 \%$ dos exatos $(\mathbf{\bullet})$ 


\section{Capítulo 6}

\section{Estado Fundamental Numericamente Exato}

Uma das etapas mais interessantes deste trabalho é a obtenção de resultados exatos que dêem respaldo aos funcionais elaborados. Embora o objetivo principal seja obter funcionais que por sua natureza sejam simples mesmo em sistemas com impurezas ou imperfeições, na etapa de elaboração dos mesmos se tornam necessárias, ou ao menos bem vindas, comparações com resultados exatos, mesmo que para cadeias pequenas em razão das dificuldades computacionais envolvidas (alias, são essas dificuldades que motivam a busca por funcionais). Apresentamos aqui dois procedimentos utilizados para obtenção dos dados presentes nos capítulos anteriores. O primeiro, baseado no método de potências sucessivas do Hamiltoniano, é apropriado para se obter a energia do estado fundamental de cadeias com poucas impurezas, enquanto o segundo método, de diagonalização iterativa, obtem todo o espectro do Hamiltoniano, mesmo para um núnero maior de impurezas, cubora para cadeias grandes apenas os estados de mais baixa energia são computados com grande precisão. A seguir detalhamos cada um desses métodos.

\subsection{O Método de Potências Sucessivas do Hamilto- niano}

Embora esse método possa ser formulado de maneira mais geral, vamos descrevê-lo para o caso de cadeias de $N$ spins $1 / 2$ descritas pelo Hamiltoniano de Heisenberg, ${ }^{*}$

$$
\hat{H}=\sum_{i}^{N} J_{i} \hat{\mathrm{S}}_{i} \cdot \hat{\mathrm{S}}_{i+1} .
$$

com $J_{i}$ sendo as integrais de troca entre spins primeiros vizinhos.

Mesmo na presença de impurezas de spins e/ou defeitos de ligações, esse Hamiltoniano conserva a componente $z$ do spin total, $\hat{S}_{z}$, o qual bloco-diagonaliza $\hat{H}$ para *Agradeço ao Prof. Alcaraz por ter me chamado à atenção sobre esse método, que foi muito impor-
tante neste trabalho. 
diferentes autovalores $S_{z}$ do operador $\hat{S}_{z}$. O teorema de Lieb-Mattis[28] garante que o estado fundamental (EF) pertence ao subespaço de menor valor de $\left|S_{z}\right|$ permitido. Então, como vetores de base nós usamos o conjunto de números quânticos $\left\{\left|m_{1}, m_{2}, \ldots, m_{n}\right\rangle\right\}$. onde $m_{i}$ são os autovalores de $\hat{S}_{z, i}$, e podem ter os valores $-S_{i},-S_{i}+1, \ldots, S_{i}$. Um método prático de gerar esse conjunto de estados é pela decomposição de números inteiros. Por exemplo, para uma cadeia com quatro spins $1 / 2$, a decomposição binária do número inteiro 6 fornece a sequência 0110, que usamos para representar o vetor de estado $|-1 / 2,1 / 2,1 / 2,-1 / 2\rangle$, que é um entre outros cinco do subespaço com $S_{z}=0$. É trivial nontar a representiação matricial de $\hat{H}$ nessa base. A questão principal é como armazenar convenientemente essa representação, uma vez que se trata de uma matriz enorme (felizmente esparça): para 20 spins 1/2 a ordem dessa matriz é 184.756, com 1.108.536 elementos não nulos. Para cadeias maiores que 25 spins nós não armazenamos essa matriz, mas computamos seus elementos sempre que o código computacional exigir e, nesse ponto do processamento, os vetores de base são recuperados via um procedimento definido na Ref. [64] e denominado codificação por subrede (ou sublattice coding, que substitui a tabela hash). Com isso há liberação de memória, a um custo mais alto de tempo de processamento. Através desse procedinento, com uso de duas subredes, podemos obter o estado fundamental para cadeias de até 30 spins $1 / 2$ utilizando microcomputadores comuns. Esse número pode aumentar utilizando mais subredes na codificação dos vetores dè base.

Para obter o EF de $\hat{H}$ nós poderíamos utilizar o método de Lanczos, [45, 65] mas optamos por un procedimento bascado en argumentos básicos de Mecânica Quântica, e simples de se codificar. Ele utiliza em geral menos memória que Lanczos, embora normalmente seja mais lento para extrair a EEF. O procedimeto começa decompondo um vetor tentativa para o $\mathrm{EF},\left|\psi_{T}\right\rangle$, na base dos autovetores $\left|\psi_{n}\right\rangle$ de $\hat{H}$, isto ć, escrevendo

$$
\left|\psi_{T}\right\rangle=\sum_{n} \alpha_{n}\left|\psi_{n}\right\rangle
$$

com $\alpha_{n}$ constantes. Escolhendo $\epsilon$ como um limite superior para o espectro de energias, atuando $k$-vezes o operador $\hat{H}-\epsilon I$ no estado $\left|\psi_{T}\right\rangle$ resulta em

$$
(\hat{H}-\epsilon)^{k}\left|\psi_{T}\right\rangle=\sum_{n} \alpha_{n}\left(E_{n}-\epsilon\right)^{k}\left|\psi_{n}\right\rangle
$$

onde $\hat{H}\left|\psi_{n}\right\rangle=E_{n}\left|\psi_{n}\right\rangle$. Para $k \rightarrow \infty$ a soma acima é dominada pelo maior valor em módulo de $\alpha_{n}\left(E_{n}-\epsilon\right)^{k}$, que denominamos $\alpha_{0}\left(E_{0}-\epsilon\right)^{k}$, de onde tiramos $E_{0}$. Portanto, $E_{0}$ é obtido pelo seguinte limite:

$$
E_{0}=\lim _{k \rightarrow \infty} \frac{\left\langle\phi\left|(H-\epsilon)^{k+1}\right| \psi_{T}\right\rangle}{\left\langle\phi\left|(H-\epsilon)^{k}\right| \psi_{T}\right\rangle}+\epsilon,
$$

onde $|\phi\rangle$ é qualquer vetor não ortogonal ao EF. Sem a constante $\epsilon$ o método forneceria o maior autovalor em módulo. Para cadeias antiferromagnéticas, o maior autovalor $\epsilon$ corresponde à configuração ferromagnética, cujo valor é trivial mesmo com impurezas ou defeitos na cadeia. 
A convergência do limite acima ao valor $E_{0}$ é caracterizada por atingir duas iterações successivas com valores de $E_{0} / N$ diferindo por menos que $10^{-13}$. Tipicamente isso requer $h$ da ordem de centenas para cadeias maiores que 20 spins, e apenas algumas dezenas de $k$ para cadcias menores. Para acelerar essa convergencia. nós implementamos o código com alguns ingredientes:

1. partimos da solução de campo médio: nossa experiência mostra que a melhor função tentativa $\left|\psi_{T}\right\rangle$ é a de campo médio para o EF. Para uma cadeia homogênea consiste em uma sequência de spins $\uparrow$ ou $\downarrow$. Se o número $N$ de spins for ímpar: começamos com $\left|\psi_{T}\right\rangle=|\uparrow \downarrow \uparrow \downarrow \ldots \uparrow\rangle$, mas se $N$ for par, começamos com

$$
\left|\psi_{T}\right\rangle=\frac{|\uparrow \downarrow \uparrow \downarrow \ldots \uparrow \downarrow\rangle+(-1)^{N / 2}|\downarrow \uparrow \downarrow \uparrow \ldots \downarrow \uparrow\rangle}{\sqrt{2}} .
$$

O peso $1 / \sqrt{2}$, exato para dois spins $1 / 2$, cai bastante para cadeias com muitos spins, mas ainda assim esse $\left|\psi_{T}\right\rangle$ ó um bom começo.

2. calculamos iterativamente: utilizamos para $|\phi\rangle$ no $k$-ésimo passo do limite acima o estado $\left|\phi_{k-1}\right\rangle=(\hat{H}-\epsilon I)^{k-1}\left|\phi_{k-2}\right\rangle$ obtido no passo anterior; lembre-se que $\left|\phi_{0}\right\rangle=$ $\left|\psi_{T}\right\rangle$.

3. usamos aceleração via procedimento de Aitken: o valor assintótico da sequência em $k$ definida na Eq. (6.4) pode ser alcançado mais rapidamente utilizando o seguinte esquema. Suponha que $E_{k+1}=g\left(E_{k}\right)$, com $g(E)$ uma função desconhecida, porém diferenciável. Para valores grandes de $k$, isto é, para $E_{k}$ já próximo do valor assintótico $E_{0}$, podemos escrever que

$$
g^{\prime}\left(\epsilon_{n+1}\right)=\frac{g\left(E_{0}\right)-g\left(E_{n}\right)}{E_{0}-E_{n}} \quad \text { e } \quad g^{\prime}\left(\epsilon_{n+2}\right)=\frac{g\left(E_{0}\right)-g\left(E_{n+1}\right)}{E_{0}-E_{n+1}},
$$

onde $g^{\prime}$ é a derivada de $g$ e $\epsilon_{m}$ é um número entre $E_{m}$ e $E_{0}$. A hipótese fundamental ć que perto dia convergência as duas derivadas são praticamente iguais, resultando em

$$
E_{0} \approx \frac{E_{n} E_{n+2}-E_{n+1}^{2}}{E_{n+2}-2 E_{n+1}+E_{n}}=E_{n}-\frac{\left(\Delta E_{n}\right)^{2}}{\Delta^{2} E_{n}},
$$

sendo a segunda igualdade apenas una escrita alternativa, onde $\Delta E_{n}=E_{n+1}-E_{n}$ e $\Delta^{2} E_{n}=E_{n+2}-2 E_{n+1}+E_{n}$; dada essa forma de escrever. o procedimento também é chamado de método $\Delta^{2}$ de Aitken.[66]

A Fig (6.1) mostra a vantagem computacional de cada um desses procedimentos ao se obter a EEF de uma cadeia de 20 spins 1/2. Para cadeias maiores, essas implementações são ainda mais eficientes. Outros procedimentos para se achar melhores funçōes tentativas. como o uso de teoria de perturbação, mostraram-se ineficientes.

O código para o método de potências sucessivas é bem flexível, permitindo que se adicione com relativa facilidade interações entre dois spins quaisquer da cadeia, mesmo que não sejam primeiros vizinhos. Isso permitiu utilizar os códigos para cadeias em redes quadradas ou retangulares, da forma como descrita na Fig. (4.4). 


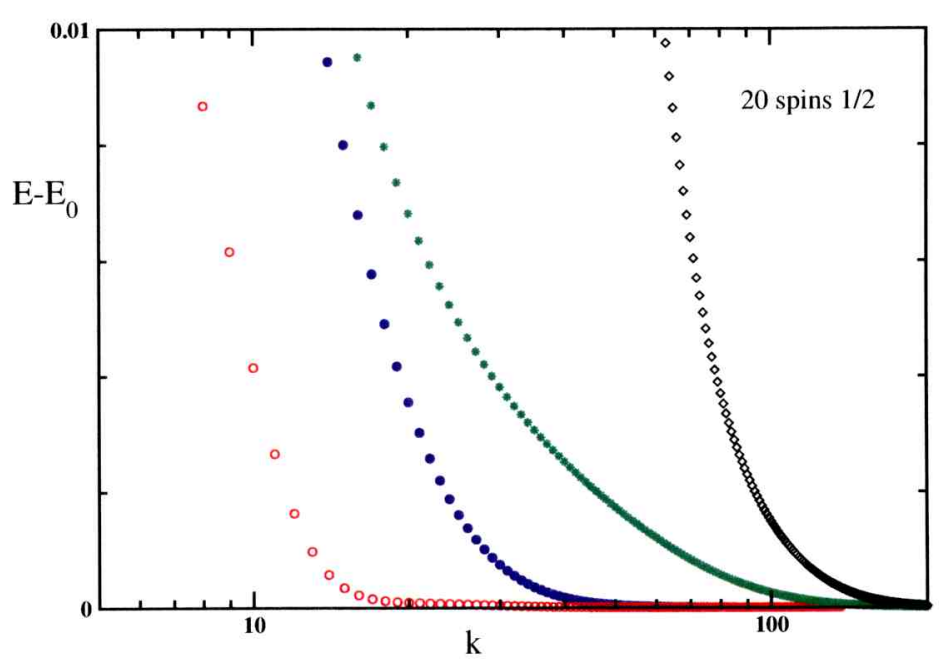

Figura 6.1: Comparação entre as diferentes implementações do método de potência: (o) $\left|\psi_{T}\right\rangle$ como definido na Eq. (6.5) mais aceleração via Aitken; $(\bullet)\left|\psi_{T}\right\rangle$ como definido na Eq. (6.5), porém sem a aceleração Aitken; $(\star)\left|\psi_{T}\right\rangle$ igual a campo médio, porém sem a combinação linear presente em Eq. (6.5). Finalmente, $(\diamond)$ escolhendo um vetor qualquer da base para ser o $\left|\psi_{T}\right\rangle$.

O método de potências sucessivas também fornece o autovetor $|0\rangle$ correspondente ao autovalor $E_{0}$. Se para o vetor tentativa escolhermos um que é ortogonal a $|0\rangle$, o método fornecerá o autovalor correspondente ao primeiro estado excitado. Em princípio poderíamos obter todo o espectro desse jeito, mas a cada novo autovetor temos que criar um $\left|\psi_{T}\right\rangle$ ortogonal a todos os anteriores, o que torna o procedimento inviável. O método que descrevemos a seguir permite obter todos os autoestados de forma mais elegante, com certo controle de precisão.

\subsection{Método de Diagonalização Iterativa}

A diagonalização direta de cadeias de $N$ spins no espaço gerado pelos autovetores da componente $z$ de cada operador de spin $\hat{S}_{i, z}$ se torna inviável para cadeias grandes devido ao imenso tamanho do espaço de Hilbert, mesmo se levarmos em conta a conservação da componente $z$ do spin total. Essa tarefa se torna ainda mais difícil se alguns spins do sistema forem maiores que $1 / 2$, como por exemplo quando temos impurezas substitucionais em um substrato de spins $1 / 2$. O procedimento descrito abaixo utiliza a conservação do spin total para ajudar na diagonalização do Hamiltoniano. Nosso método, iterativo, é em parte inspirado no procedimento de Wilson[67] para impurezas magéticas embebidas num substrato metálico. No entanto, nossas cadeias de spins localizados não exibem uma propriedade exclusiva dos metais, a invariância de escala de energia ao redor do nível de Fermi e que origina a transformação do Grupo de Renormalização Numérico que por sua vez possibilita a diagonalização de sistemas com muitos graus de liberdade (no espaço de momento). Os detalhes desse método iterativo estão no Apêndice. Para uma descrição completa do procedimento, ver Tese de Doutorado de Fabiano Caetano de Souza.[36] 
Esse procedimento iterativo é capaz de obter de forma numericamente exata o espectro de energias completo de cadeias com até 20 spins 1/2, e com precisão de seis (duas) casas decimais a EFF (estados excitados) de cadeias com até uma centena de spins. Nós estamos interessados principalmente cm sistemas sem simetria translacional, sendo assim, explicitamos aqui o método para sistemas com condições abertas de contorno, embora o procedimento possa também ser aplicado para condições periódicas de contorno (e neste caso invariância translacional poderia ser incorporada). Ilustraremos o procedimento para cadeias de spins 1/2. mas a generalização para outros spins, ou para carleias com impurezas, pode ser feita seguindo esse procedimento.[36] Não há dificuldade alguma em se aplicar o método para distribuições não uniformes dos acoplamentos de troca $J_{i, j}$.

Para condições abertas de contorno, o Hamiltoniano de Heisenberg para $N$ spins pode ser escrito como

$$
\hat{H}_{N}=\sum_{i}^{N-1} J_{i} \hat{\mathbf{S}}_{i} \cdot \hat{\mathbf{S}}_{i+1}=\hat{H}_{N-1}+J_{N} \hat{\mathrm{S}}_{N-1} \cdot \hat{\mathrm{S}}_{N}
$$

Essa relação permite que uma vez conhecidos os autoestados de $\hat{H}_{N-1}$ se possa computar o espectro de $\hat{H}_{N}$ de maneira recursiva, descrita em detalhe no Apêndice. A Fig. (6.2) ilustra o modo como a cadcia ć construída itcrativannente.

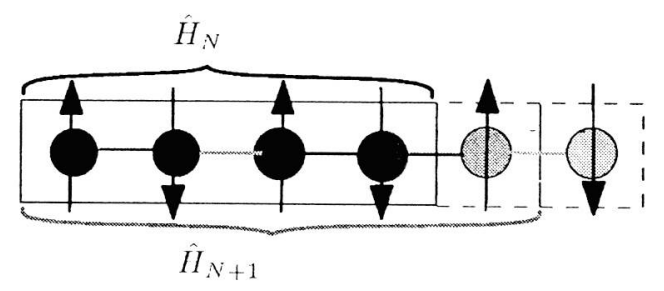

Figura 6.2: Crescimento iterativo da cadeia de $N$ spins. A partir da diagonalização de uma cadeia com $N$ spins construímos a base de estados em que a cadeia com $N+1$ spins será diagonalizada.

Para integrais de troca $J_{i, j}$ isotrópicas (isto é, iguais para todas as direções), e campo externo homogêneo uniaxial, o modelo conserva o quadrado do spin total, $\hat{\mathrm{S}}^{2}$, e sua componente $z, \hat{S}_{z}$. Portanto, na $N$-ésima iteração um estado de $N$ spins pode ser expresso pelo ket $|s, m\rangle_{N}$, com $\hat{\mathrm{S}}^{2}|s, m\rangle_{N}=s(s+1)|s, m\rangle_{N}$ e $\hat{S}_{z}|s, m\rangle_{N}=m|s, m\rangle_{N}$.

Para diagonalizar $\hat{H}_{N}$, após a diagonalização de $\hat{H}_{N-1}$ nós construímos o produto direto de seu autovetor $|s, m\rangle_{N-1}$ com o estado $|\sigma\rangle_{N}, \sigma=\uparrow$ ou $\downarrow$, do $N$-ésimo spin adicionado, criando o vetor de base $|s, m ; \sigma\rangle_{N}$. Para construir novos estados de base onde $\hat{H}_{N}$ seja diagonalizado. esses retores são apropriadamente combinados, através de coeficientes de Clebsh-Gordan,[68] para resultar em autoretores simultâneos de $\hat{S}_{z}$ e $\hat{\mathbf{S}}^{2}$. Portanto, $\hat{H}_{N}$ nessa base ć bloco-diagonal.

Sem campos externos as energias não dependem da componente $\approx$ do spin e portanto é necessário apenas diagonalizar $\hat{H}_{N}$ em um único subespaço de $\hat{S}_{z}$ para cada autovalor $S$. Isso economiza muito tempo de processamento e espaço de memória. Um exemplo 
simples para se ver essa economia é diagonalizar $\hat{H}_{4}$ uma vez tendo diagonalizado $\hat{H}_{3}$. Para $N=4$ nós temos dezesseis estados de base; a conservação de apenas $\hat{S}_{z}$ nos levaria a diagonalizar uma matriz $6 \times 6$ e uma $4 \times 4$. Levando em conta também a conservação de $\hat{\mathbf{S}}^{2}$, temos que diagonalizar un subespaco $2 \times 2$, correspondente a $s=0$ e outro $3 \times$ 3 , correspondente a $s=1$. Como o procedimento é iterativo. essa economia se reflete diretamente na construção da base de estados onde $\hat{H}_{5}$ será em seguida diagonalizada e assim por diante.

Embora as conservações de $\hat{\mathbf{S}}^{2}$ e $\hat{S}_{z}$ reduzam consideravelmente o tamanho das matrizes envolvidas, o número de estados cresce exponenciahmente com $N$. Alcanca-se o máximo de memória de microcomputadores usuais para cadeias com cerca de 20 spins 1/2. O procedimento recursiro de diagonalização, no entanto, permite esquemas simples de truncamento do número de estados a ser mantido a cada iteração. Nós podemos estabelecer, por exemplo, uma energia de corte $E_{c}(s)$ para cada subespaço de spin total $s$, e/ou, alternativamente, podemos também fixar o número de autovetores mantidos em cada diagonalização. Esses cortes são escolhidos de acordo com os recursos computacionais disponíveis e precisão desejada para o espectro. A Fig. (6.3) mostra o desvio no valor da encrgia do estado fundanchtal para algumas carleias, em função do número $m$ de estados mantidos a cada iteração. É bom observar que o número máximo de estados mantidos, 2000, é ainda muito pequeno perto do número total de estados presentes na diagonalização das cadeias envolvidas. Note a rápida convergência do estado fundamental para cadeias relativamente pequenas. Já para cadeias com cerca de 100 spins essa convergência é mais lenta, mas a precisão ainda é aceitável em algumas aplicaçóes, como no atual estágio da DFT no desenvolvimento de novos funcionais de spins. Somente para comparação, nosso resultado para $N=128$ spins $1 / 2$ é $E_{0} / N J=-0.44167$, que difere na quinta casa decimal do obtido por Bethe ansat'z na Ref.[52] (que é -().44168).

Ao se estudar a dependência de uma grandeza com o tamanho da rede, o método iterativo trás a vantagem que. para se chegar numa rede de $N$ spins, necessariamente se diagonalizou todas as demais desde $N=2$, como é o caso na Fig. (6.3) em que, para cada $m$ fixado, uma única corrida do programa gerou todos os dados até a cadeia com $N=128$ spins.

Para estudar o efeito do truncamento nos estados excitados, na Fig. (6.4) fixamos o tamanho da cadeia em 20 spins, situação em que podemos obter o espectro sem necessidade de truncamento, ou seja, numericamente exato. As curvas referem-se ao desvio do $i$-ésimo estado excitado quando um truncamento é utilizado. mantendo-se $m$ estados a cada iteração. A primeira centena de estados excitados tem boa precisão, mas esta cai a medida que estados mais excitados são considerados. 


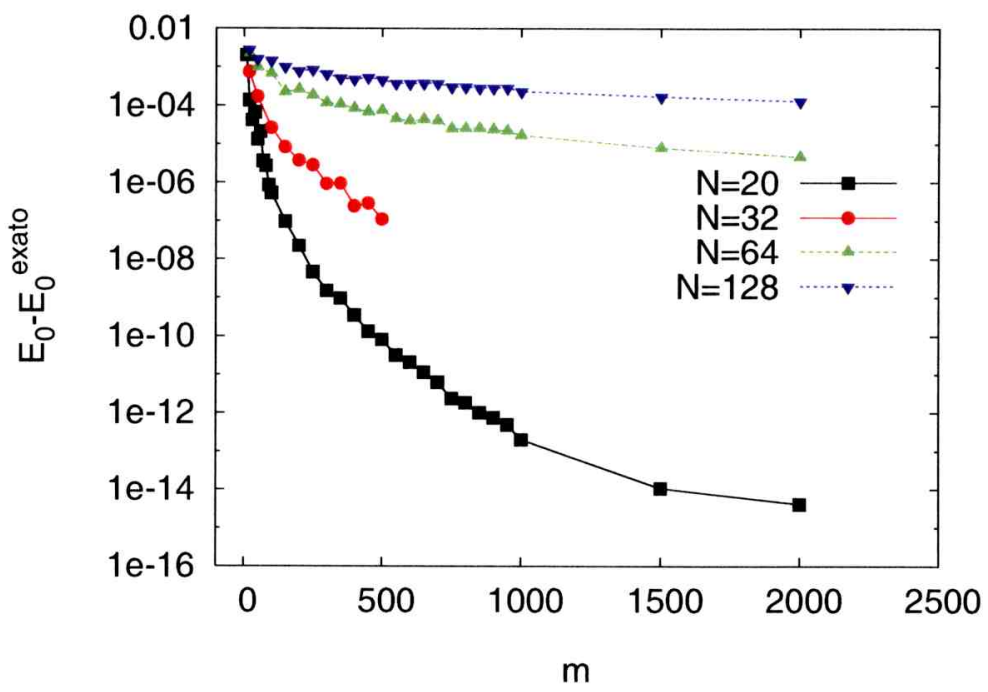

Figura 6.3: Desvio no valor da energia do estado fundamental em função do número $m$ de estados mantidos após o truncamento, para cadeias com $N=20,32,64$ ou 128 spins $1 / 2$ e condições abertas de contorno. A Ref.[52] forneceu os valores exatos para $N=32,64$ e 128. (Fig. (3.1) da Ref.[36]).

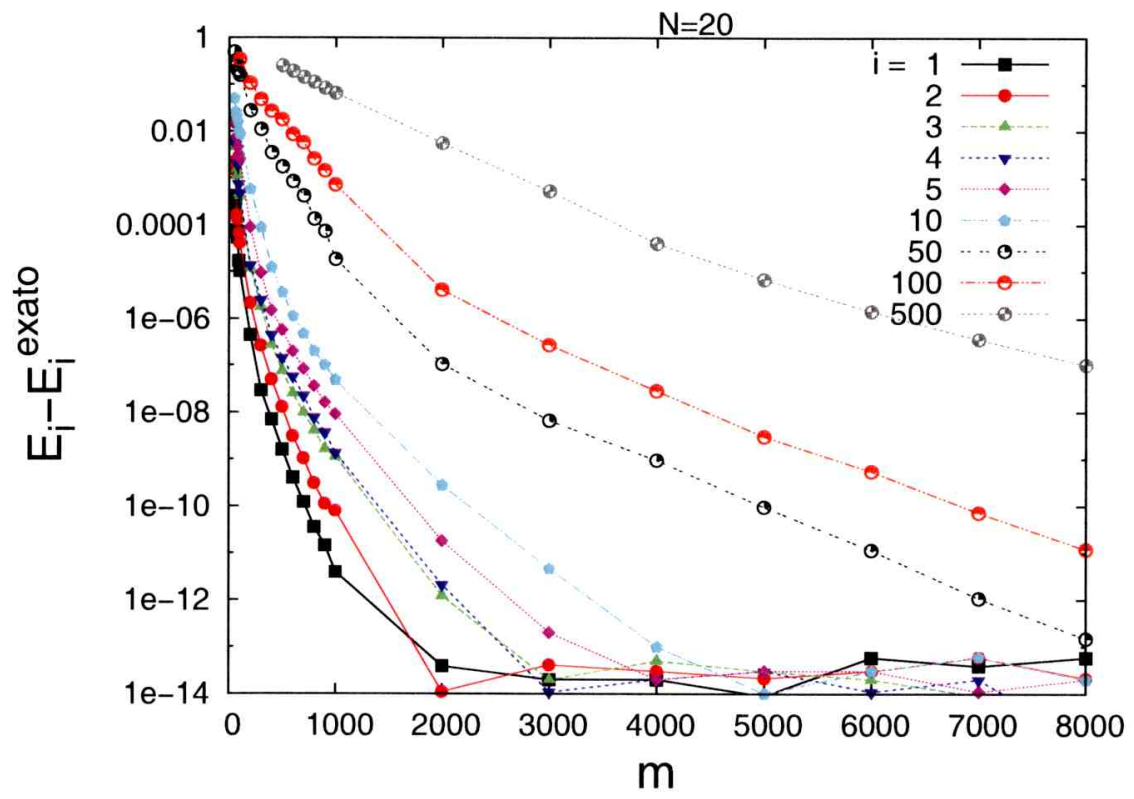

Figura 6.4: Desvio no valor da energia de estados excitados em função do número $m$ de estados mantidos após o truncamento, para uma cadeia com $N=20$ spins $1 / 2$ e condição aberta de contorno. Os valores exatos são obtidos diagonalizando essa cadeia sem truncamento (Fig. (3.13) da Ref.[36]). 


\subsection{Escadas de Spins}

O método iterativo descrito acima pode ser generalizado com relativa facilidade para sistemas de spins com topologia de escada,[53] como ilustrada na Fig. (6.5). O Hamiltoniano de Heisenberg para uma escada de $L$ degraus é dado por

$$
\hat{H}_{L}=\sum_{l=1}^{L-1}\left(J_{1, l} \hat{\mathbf{S}}_{1, l} \cdot \hat{\mathbf{S}}_{1, l+1}+J_{2, l} \hat{\mathbf{S}}_{2, l} \cdot \hat{\mathbf{S}}_{2, l+1}\right)+\sum_{l=1}^{L} J_{l}^{\prime} \hat{\mathbf{S}}_{1, l} \cdot \hat{\mathbf{S}}_{2, l},
$$

com os acoplamentos $J_{1, l}$ e $J_{2, l}$ entre spins das pernas da escada e $J_{l}^{\prime}$ entre spins dos degraus (ver Fig. (6.5)). A transformação em $\hat{H}$ que permite implementar o método iterativo é:

$$
\hat{H}_{L}=\hat{H}_{L-1}+J_{1, L-1} \hat{\mathbf{S}}_{1, L-1} \cdot \hat{\mathbf{S}}_{1, L}+J_{2, L-1} \hat{\mathbf{S}}_{2, L-1} \cdot \hat{\mathbf{S}}_{2, L}+J_{L}^{\prime} \hat{\mathbf{S}}_{1, L} \cdot \hat{\mathbf{S}}_{2, L} .
$$

A base de estados em que a representação matricial de $\hat{H}_{L}$ é escrita é obtida do produto direto entre os autovetores de $\hat{H}_{L-1}$ e os autovetores singleto e tripleto da dupla de spins $\hat{\mathbf{S}}_{1, L}$ e $\hat{\mathbf{S}}_{2, L}$ da ponta em que a escada é crescida. O processo iterativo para esse caso é descrito em detalhe na Ref.[36], onde também são incluídas escadas com interações entre primeiros vizinhos diagonais. Escolhendo adequadamente os acoplamentos $J_{1, l}, J_{2, l}$ e os diagonais, aparece uma grande variedade de topologias possíveis. Em particular, escadas com $J_{l}^{\prime}=0$, isto é, com pernas desacopladas, recaem na cadeia com condições periódicas de contorno. Na Ref.[36] também é desenvolvido o método iterativo para escadas com simetria de reflexão, isto é, para quando $J_{1, l}=J_{2, l}$ (ver Fig. (6.5)).
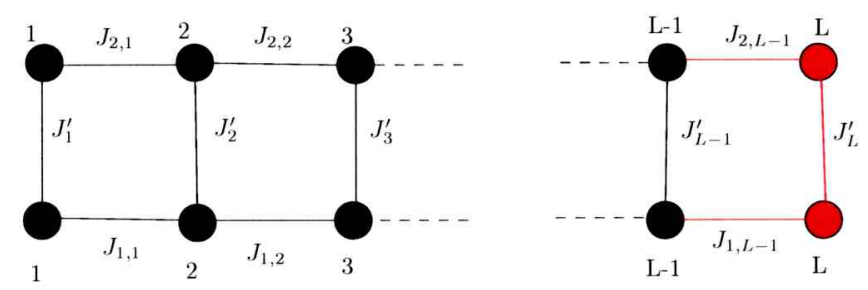

Figura 6.5: Escada $2 \times L$ de spins, com acoplamentos $J_{1, l}$ e $J_{2, l}$ nas pernas e $J_{l}^{\prime}$ entre spins dos degraus. A dupla de spins $\hat{\mathbf{S}}_{1, L}$ e $\hat{\mathbf{S}}_{2, L}$ é acrescida à escada para dar sequência ao processo iterativo.

Os desvios nos autovalores em função do número de estados mantidos a cada iteração para a escada seguem o mesmo comportamento daqueles para cadeias (ver Fig. (6.3) e $(6.4))$.

A Tab. 6.1 fornece valores para a EEF, por spin, para escadas de dimensões $2 \times L$, para diversos valores dos acoplamentos $J^{\prime}$ dos degraus. Entre parênteses estão estimativas dos erros nas respectivas energias. Esse erro cresce com o aumento da cadeia, mas diminui com o aumento da razão $J^{\prime} / J$. Para comparação, no caso $J^{\prime}=0$ a escada se reduz a duas cadeias abertas, cujo valor da EEF, para cada uma, no limite 
termodinâmico é -0.443147; já para $J^{\prime} / J=1$, temos uma escada uniforme e a Ref.[53] fornece o valor -0.578 para o limite termodinâmico obtido pela extrapolação de resultados para escadas finitas. A convergência ao limite termodinâmico é mais rápida no caso da escada uniforme que no caso da cadeia.

Tabela 6.1: EEF, $-E_{0} / 2 L J$, para escadas de tamanho $2 \times L$. em função da razão $J^{\prime} / J$ entre os acoplamentos dos degraus e das pernas. Foram matidos 12000 estados a cada iteração. O erro indicado ć na última casa decimal e é relativo às encrgias obtidas mantendo-se 6000 estados. Para cadcias com até 64 spins, as energias são exatas até a sexta casa. A última linha da tabela mostra os resultados da Ref.[53] para o limite termodinâmico, extrapolados de cadeias finitas (Tab. 4.3 da Ref.[36]).

\begin{tabular}{lllllll}
\hline & \multicolumn{1}{c}{0} & \multicolumn{2}{c}{$J^{\prime} / J$} \\
$L$ & \multicolumn{1}{c}{0.0} & \multicolumn{1}{c}{0.2} & \multicolumn{1}{c}{0.4} & \multicolumn{1}{c}{0.6} & \multicolumn{1}{c}{0.8} & \multicolumn{1}{c}{1.0} \\
\hline \hline 4 & 0.404006 & 0.408912 & 0.425096 & 0.452963 & 0.490859 & 0.536633 \\
8 & 0.421867 & 0.427829 & 0.446325 & 0.475390 & 0.512833 & 0.557217 \\
12 & 0.428508 & 0.435168 & 0.454459 & 0.483438 & 0.520386 & 0.564158 \\
16 & 0.431984 & 0.439116 & 0.458664 & 0.487491 & 0.524168 & 0.567629 \\
20 & $0.434123(1)$ & $0.441578(1)$ & 0.461206 & 0.489924 & 0.526436 & 0.569712 \\
24 & $0.435571(7)$ & $0.443252(5)$ & $0.462903(1)$ & 0.491546 & 0.527949 & 0.571100 \\
28 & $0.436615(21)$ & $0.444458(11)$ & $0.464115(4)$ & $0.492705(1)$ & $0.529029(1)$ & 0.572092 \\
32 & $0.437399(35)$ & $0.445364(20)$ & $0.465022(7)$ & $0.493573(3)$ & $0.529838(1)$ & $0.572836(1)$ \\
\hline$\infty$ & 0.443 & 0.453 & 0.472 & 0.500 & 0.535 & 0.578 \\
\hline
\end{tabular}

Una ve\% que o método iterativo fornece o espectro de energias, podemos computar, por exemplo, a dependência do gap singleto-tripleto para escadas com os acoplamentos das duas pernas iguais a $J$ e dos degraus iguais a $J^{\prime}$. A Fig. (6.6) apresenta nossos dados para diversos tamanhos de escadas. A curva contínua refere-se ao limite termodinâmico inferido na Ref.[53]. O gap diminui com o aumento do número de degraus da cadeia, mas, ao contrário de sua diminuição com a diminuição de $J^{\prime}$ vista no limite termodinânico, para sistemas finitos há um aumento do gap para $J^{\prime}$ pequenos, ao menos para escadas com até 64 spins. 


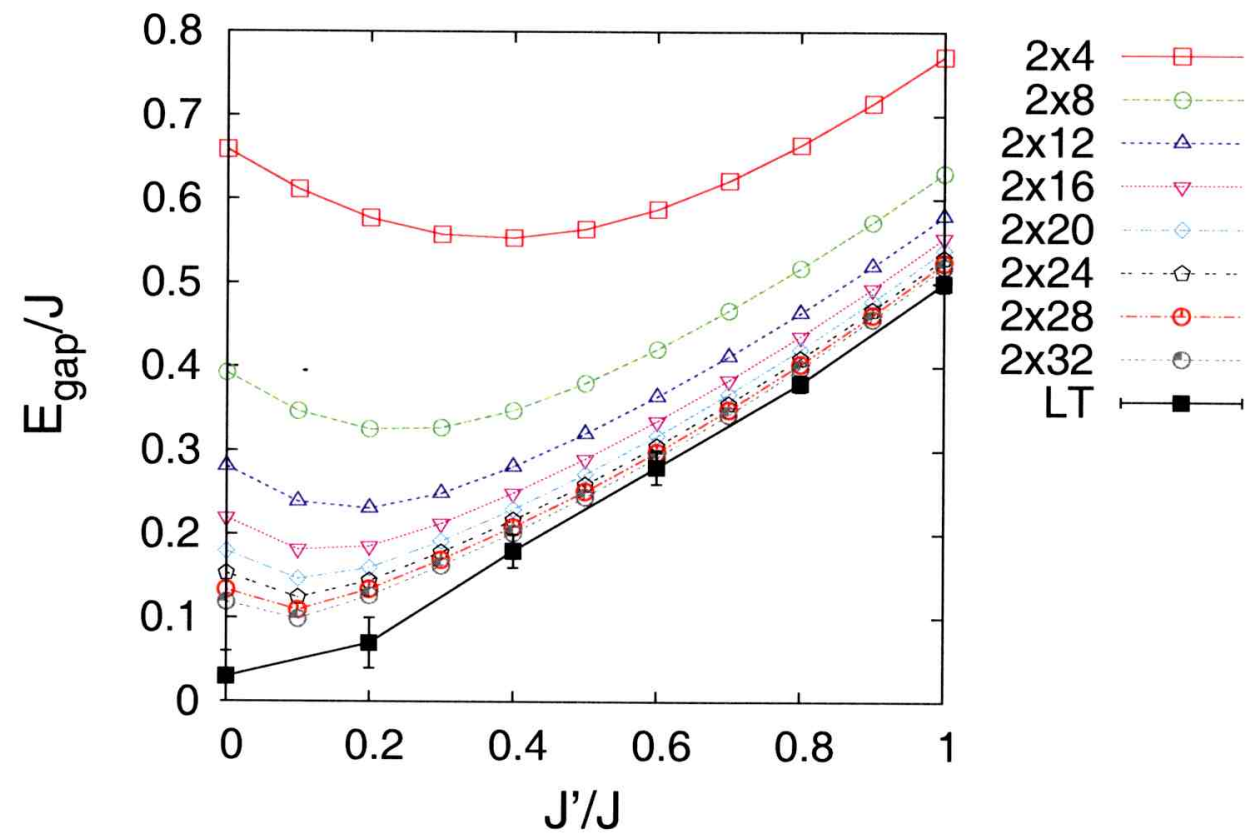

Figura 6.6: Gap singleto-tripleto para escadas $2 \times L$ de spins $1 / 2$, em função da razão $J^{\prime} / J$, sendo os acoplamentos $J_{1, l}=J_{2, l}=J$ nas pernas e $J_{l}^{\prime}=J^{\prime}$ nos degraus. O limite termodinâmico (LT) foi extraído da Ref[53] (Fig. (4.6) da Ref.[36]). 


\section{Capítulo 7}

\section{Conclusões e Propostas de Trabalho}

Através da Teoria do Funcional da Densidade aplicada ao modelo de Heisenberg foram obtidas estimativas da cnergia do estado fundanental de redes antiferromagnéticas em uma, duas ou três dimensões, com simetria translacional quebrada, complicação presente em sistemas reais. como nos atuais dispositivos nanomagnéticos de diversas geometrias e com diferentes tipos de impurezas ou defeitos.

Nossos resultados mostram que a aproximação LSA aplicada ao modelo de Heisenberg vai bem além de campo médio, possibilitando cáleulos em sistemas de tamanho considerável, mas a um custo computacional muito inferior aos de outros métodos como QMC ou DMRG. Além de trazer informações úteis a sistemas magnéticos em escala nanométrica, os valores obtidos via LSA podem servir como referência na aplicação de outros métodos de muitos corpos ao mesmo tipo de sistema.

Os funcionais apresentados são bastante simples, refletindo um estágio inicial de construção dos mesmos, e limitados a sistemas de pouca complexidade. Não são aplicáveis por exemplo, a configurações que não sejam ferro, antiferro, ou ferrimagnéticas, como por exemplo as que exibem helinagnetismo. Também são formulados para redes retangulares; redes importantes como triangulares ou hexagonais devem ainda ser analisadas. A limitação mais séria. no entanto, vem da natureza local dos mesmos. Funcionais não locais deverão dar um passo importante na aplicação da DFT a sistemas de spins, e a aproximação LUCA apresentada no Cap. 5 é apenas um singelo exemplo em um caso especial em que as interaçóes de troca possam mudar de sítio a sítio. Apesar dessas limitações, surpreende que os resultados sejam bons, particularmente frente à simplicidade dos funcionais e a facilidade no uso dos mesmos.

Una formulacão sofisticarla para cardcias de spins usando a DFT aparece na Ref.[69], cujos resultados são em sua maioria posteriores aos nossos e algumas grandezas além de energia são determinadas, como por exemplo, expoentes críticos. Acredito que com o tempo a DFT aplicada ao modelo de Heisenberg venha alcançar um patarmar equivalente ao da atual DFT para sistemas eletrônicos.

As próximas seçóes sugerem possibilidarles de trabalho na linha desta Tese. 


\subsection{Spin Wave para cadeias com spins alternados}

Os funcionais existentes até o momento surpreendentemente fornecem estimativas melhores que alguns porcento, erro que tende a aumentar com o número de impurezas. A Fig. (7.1) mostra que para uma cadeia de spin $1 / 2$ os funcionais $\operatorname{LSA}^{S W}$ ou LSA ${ }^{D M R G}$ reproduzem bem os resultados exatos; o mesmo acontece para uma cadeia de spins 1 . Já para uma cadeia em que os valores dos spins se alternam entre $1 / 2$ e 1 , os funcionais não são tão satisfatórios.

Uma cadeia alternada pode ser pensada como duas subcadeias intercaladas, uma de spin $1 / 2$ e outra de spin 1 . de spins $1 / 2$ com os spins 1 como impurezas, ou uma de spins 1 com os spins 1/2 como impureza. Ela é altamente não homogênea e por isso os funcionais desviam mais dos resultados exatos.

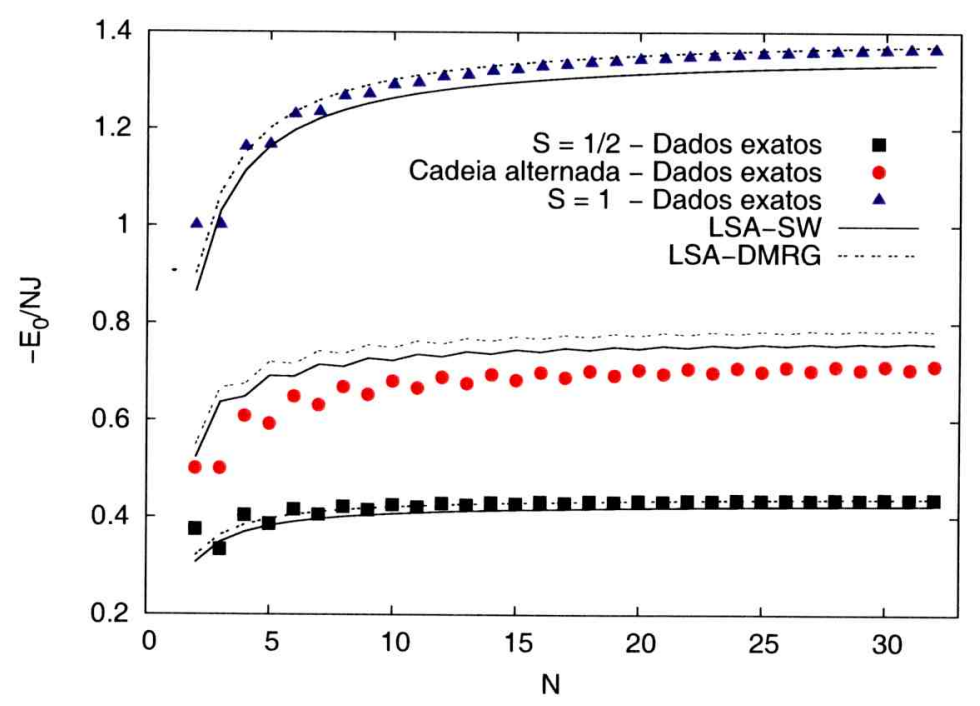

Figura 7.1: Energia do estado fundamental em função do número de sítios $N$ para cadeias contendo somente spins $1 / 2$, ou somente spins 1 . Nestes casos, os funcionais reproduzem bem os resultados exatos, com LSA ${ }^{D M R G}$ ligeiramente melhor. Para uma cadeia altamente não homogênea, com spins $1 / 2$ e 1 intercalados, os funcionais já não repoduzem bem os resultados exatos, sendo neste caso LSA ${ }^{S W}$ um pouco melhor (Fig. (3.19) da Ref.[36]).

A ideia de usar uma cadeia de spins cujos valores alternam entre $S_{1}$ e $S_{2}$, a exemplo da cadeia alternada em ligações tratada no Cap. 6, pode ser um bom começo para se gerar um funcional não local $E\left[S_{i}\right]$. A partir da teoria de ondas de spin podemos determinar a função (e não funcional) $E_{0}\left(S_{1}, S_{2}\right)$ que dá a energia do estado fundamental para essa 
cadeia:* $^{*}$

$$
\begin{aligned}
E_{0}\left(S_{1}, S_{2}\right) & =-\sqrt{S_{1}\left(S_{1}+1\right) S_{2}\left(S_{2}+1\right)} \\
& +\frac{1}{\pi}\left(S_{1} \sqrt{\frac{S_{1}+1}{S_{2}+1}}+S_{2} \sqrt{\frac{S_{2}+1}{S_{1}+1}}\right) .
\end{aligned}
$$

Subtraindo o valor de campo médio temos a energia de correlação nessa aproximação SW. Com ela, via uma aproximação local similar aquela feita na Seção 3.4, podemos construir um funcional LSA ${ }^{S W-a l t}$ agora baseado nessa cadeia de spins alternados. A Fig. (7.2) compara nossos resultados para cadeias pequenas e abertas com spins $1 / 2$ e 1 intercalados. O novo funcional reproduz bem melhor os resultados exatos que o anterior LSA $^{S W}$. Para $N$ par, portanto um número inteiro de pares $\left\{S_{1}, S_{2}\right\}$, esse funcional reproduz ainda melhor os resultados exatos do que para $N$ ímpar. No entanto, quando levado a cadeias com poucas impurezas não, $\mathrm{LSA}^{S W-\text { alt }}$ não fornece resultos valores melhores que aqueles fornecidos pela aproximação $\operatorname{LSA}^{S W}$ abordada anteriormente, que foi baseada numa cadeia uniforme. Esforços ainda são necessários para se obter, através de um único funcional, melhores resultados para esses dois limites de alta inomogeneidade.

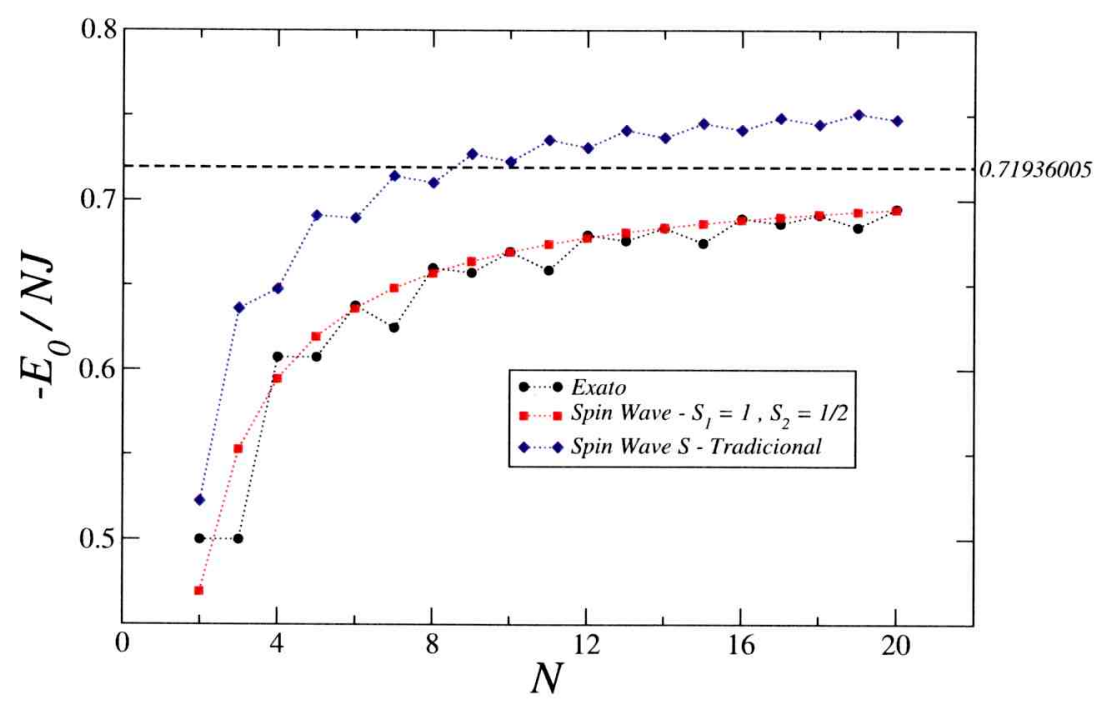

Figura 7.2: Comparação entre os resultados do funcional LSA ${ }^{S W}$ dado na Eq. (3.27) e aqueles fornecidos pelo funcional local gerado através da Eq. (7.1) acima, para uma cadeia aberta de $N$ spins $1 / 2$ e 1 intercalados, LSA $^{S W-\text { alt }}$. Os pontos $(\bullet)$ representam resultados exatos e a linha tracejada indica o limite termodinâmico obtido da Eq. (7.1).

${ }^{*}$ A determinação dessa função foi feita por Rodrigo S. Veiga no seu trabalho de Iniciação Científica. 


\subsection{Funcionais para o Modelo de Heisenberg Aniso- trópico}

Funcionais válidos para quaisquer distribuições de spins para sistemas descritos pelo Hamiltoniano de Heisenberg anisotrópico. Eq. (2.8), são bem mais lifíceis de se construir, dada a escassez de expressões analíticas, exatas ou aproximadas, para a energia do estado fundamental mesmo para sistemas homogêneos. Nas referências [35] e [58], os primeiros passos nessa direção exploram a Teoria não linear de Ondas de Spins, válida para o parâmetro de anisotropia $\Delta$ maior ou igual à unidade e restrita a setores de magnetização nula do modelo. Para romper esses limites, essas referências exploram um resultado bastante interessante dado por Alcaraz e Bariev, [70] que expressa a EEF, por spin, de uma cadeia de spins $1 / 2$ no setor de magnetização $m=\sum_{i} S_{i, z}$ como

$$
c_{0}(m)=\frac{\Delta}{4}(1-4 \rho)-\frac{1-t \rho}{\pi} \sin \frac{\pi \rho}{1-t \rho} .
$$

onde $\rho=(1+2 m / N)$ e $t$ é ajustado numericamente para se ter o resultado exato no limite $m=0$. Em [35] e [58] mostramos que a parametrização

$$
\cdot t(\Delta)=\frac{1}{3} \tanh \left(\frac{2 \Delta}{\pi}\right)+\frac{2}{3} \frac{\Delta}{\Delta+\sqrt{3} / 2}
$$

reproduz bastante bem os resultados. Para obtî-la foram considerados os limites $\Delta=0$, para o qual $e_{0}=-1 / \pi$, e $\Delta \rightarrow \infty$. no qual $e_{0}=-\Delta / 4$. Para $\Delta>1$ sabemos $e_{0}$ da fórmula de Walker, Eq. (2.9), de onde tiramos $t$. No entanto. essas expressões são válidas apenas para cadeias de spin $1 / 2$ e a Eq. (7.3) restrita a $m=0$. Para construirmos um funcional, essas limitações precisam ser removidas e generalizá-las para spin $S$ qualquer não é trivial. O aspecto principal que torna a Eq. (7.2) atraente é que o primeiro termo do lado direito dela é o resultado de campo médio e, portanto, o segundo termo é o de correlação, que incorpora a dependência com $m$ explicitamente. Esse parece ser um aspecto relevante a ser explorado, que depende de um bom conhecimento do modelo de Heisenberg. Outros resultados numéricos também podem ser valiosos.[72] A exemplo do caso em que resultados vindos de DMRG foram usados na construção do funcional $E^{D M R G}\left[\vec{S}_{i}\right]$, aqui também a interpolação de dados numéricos pode ajudar na construção de um funcional mais geral.

\subsection{Termodinâmica de cadeias ou de escadas de spins}

O método iterativo descrito com detalhe no Apêndice não compete em rapidez com outros métodos, tais como Monte Carlo ou DMRG, na obtenção da energia do estado fundamental de cadeias miformes relativanente grandes. No entanto, além de podermos utilizá-lo em cadeias com impurezas ou defeitos, ele permite obter com boa precisão (e de forma exata até 20 spins 1/2) o espectro de energias do Hamiltoniano de Heisenberg. Sendo assim, é possível estudar a termodinâmica de cadeias, ou mesmo escadas, com imperfeições. Alguns resultados nessa direção são apresentados na Ref.[36]. A Fig. (7.3) 
mostra curvas de calor específico em função da temperatura para cadeias com ligações alternadas para diferentes razões $\alpha$ entre interações de troca vizinhas (ver Cap. 5). Os pontos nessas curvas representam resultados exatos, uma vez que para esse tamanho de cadeia não há necessidade de truncamento. Em cadeias maiores o efeito do truncamento aparece na imprecisão do calor específico para $k_{B} T>J$.

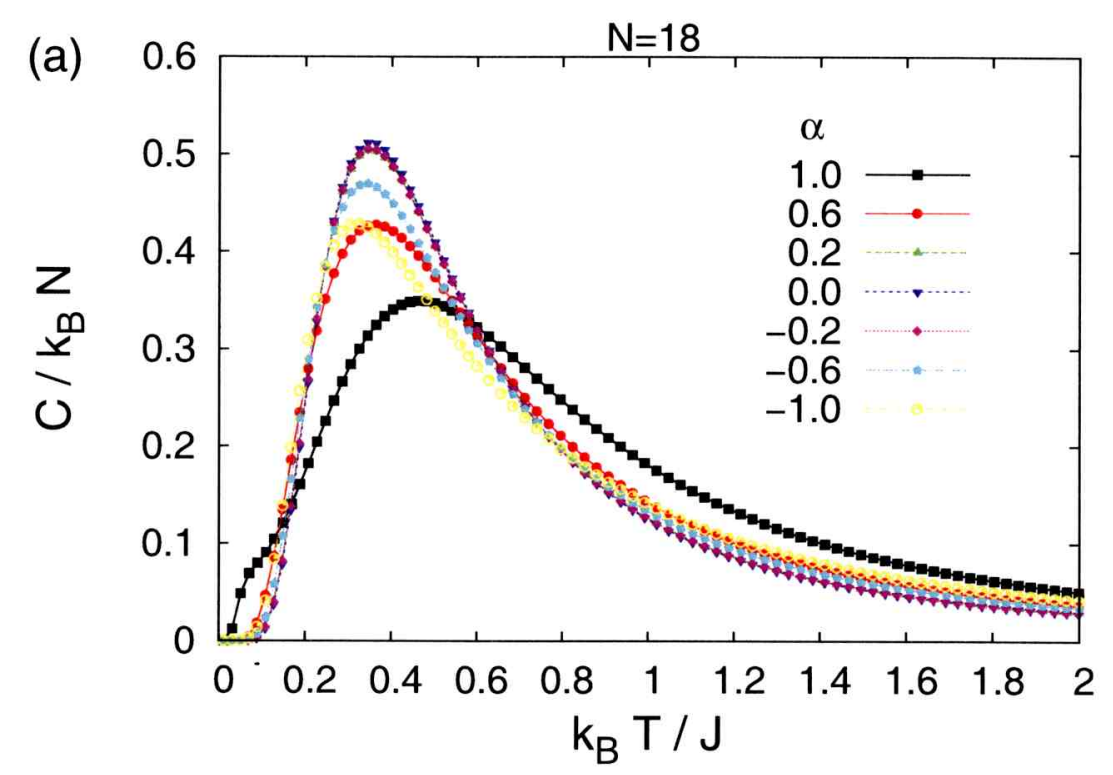

Figura 7.3: Dependência com a temperatura do calor específico de uma cadeia com 18 spins $1 / 2$, com ligações alternada para diversas razões $\alpha$ entre interações de trocas vizinhas. Note valores de $\alpha$ negativos, que correspondem à alternância de ligações ferro- anti-ferromagnética. Há uma temperatura, $\approx 0.15 J / k_{B}$, em que o valor do calor específico depende muito fracamente de $\alpha$ (Fig. (3.12) da Ref.[36]).

O que ainda precisa ser feito é, para grandes cadeias, melhorar a precisão nos valores das energias dos estados excitados, para se obter bons resultados para as propriedades termodinâmicas em temperaturas tais que $k_{B} T>J$. Uma possibilidade aventurada é a implementação do método iterativo por faixa de energia, de forma que espectros seriam obtidos especificamente para cada faixa de temperatura de interesse; dentro de cada faixa haveria um corte apropriado de energia. Outra possibilidade é paralelizar os programas de computador e rodá-los em cluster (ou microcomputadores multi-core), o que possibilitaria manter mais estados entre uma iteração e outra; isso certamente melhoraria a precisão dos estados de alta energia.

Por fim, uma abordagem mais arrojada seria usar a transformação de JordanWigner[71] e escrever o Hamiltoniano de Heisenberg em termos de operadores fermiôni$\cos [28,72]$ e em seguida explorar o formalismo do Grupo de Renormalização Numérico (tradicioanalmente desenvolvido para férmions) para se tentar um método iterativo de diagonalização em que, se houver uma hierarquia dos operadores (esta aparece no caso Kondo dado o desacoplamento de escalas de energia), possa-se introduzir um corte que não afete demasiadamente os estados de alta energia. 


\section{Apêndice}

\section{Método de Diagonalização Iterativa}

O Hamiltoniano de Heisenberg para uma cadeia aberta com $N$ spins pode ser escrito como

$$
\hat{H}_{N}=\sum_{i}^{N-1} J_{i} \hat{\mathbf{S}}_{i} \cdot \hat{\mathbf{S}}_{i+1}=\hat{H}_{N-1}+J_{N} \hat{\mathbf{S}}_{N-1} \cdot \hat{\mathbf{S}}_{N}
$$

Essa relação permite que, uma vez conhecidos os autoestados de $\hat{H}_{N-1}$, possamos computar o espectro de $\hat{H}_{N}$ de uma maneira recursiva, descrita em detalhe abaixo. A Fig. (6.2) ilustra o morlo como a carleia é construída itcrativamente.

Com integrais de troca $J_{i, j}$ isotrópicas (isto é, iguais para todas as direções), e campo externo homogêneo uniaxial, o modelo conserva o quadrado do spin total, $\hat{\mathrm{S}}^{2}$, e sua componente $z, \hat{S}_{z}$. Portanto, um estado de $N$ spins pode ser expresso pelo ket $|s, m\rangle_{N}, \operatorname{com} \hat{\mathbf{S}}^{2}|s, m\rangle_{N}=s(s+1)|s, m\rangle_{N}$ e $\hat{S}_{z}|s, m\rangle_{N}=m|s, m\rangle_{N}$.

Para diagonalizar $\hat{H}_{N}$, após a diagonalização de $\hat{H}_{N-1}$ nós construímos produtos diretos de seus autovetores $|s, m\rangle_{N-1}$ com os estados $|\sigma\rangle_{N}, \sigma=\uparrow$ ou $\downarrow$, do $N$-ésimo spin adicionado, criando vetores de base do tipo $|s, m ; \sigma\rangle_{N}$. Esses vetores são apropriadamente combinados, através de coeficientes de Clebsh-Gordan, [68] resultando em autovetores simultâneos de $\hat{S}_{z}$ e $\hat{\mathbf{S}}^{2}$; o conjunto desses autovetores forma uma base onde $\hat{H}_{N}$ ć bloco diagonal. Há dois tipos $t$ desses autovetores:

$$
\begin{aligned}
& |t=1\rangle_{N}=\left|s-\frac{1}{2} \cdot s-\frac{1}{2} ; \uparrow\right\rangle \\
& |t=2\rangle_{N}=\sqrt{\frac{2 s+1}{2 s+2}}\left|s+\frac{1}{2}, s+\frac{1}{2} ; \downarrow\right\rangle-\sqrt{\frac{1}{2 s+2}}\left|s+\frac{1}{2}, s-\frac{1}{2} ; \uparrow\right\rangle .
\end{aligned}
$$

Nessas cquaçóes fizemos a escolha $m=s$, uma vez que sem campos externos as energias não dependem da componente $z$ do spin e, portanto, é necessário apenas diagonalizar $\hat{H}_{N}$ em um único subespaço de $\hat{S}_{z}$. Isso economiza muito tempo de processamento e espaço de memória. O procedimento iterativo definido na Eq. (F.1) requer o cálculo de elementos de matriz da forma $\left\langle s^{\prime} \cdot m^{\prime} ; \sigma^{\prime}\left|\hat{\mathbf{S}}_{N-1} \cdot \hat{\mathbf{S}}_{N}\right| s, m, \sigma\right\rangle=\left\langle s^{\prime}, m^{\prime}\left|\hat{\mathbf{S}}_{N-1}\right| s, m\right\rangle_{N-1} \cdot\left\langle\sigma^{\prime}\left|\hat{\mathbf{S}}_{N}\right| \sigma\right\rangle_{N}$. Os elementos $\left\langle\sigma^{\prime}\left|\hat{\mathbf{S}}_{N}\right| \sigma\right\rangle_{N}$ são triviais de se calcular, mas a determinação de todos os elementos do tipo $\left\langle s^{\prime}, m^{\prime}\left|\hat{\mathbf{S}}_{N-1}\right| s, m\right\rangle_{N-1}$ é altamente custoso computacionalmente. No entanto, usando o teorema de Wigner-Eckardt,[68] esses elementos podem ser expressos em termos de elementos de matriz invariantes, $\left\langle s^{\prime}|| S|| s\right\rangle$, os quais não dependem de 
qualquer componente $m$ do operador $\hat{S}_{z}$ e portanto armazená-los é muito mais prático e econômico que armazenar os elementos de matriz de $\hat{H}_{N}$. Essa operação requer as seguintes relações válidas para operadores vetoriais:[68]

$$
\begin{aligned}
\left\langle s, m\left|S^{z}\right| s, m\right\rangle & =m\langle s\|S\| s\rangle \\
\left\langle s-1, m\left|\hat{S}^{z}\right| s, m\right\rangle & =\sqrt{(s+m)(s-m)}\langle s-1\|S\| s\rangle \\
\left\langle s, m \pm 1\left|\hat{S}^{ \pm}\right| s, m\right\rangle & =\sqrt{(s \mp m)(s \pm m+1)}\langle s\|S\| s\rangle \\
\left\langle s-1, m \pm 1\left|\hat{S}^{ \pm}\right| s, m\right\rangle & = \pm \sqrt{(s \mp m)(s \mp m-1)}\langle s-1\|S\| s\rangle .
\end{aligned}
$$

Entre dois vetores do tipo $t=1$, os elementos de matriz de $\hat{H}_{N}$ no subespaço $(s, m=s)$ são calculados da seguinte maneira (notação: $i$ rotula o $i$-ésimo autovetor da iteração $N-1$ que gera o estado de base $i_{b}$ da iteração $N$, de acordo com a Eq. (F.2)):

$$
\begin{aligned}
\left\langle 1\left|\hat{H}_{N}\right| 1\right\rangle_{N} & =\left\langle s, s, i_{b}\left|\hat{H}_{N}\right| s, s, j_{b}\right\rangle_{N} \\
& =\left\langle s-\frac{1}{2}, s-\frac{1}{2}, i ; \uparrow\left|\hat{H}_{N-1}+J \hat{\mathbf{S}}_{N-1} \cdot \hat{\mathbf{S}}_{N}\right| s-\frac{1}{2}, s-\frac{1}{2}, j ; \uparrow\right\rangle \\
& =\left\langle s-1 / 2, s-1 / 2, i\left|\hat{H}_{N-1}\right| s-\frac{1}{2}, s-\frac{1}{2}, j\right\rangle_{N-1}\langle\uparrow \mid \uparrow\rangle_{N} \\
& +J\left\langle s-\frac{1}{2}, s-\frac{1}{2}, i\left|\hat{\mathbf{S}}_{N-1}\right| s-\frac{1}{2}, s-\frac{1}{2}, j\right\rangle_{N-1} \cdot\left\langle\uparrow\left|\hat{\mathbf{S}}_{N}\right| \uparrow\right\rangle_{N} \\
& =E_{N-1}\left(s-\frac{1}{2}, i\right) \delta_{i}^{j} \\
& +J \frac{1}{2}\left\langle s-\frac{1}{2}, s-\frac{1}{2}, i\left|\hat{S}_{N-1}^{z}\right| s-\frac{1}{2}, s-\frac{1}{2}, j\right\rangle_{N-1} \\
& =E_{N-1}\left(s-\frac{1}{2}, i\right) \delta_{i}^{j} \\
& +J \frac{1}{2}\left(s-\frac{1}{2}\right)\left\langle s-\frac{1}{2}, i|| S_{N-1}|| s-\frac{1}{2}, j\right\rangle_{N-1} .
\end{aligned}
$$

Seguindo essas mesmas linhas, entre dois vetores do tipo 2 nós temos

$$
\begin{aligned}
\left\langle 2\left|\hat{H}_{N}\right| 2\right\rangle_{N} & =\left\langle s, s, i_{b}\left|\hat{H}_{N}\right| s, s, j_{b}\right\rangle_{N}=E_{N-1}\left(s+\frac{1}{2}\right) \delta_{i}^{j} \\
& -\frac{2 s^{2}+5 s+3}{4(s+1)}\left\langle s+\frac{1}{2}, i\left\|S_{N-1}\right\| s+\frac{1}{2}, j\right\rangle_{N-1} .
\end{aligned}
$$

Finalmente, entre tipo 1 e tipo 2,

$$
\begin{aligned}
\left\langle 1\left|\hat{H}_{N}\right| 2\right\rangle_{N} & =\left\langle s, s, i_{b}\left|\hat{H}_{N}\right| s, s, j_{b}\right\rangle_{N} \\
& =-J \sqrt{s(s+1)}\left\langle s-\frac{1}{2}, i \| S_{N-1}|| s+\frac{1}{2}, j\right\rangle_{N-1} .
\end{aligned}
$$

Os invariantes presentes nas Eq. (F.4-F.6) são de dois tipos que podemos indicar genericamente por: $\left\langle s, i\left\|S_{N-1}\right\| s, j\right\rangle_{N-1} \mathrm{e}\left\langle s-1, i\left\|S_{N-1}\right\| s, j\right\rangle_{N-1}$. Os autovetores $|s . i\rangle_{N-1}$ não são armazenados para calcular esses invariantes, mas em uma dada iteração nós computamos e armazenamos os invariantes a serem usados na próxima iteração. Para isso, na iteração $N$, nós escrevemos o $i$-ésimo autovetor $|s, s, i\rangle_{N}$ de $\hat{H}_{N}$ como combinação linear dos $i_{b}$-ésimo vetores de base do tipo $t,\left|s^{\prime}: m^{\prime}, i_{b}, t\right\rangle$ :

$$
|s, i\rangle_{N}=\sum_{k_{b}, t=1,2} v_{t}\left(k_{b}, i\right)|t\rangle_{N}
$$

onde $|t\rangle_{N}$ significa um vetor de base do tipo $t$ de acordo com a Eq. (F.2) e $v_{t}\left(k_{b} . i\right)=$ $\left\langle s . s . k_{b} \mid s, s, i\right\rangle$ é a projeção do $i$-ésimo autoretor de $\hat{H}_{N}$ no $k_{b}$-ésimo retor de base do 
tipo t. Portanto,

$$
\begin{aligned}
& \left\langle s, i|| S_{N} \| s, j\right\rangle_{N}=\frac{1}{s}\left\langle s, s . i\left|\hat{S}_{N}^{z}\right| s, s, j\right\rangle_{N} \\
= & \frac{1}{s} \sum_{k_{b}, l_{b}, t, t^{\prime}} v_{t}\left(k_{b}, i\right) v_{t^{\prime}}\left(l_{b}, j\right)\left\langle s, s, k_{b}, t\left|\hat{S}_{N}^{z}\right| s, s, l_{b}, t^{\prime}\right\rangle_{N}^{\text {base }} \\
= & \frac{1}{s} \sum_{k_{b}, l_{b}}\left\{v_{1}\left(k_{b}, i\right) v_{1}\left(l_{b}, j\right)\left\langle s-\frac{1}{2}, s-\frac{1}{2}, k ; \uparrow\left|\hat{S}_{N}^{z}\right| s-\frac{1}{2}, s-\frac{1}{2}, l: \uparrow\right\rangle\right. \\
+ & v_{2}\left(k_{b}, i\right) v_{2}\left(l_{b}, j\right)\left[\frac{2 s+1}{2 s+2}\left\langle s+\frac{1}{2}, s+\frac{1}{2}, k ; \downarrow\left|\hat{S}_{N}^{z}\right| s+\frac{1}{2}, s+\frac{1}{2}, l ; \downarrow\right\rangle\right. \\
+ & \left.\left.\frac{1}{2 s+2}\left\langle s+\frac{1}{2}, s-\frac{1}{2}, k ; \uparrow\left|\hat{S}_{N}^{z}\right| s+\frac{1}{2}, s-\frac{1}{2}, l ; \uparrow\right\rangle\right]\right\} \\
= & \frac{1}{2 s} \sum_{k_{b}, l_{b}}\left\{\left(v_{1}\left(k_{b}, i\right) v_{1}\left(l_{b}, j\right)-v_{2}\left(k_{b}, i\right) v_{2}\left(l_{b}, j\right) \frac{s}{s+1}\right\} \delta_{k}^{l},\right.
\end{aligned}
$$

onde $k$ (oul) rotula o autoestado da iteração $N-1$ o qual gera o estado de base $k_{b}$ (ou $l_{b}$ ). Todos os $v_{1}$ e $v_{2}$ são obtidos na diagonalização numérica de $\hat{H}_{N}$ no subespaço $(s, m=s)$. Da mesma forma,

$$
\begin{aligned}
& \left\langle s-1, i\left\|S_{N}\right\| s, j\right\rangle_{N}^{e s t a d o}=-\frac{\left\langle s-1, s-1, i\left|\hat{S}_{N}^{-}\right| s, s, j\right\rangle_{N}^{\text {estado }}}{\sqrt{2 s(2 s-1)}}= \\
= & \operatorname{cte} \sum_{k_{b}, l_{b}, t t^{\prime}} v_{t}\left(k_{b}, i\right) v_{t^{\prime}}\left(l_{b}, j\right)\left\langle s, s-1, k_{b}, t\left|\hat{S}_{N}^{-}\right| s, s, l_{b}, t^{\prime}\right\rangle_{N}^{\text {base }}= \\
= & c t e \sum_{k_{b}, l_{b}} v_{2}\left(k_{b}, i\right) v_{1}\left(l_{b}, j\right) \sqrt{\frac{2 s-1}{2 s}}\left\langle s-\frac{1}{2}, s-\frac{1}{2}, k ; \downarrow\left|\hat{S}_{N}^{-}\right| s-\frac{1}{2}, s-\frac{1}{2}, l ; \uparrow\right\rangle_{N-1}^{\text {base }} \\
= & -\frac{1}{2 s} \sum_{k_{b}, l_{b}} v_{2}\left(k_{b}, i\right) v_{1}\left(l_{b}, j\right) \delta_{k}^{l},
\end{aligned}
$$

onde cte $=-1 / \sqrt{2 s(2 s-1)}$. Os coeficientes $v_{2}$ e $v_{1}$ são obtidos na diagonalização de $\hat{H}_{N-1}$ nos subespaços $\left(s-1, s_{z}=s-1\right)$ e $\left(s, s_{z}=s\right)$, respectivamente.

Um exemplo trivial, mas instrutivo, é diagonalizar $\hat{H}_{3}$ uma vez tendo diagonalizado $\hat{H}_{2}$. Com dois spins nós temos os seguintes autovetores (notação: $|s, m=s\rangle$ ):

$$
\begin{aligned}
& |0,0\rangle=\frac{|\uparrow, \downarrow\rangle-|\downarrow, \uparrow\rangle}{\sqrt{2}}, \\
& |1,1\rangle=|\uparrow, \uparrow\rangle,
\end{aligned}
$$

que são o estado singleto e tripleto, com energias $E_{2}(0)=-3 J / 4$ e $E_{2}(1)=J / 4$. Sem a conservação de $\hat{\mathbf{S}}^{2}$ e $\hat{S}_{z}$ nós teríamos quatro autovetores. Para a construção de $\hat{H}_{3}$ precisanos também prover os seguintes invariantes, facilmente calculados usando a Eq. (F.3):

$$
\begin{aligned}
\left\langle 0|| S_{2} \| 1\right\rangle_{2} & =\frac{\left\langle 0,0\left|\hat{S}_{2}^{-}\right| 1,1\right\rangle}{-\sqrt{2(2-1)}}=-\frac{1}{2} \\
\left\langle 1|| S_{2}|| 1\right\rangle_{2} & ==\frac{\left\langle 1,1\left|\hat{S}_{2}^{z}\right| 1,1\right\rangle}{\sqrt{1}}=\frac{1}{2} .
\end{aligned}
$$


Seguindo as Eq. (F.4-F.6), os elementos de matriz de $\hat{H}_{3}$ no subespaço de spin total $s=1 / 2$ são

$$
\begin{aligned}
& H_{3}^{11}=E_{2}(0)=-\frac{3}{4} J \\
& H_{3}^{22}=E_{2}(1)-J\left\langle 1\left\|S_{2}\right\| 1\right\rangle_{2}=-\frac{J}{4} \\
& H_{3}^{12}=-J \sqrt{\frac{3}{4}}\left\langle 0\left\|S_{2}\right\| 1\right\rangle_{2}=\frac{\sqrt{3}}{4} J,
\end{aligned}
$$

e no subespaço de $s=3 / 2$ é

$$
H_{3}^{11}=E_{2}(1)+\frac{J}{2} 1\left\langle 1|| S_{2} \| 1\right\rangle_{2}=\frac{J}{2} .
$$

Portanto, precisamos diagonalizar apenas uma matriz $2 \times 2$. Com o uso apenas da conservação de $\hat{S}_{z}$ resultaria em uma matriz $4 \times 4$ e duas $2 \times 2$. Sem qualquer lei de conservação teríamos que diagonalizar uma matriz $8 \times 8$. Essas reduções são muito maiores para $N$ grandes. Por exemplo, para $N=10$, o Hamiltoniano $\hat{H}_{10}$ tem 1024 autoestados. Usufiuindo apenas da conservação de $\hat{S}_{z}$, o maior subespaço a ser diagonalizado é de ordem 252. Implementando também a conservação de $\hat{\mathbf{S}}^{2}$, a maior matriz a ser diagonalizada cai para $90 \times 90$, uma redução considerável. O estado fundamental pertence ao subespaço com menor's, de acordo com a Ref.[28]. Neste caso de $N=10$, é aquele com $s=0$, de dimensão $42 \times 42$.

\section{F.0.1 Truncamento de estados}

As conservaçóes dos operadores $\hat{\mathbf{S}}^{2}$ e $\hat{S}_{z}$ reduzem consideravelmente o tamanho das matrizes envolvidas, mas como o número de estados cresce exponencialmente com $N$, alcança-se o máximo tamanho de memória de microcomputadores usuais para cadeias com cerca de 20 spins 1/2. Para cadeias maiores, ou spins maiores, há a necessidade de se limitar o número de autovetores que dão origem aos estados de base da próxima iteração. Como consequência, perde-se precisão principalmente nos estados de mais alta energia, comprometendo a determinação de propriedades termodinâmicas em temperaturas tais que $k_{B} T>J$. O procedimento recursivo de diagonalização permite esquemas simples de truncamento do número de estados. por exemplo, uma energia de corte $E_{c}(s)$ para cada subespaço de spin total $s$. Diferentemente dos sistemas metálicos abordados pelo Grupo de Renormalização Numérico, aqui o número de estados cresce, a medida que a rede cresce, mesmo com uma energia de corte fixada, o que limita computacionalmente o método. Seria interessante estudar procedimentos de corte alternativos, como por exemplo, $111 n$ semelhante aquele (uue ć feito cm DNRG. 


\section{Referências Bibliográficas}

[1] William Gilbert, De Magnte, Magneticisque Corporibus, et de Magno Magneto Tellure, 1600. Muito da nomenclatura que usamos hoje no magnetismo se deve a essa obra de Gilbert, considerada por alguns como uma das mais relevantes em ciência. Particularmente importante. Gilbert derruba muitos pensamentos místicos sobre o magnetismo.

[2] W. Heisenberg, Z. Phys. 38, 441 (1926), Z. Phys. 49, 619 (1928).

[3] L. Néel, Ann. de Physique 17, 5 (1932).

[4] Squire Bizette e C. R. Rsai, Acad. Sc. 207, 449 (1936). 1938

[5] C. G. Shull e J. Samuel Smart, Phys. Rev. 76, 1256 (1949).

[6] T. Haseda e A. R. Miedema, Physica 27, 1102 (1961).

[7] Y. Endoh, G. Shirane, R. J. Birgeneau, Peter M. Richards e S. L. Holt, Phys. Rev. Lett., 32,170 (1974).

[8] Sérgio Machado Resende, Magnetismo na Terra Brasilis. Rev. Bras. de Ensino de Física, 22, 293 (2000).

[9] Valter L. Líbero, and K. Capelle. Phys. Rev. B 68, 024423 (2003)

[10] P. E. G. Assis, Valter L. Líbero and K. Capelle, Phys. Rev. B 71, 052402 (2005).

[11] P. Weiss, J. Phys. 6, 667 (1907). P. Weiss, J. Phys. Radium 4, 661 (1907).

[12] P. R. Weiss, Phys. Rev. 74, 1493 (1948).

[13] H. A. Bethe, Proc. Roy. Soc. London A 150, 552 (1935); R. E. Peierls, Proc. Roy. Soc. (London) A 154, 207 (1936).

[14] Valter L. Líbero, Rer. Bras. Ens. Fis.. bf 22, 346 (2000)

[15] Alzira C. M. Stein-Barana, Makoto Yoshida e Valter L. Líbero, Rer. Bras. Ens. Fis., 26, 385 (2004).

[16] J. S. Smart, Effective Field Theories of Magnetism (W. B. Saunders Company, Philadelphia, 1966). 
[17] P. A. M. Dirac, Proc. Roy. Soc. 112A, 661 (1926), Proc. Roy. Soc. 123A, 714 (1929).

[18] R. K. Nesbet, Annals of Physics 4, 87 (1958). Nesta referência tem-se uma discussão detalhada sobre a obtenção desse Haniltoniano para spin $S$ qualquer. É mostrado que as integrais de troca $J_{i, j}$ são combinações lineares de um termo de troca propriamente e outro de supertroca, podendo ter sinais opostos, possibilitando $J$ ser positivo ou negativo. Uma discussão mais simples, para dois elétrons, pode ser encontrada na Ref.[19].

[19] Ana P. Fávaro, Energia do Estado Fundamental no Modelo de Heisenberg para Cadeias de Spins com Ligações Alternadas e com Defeitos Locais. Dissertação (Mestrado em Física). Instituto de Física de São Carlos, Universidade de São Paulo, São Carlos, 2007.

[20] Efstratios Manousakis, Rev. Mod. Phys. 63, 1 (1991).

[21] N. Guihery, N. Ben Amor, D. Maynau and J. P. Malrieu, J. Chem. Phys. 104, 3701 (1996).

[22] M. Said, D. Maynau, J. P. Malrieu and M. A. Garcia Bach, J. Am. Chem. Soc. 106, 571 (1984).

[23] A. L. Tchougreeff, J. Chem. Phys. 96, 6026 (1992).

[24] C. Kollmar and O. Kahn, J. Chem. Phys. 98, 453 (1993).

[25] M. Matusiewicz, M. Czerwinski, J. Kasperczyk and I. V. Kityk, J. Chem. Phys. 111, 6446 (1999).

[26] J. H. Luscombe, M. Luban and F. Borsa, J. Chem. Phys. 108, 7266 (1998).

[27] E. Ising, Z. Physik 31, 253 (1925).

[28] E. Lieb. T. Schultz e D. Mattis, Ann. Phys. (NY) 16, 407 (1961).

[29] H. A. Bethe, Z. Phys. 71, 205 (1931). Traduzido em

[30] L. Hulthen, Arkiv Mat. Astron. Fysik 26A, No.11, 1 (1938).

[31] P. Hohenberg and W. Kohn, Phys. Rev. 136, B864 (1964).

[32] W. Kohn, Rev. Mod. Phys. 71, 1253 (1999).

[33] W. Kohn and L. J. Sham, Phys. Rev. 140, A1133 (1965).

[34] P. H. Penteado, Modelo de Heisenberg Antiferromagnético com Interações Não Uniformes. Dissertação, Mestrado em Física, Instituto de Física de São Carlos, Universidade de São Paulo. São Carlos, 2008. Orientador: Valter L. Líbero. 
[35] G. N. Prata, Noros Funcionais para o Modelo de Heisenberg Anisotrópico. Dissertação, Mestrado em Física, Instituto de Física de São Carlos, Universidade de São Paulo. São Carlos, 2008. Orientador: Valter L. Líbero.

[36] Fabiano C. do Sonza, Método de Diagonalização Iterativa para o Modelo de Heisenberg. Tese, Doutorado em Física, Instituto de Física de São Carlos, Universidade de São Paulo. São Carlos, 2010. Orientador: Valter L. Líbero.

[37] F. Bloch, Z. Physik 61, 206 (1930).

[38] N. A. Lima, M. F. Silva, 1. N. Oliveira e K. Capelle, Phys. Rev. Lett 90, 146402 (2003).

[39] R. L. Orbach, Phys. Rev. 112, 309 (1958).

[40] P. W. Kasteleijn, Physica 18, 104 (1952).

[41] L. R. Walker, Phys. Rev. 116, 1089 (1959).

[42] C. N. Yang e C.P. Yang, Phys. Rev. 150, 321 (1966).

[43] P. W. Anderson, Phys. Rev. 83, 1260 (1951).

[44] P. W. Anderson, Phys. Rev. 86, 694 (1952).

[45] André Luiz Malvezzi, Braz. J. Phys. 33, 55 (2003).

[46] J. Lou, S. Qin, T.-K. Ng and Z. Su, Phys. Rev. B 65, 104401 (2002).

[47] L. N. Bulaevskii, Sov. Phys. JETP 16, 685 (1963).

[48] Klaus Capelle, Bras. J. Phys., 36, 1318 (2006).

[49] José David M. Vianna, Adalberto Fazzio e Sylvio Canuto, Teoria Quântica de Moléculas e Sólidos, Editora Livraria da Física, 2004.

[50] M. Levy, Phys. Rev. A 26, 1200 (1982).

[51] E. H. Lieb, Density Functional Methods in Physics, R. M. Dreizler e J. da Providência, (Plenum, New York, 1985).

[52] F. C. Alcaraz, M. N. Barber, M. T. Batchelor, R. J. Baxter e G. R. W. Quispel, J. Phys. A 20, 6397 (1987).

[53] T. Barnes, E. Dagotto, J. Riera e E. S. Swanson, Phys. Rev. B 47, 3196 (1993).

[54] N. Bulut, D. Hone, J. Scalapino and E.Y. Loh, Phys. Rev. Lett. 62, 2192 (1989).

[55] J. E. Padilha, R. G. Amorim. A. R. Rocha, A. J. R. da Silva e A. Fazzio, Sol. State Comm. 151, 482 (2011). 
[56] Valter L. Líbero e K. Capelle, Physica B 384, 179 (2006).

[57] K. Capelle e Valter L. Líbero, Int. J. Quantum Chem. 105, 679 (2005).

[58] G. N. Prata. P. H. Penteado. F. C. Souza e Valter L. Líbero, Physica B 404, 3151 (2009).

[59] V. L. Líbero, K. Capelle, F. C. Souza, A. P. Fávaro, JM.MM 320, e421-e424 (2008).

[60] Poliana H. Penteado e Valter L. Líbero. Phys. Rev. B 82, 092401 (2010).

[61] T. Barnes, J. Riera and D. A. Tennant, Phys. Rev. B 59, 11384 (1999).

[62] Hao-Yu Shem, Wei-Ming Bu, En-Qing Gao, Dai-Zheng Liao, Song-Hui Jiang, ShiPing Yan, Geng-Lin Wang, Inorg. Chem. 76, 184428 (2000).

[63] Shou-Shu Gong, Song Gao, Gang Su, Phys. Rev. B 80, 014413 (2009).

[64] H. Q. Lin, Phys. Rev. B 42,6561 (1990).

[65] Jürgen Schnack, Peter Hage e Heinz-Jürgen Schmidt, J. Comput. Phys. 227, 4512 (2008).

[66] www.maths.lancs.ac.uk/ gilbert/m243b/node5.html. Ver também Proc. Roy. Soc. Edinburgh, 46, 289 (1926).

[67] K. G. Wilson, Rev. Mod. Phys. 47, 773 (1975); H. R. Krishna-murthy, J. W. Wilkins e K. G. Wilson, Phys. Rev. B 21, 1003 (1980).

[68] M. TinKham, Group Theory and Quantum Mechanics. New York:McGraw-Hill, 1964 (International series in pure and applied physics).

[69] Francisco C. Alcaraz e Klaus Capelle, Phys. Rev. B 76, 035109 (2007).

[70] F. C. Alcaraz e R. Z. Bariev, An exactly solvable constrained xxz chain. 1999. Disponível em: <http://arxiv.org/abs/cond-mat/9904042>

[71] T. Jordan e E. Wigner, Z. Phys. 47, 631 (1928).

[72] M. Lagos, M. Kiwi, E. R. Gagliano e G. G. Cabrera, Sol. State Comm. bf 67, 225 (1988). 